\title{
Metodología para la medición de prácticas de Responsabilidad Social Empresaria
}

Tesis presentada para obtener el título de

Doctora en Ciencias de la Administración

Acreditada por CONEAU en sesión Nro 423/15 CONEAU

Facultad de Ciencias Económicas Universidad Nacional de La Plata

Alumna: Estefanía Solari

Directora: Nora Liliana Gorrochategui

Año 2019 


\section{Resumen}

Si bien el tema sobre Responsabilidad Social Empresaria (RSE) ha sido ampliamente estudiado, no hay investigaciones que se centren en analizar las prácticas de RSE que están implementando las empresas argentinas, así como que indaguen si las mencionadas prácticas guardan algún tipo de relación con la rentabilidad y la reputación corporativa. La ausencia de conocimiento sobre el comportamiento de las empresas argentinas sobre esta temática se considera de interés y un desafío que implica reflexionar acerca de un problema organizacional de actualidad, puesto que no se cuenta con esta información que es clave para la gestión empresarial.

El planteo general del problema de la investigación genera un conjunto de interrogantes que pueden agruparse en dos categorías: 1) implementación y medición de prácticas de RSE de las empresas argentinas y 2) relación entre la implementación de prácticas de RSE con el desempeño económico y la reputación corporativa.

El objetivo general es:

- Desarrollar una metodología integral para la medición de prácticas de RSE.

Los objetivos específicos son:

1. Identificar indicadores relevantes para la medición integral de prácticas de RSE.

2. Diseñar la metodología para la medición integral de prácticas de RSE.

3. Validar la metodología para determinar el nivel de aplicación de prácticas de RSE en las empresas argentinas.

Respecto a la metodología, en una primera parte tiene un carácter exploratorio y cualitativo, luego para el diseño y validación de la metodología desarrollada, se efectúan análisis de tipo cuantitativo. 
La población objeto de la validación son las 37 empresas argentinas adheridas a la Global Reporting Initiative (GRI) que cotizan en la Comisión Nacional de Valores (CNV), durante el periodo 2012-2016.

Algunas de las principales conclusiones a las que se arribaron:

- Las empresas que elaboraron las memorias de sustentabilidad presentaron mayor divulgación de prácticas de RSE respecto a las dimensiones Medioambiental, Prácticas sociales, Derechos humanos y Prácticas laborales y trabajo decente.

- Cuanto menor sea el tamaño de la empresa, tanto mayor será la aplicación de prácticas de RSE de manera integral.

- "Hipótesis de las variables moderadoras" la que establece que entre la RSE y el desempeño económico no existe ninguna correlación, en cuanto la variable de RSE no puede alterar la variable desempeño económico, ni viceversa, la relación no es clara, ni significativa.

El esfuerzo por seguir estudiando este tema bien vale la pena, pues a través de la RSE es posible construir una sociedad mejor en la que se obtenga un progreso sustentable dentro de la ética hacia todos, en un camino hacia el bien común.

Palabras Clave: Responsabilidad social empresaria, metodología para la medición, indicadores, GRI, rentabilidad

Clasificación JEL: M14 (Social Responsibility); C18 (Methodological Issues: General); M21 (Business Economics) 


\section{ÍNDICE}

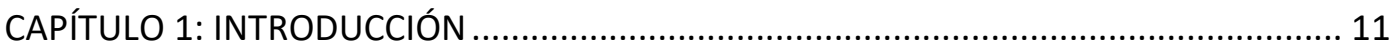

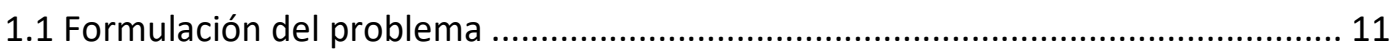

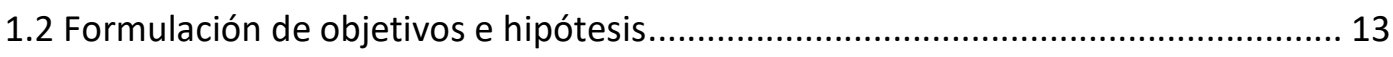

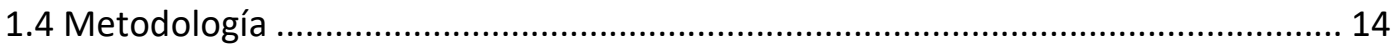

1.4.1 Tipo de investigación ............................................................................ 14

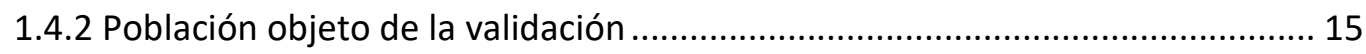

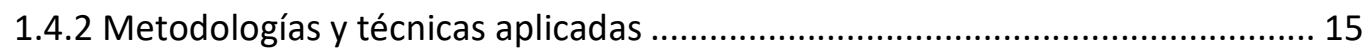

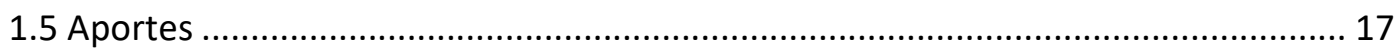

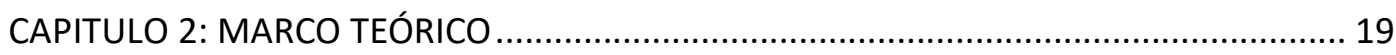

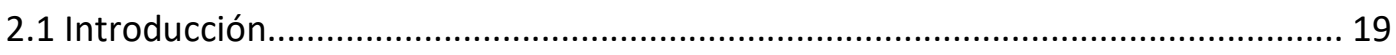

2.2 Modelos para medir los efectos de la RSE sobre las variables de creación de valor

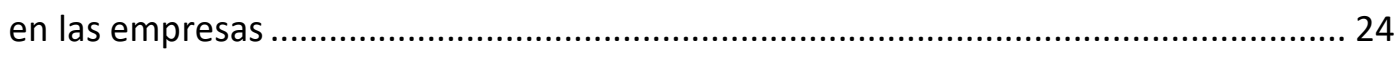

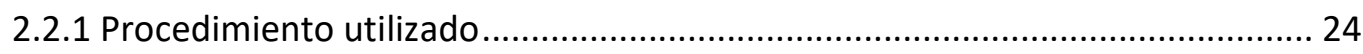

2.2.2 Investigaciones académicas que han abordado los efectos que se producen al interior de las organizaciones ante la aplicación de prácticas de RSE ........................ 25

2.2.3 Metodología abordada para el análisis bibliográfico ...................................... 53

2.2.4 Principales resultados del análisis de contenido ........................................... 59

2.2.5 Principales conclusiones del análisis bibliográfico ........................................62 62

2.2.6 Consideraciones para el desarrollo de la metodología de medición integral de

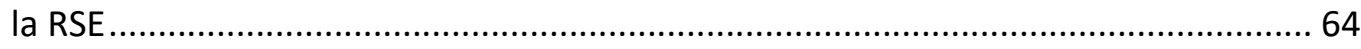

2.3 Indicadores para la medición de prácticas de RSE ............................................65

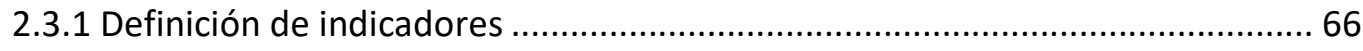

2.3.2 Indicadores desarrollados desde la academia para medir el desempeño en

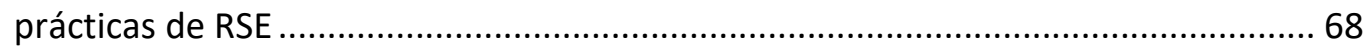

2.3.3 Metodología para el análisis de indicadores de RSE ..................................... 76 
2.3.4 Principales resultados del análisis de indicadores propuestos por la academia76

2.3.4 Indicadores desarrollados por la Global Reporting Initiative (GRI) ................... 82

2.3.5 Participación de las empresas argentinas en el GRI ....................................... 87

2.3.7 Indicadores GRI y los vínculos entre los 10 principios del Pacto Global de

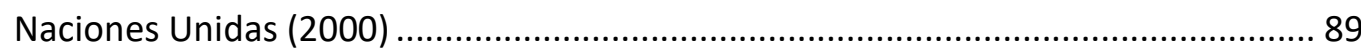

2.3.8 De los Objetivos de Desarrollo del Milenio (ODM) a los Objetivos de Desarrollo

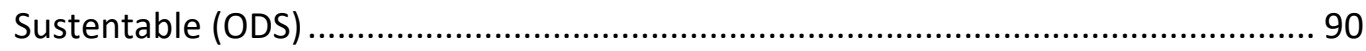

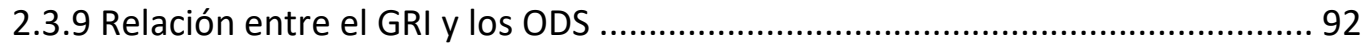

2.3.10 Conclusiones parciales del análisis bibliográfico de los indicadores para la

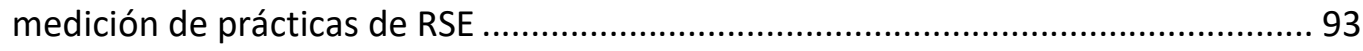

2.4 Indicadores de performance financiera y de desempeño económico ...................... 94

2.4.1 Tipos de indicadores financieros/económicos ............................................ 95

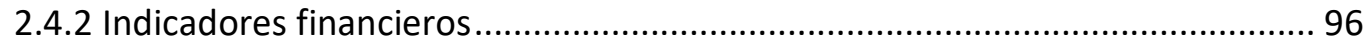

2.4.3 Clasificaciones de las Medidas de Performance Financiera (PF) y las de

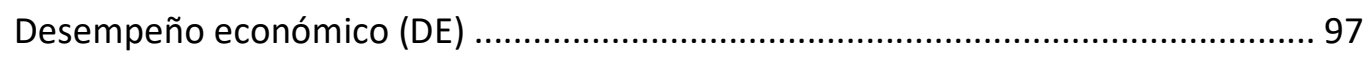

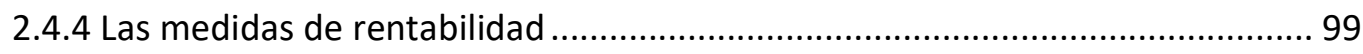

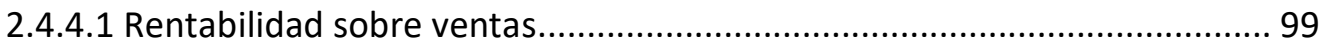

2.4.4.2 Rentabilidad sobre activos ........................................................... 100

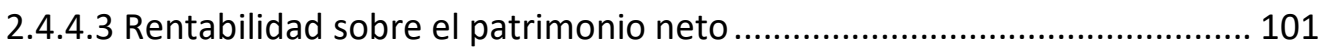

2.4.4.4 Rentabilidad de un proyecto (o de un producto) ................................... 102

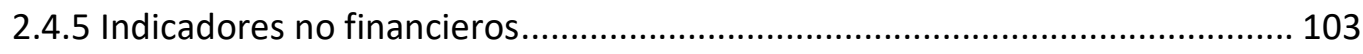

2.4.6 La importancia del Sistema de Información Contable para la generación de

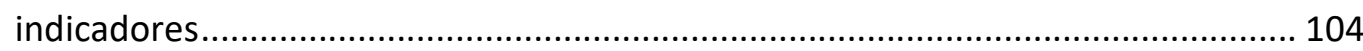

2.4.7 Conclusiones parciales del análisis teórico de los indicadores financieros y de

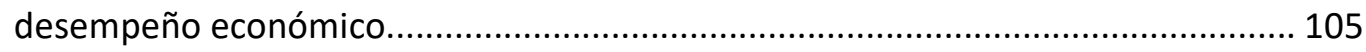

2.5 Síntesis de las conclusiones del marco teórico ................................................. 106

CAPÍTULO 3: METODOLOGÍA PARA LA MEDICIÓN DE PRÁCTICAS DE RESPONSABILIDAD

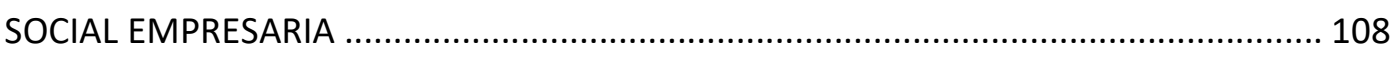

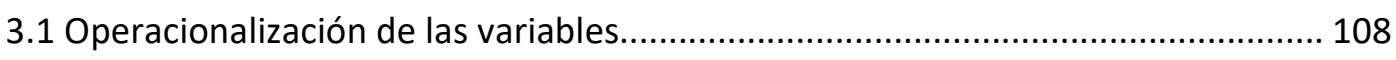


3.3 Conceptualización de la metodología desarrollada para la medición integral de la RSE

3.4 Uso de la metodología para el análisis de la RSE con el Desempeño Económico (DE)

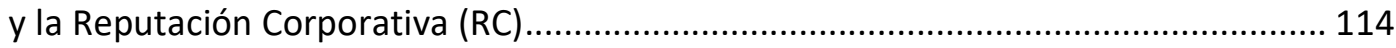

3.5 Conclusiones de la metodología propuesta ..................................................... 122

CAPÍTULO 4: VALIDACIÓN DE LA METODOLOGÍA PROPUESTA....................................... 124

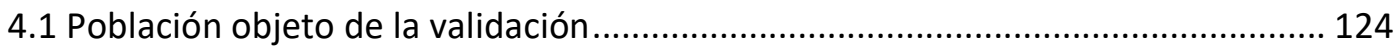

4.2 Caracterización de las empresas analizadas ..................................................... 125

4.5 Aplicación de la metodología para la medición integral de RSE .......................... 127

4.6 Relación entre el grado de divulgación de indicadores de RSE y el tamaño de las

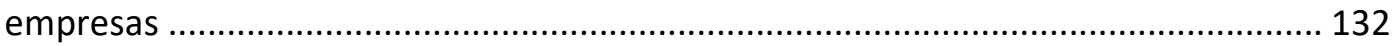

4.7 Relación entre el grado de divulgación de indicadores de RSE y la versión de la

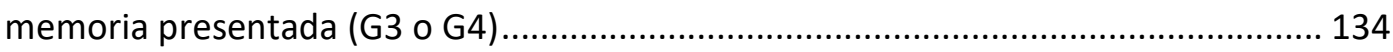

4.8 Divulgación de indicadores de RSE por la misma empresa a lo largo del tiempo . 136 4.9 Validación de la metodología para el análisis de la RSE con el Desempeño Económico (DE) y la Reputación Corporativa (RC) .................................................... 137

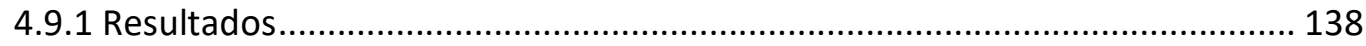

4.9.1.1 Estadísticas descriptivas de las variables independientes ...................... 138

4.9.1.2 Análisis de Correlación de las variables independientes cuantitativas .... 139

4.9.1.3 Modelos de regresión explicativos de la RSE por dimensión y a nivel

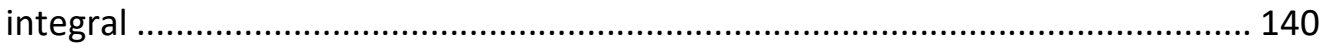

4.9.1.4 Resultados de los modelos de regresión explicativos de la RSE por dimensión y a nivel integral ........................................................................... 141

4.1.9.5 Limitaciones planteadas como resultado del análisis de regresión lineal 142 4.9.2 Metodología alternativa de análisis: árboles de decisión ........................... 143 4.9.2 Resultados para la hipótesis: “La implementación de RSE redunda en un mayor desempeño económico" 145 
4.9.3 Resultados para la hipótesis: "La implementación de RSE redunda en una mejor

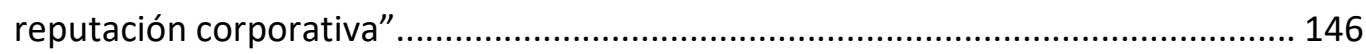

4.10 Conclusiones de la validación de la metodología........................................... 147

4.10.1 Conclusiones de la aplicación de la metodología para la medición integral de prácticas de RSE

4.10.2 Conclusiones respecto a la relación de la RSE con el desempeño económico y

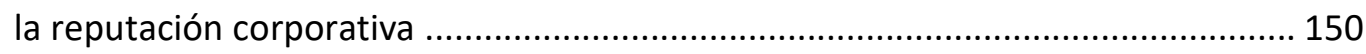

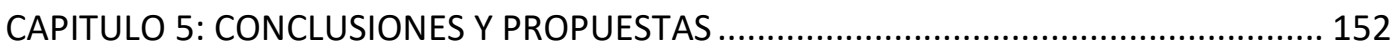

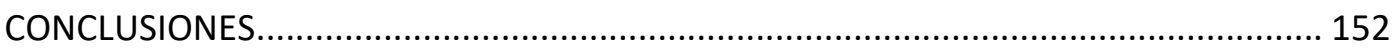

5.1 Sobre la identificación de indicadores relevantes para la medición de prácticas de RSE 152

5.2 Diseño de una metodología para la medición integral de prácticas de RSE 154

5.3 Validación de la metodología para medir el nivel de aplicación de prácticas de RSE en las empresas argentinas 158

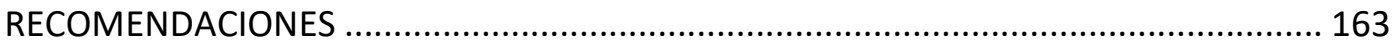

5.5 Recomendaciones y posibles líneas de investigación ......................................... 163

ANEXO 1: INDICADORES PROPUESTO POR EL GRI - GUIA G4 .................................. 166

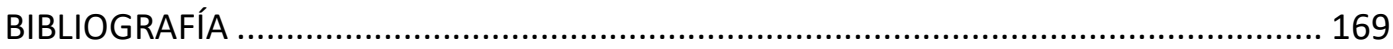

\section{ÍNDICE DE TABLAS, IMÁGENES Y GRÁFICOS}

\section{TABLAS}

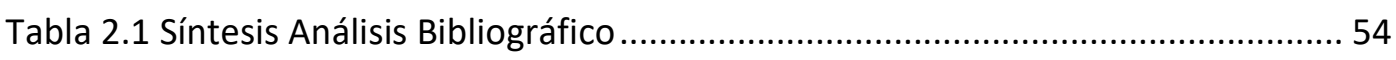

Tabla 2.2: Abordaje de la RSE por los autores.................................................... 59

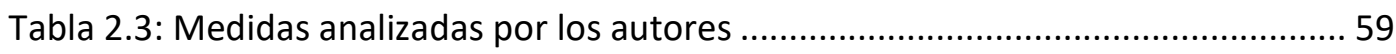

Tabla 2.3. Resumen del análisis bibliográfico según origen de los indicadores

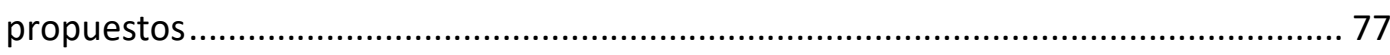

Tabla 2.4. Resumen análisis bibliográfico: dimensiones abordadas, relevamiento y tipo de indicadores 78 
Tabla 2.4. Resumen análisis bibliográfico: dimensiones abordadas, relevamiento y tipo

de indicadores

Tabla 2.5. Niveles de Aplicación del proceso de elaboración de memorias de GRI G3. 84

Tabla 2.6. Participación de las organizaciones según país en la GRI

Tabla 2.7. Vínculo entre los 10 principios del Pacto Global de Naciones Unidas (2000) y el GRI. 89

Tabla 2.8. Medidas de Performance Financiera/Desempeño Económico 97

Tabla 3.1 Operacionalización de la variable Responsabilidad Social Empresaria RSE . 110

Tabla 3.2 Operacionalización de las variables: Desempeño Económico y Reputación Corporativa

Tabla 3.3. Tabla de ponderaciones para la elaboración del indicador de reputación corporativa MERCO

Tabla 4.1. Tamaño de las empresas analizadas

Tabla 4.2. Sector de actividad de las empresas.................................................... 126

Tabla 4.3. Año de publicación de las memorias de sostenibilidad............................. 127

Tabla 4.4. Tipo de memoria de sostenibilidad (Guía G3 ó G4)................................... 127

Tabla 4.5. Indicadores de RSE reportados en las memorias de sustentabilidad, por dimensión y a nivel integral

Tabla 4.6. Indicadores de RSE reportados en las memorias de sustentabilidad, por dimensión y a nivel integral (por año reportado)

Tabla 4.7. Estadísticos descriptivos de los indicadores de RSE por dimensión y a nivel integral (para los sectores con mayor relevancia para la muestra) ............................. 130

Tabla 4.7. Análisis de correlación de los indicadores de RSE reportados, por dimensión y a nivel integral. 132

Tabla 4.8. Test de Diferencia de Medias: 134

Subíndices de RSE según tamaño de las empresas ................................................. 134

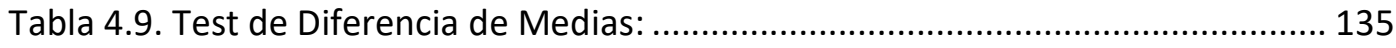

Subíndices de RSE según Tipo de Memoria Presentada (G3 o G4) ............................. 135

Tabla 4.10. Memorias Publicadas de Conformidad con la Guía G4.......................... 137 
Evolución en el Tiempo del Indicador integral de RSE

Tabla 4.11. Estadísticas descriptivas de las variables independientes (explicativas) .. 139

Tabla 4.12 Frecuencia de las variables independientes binarias 139

Tabla 4.13. Correlación de las variables independientes cuantitativas del modelo .... 140

Tabla 4.13. Coeficientes de los modelos de regresión. Variables dependientes RSE

(integral y por dimensión)

Tabla 4.15. Test de diferencia de medias: Índice integral de RSE y rentabilidad de las empresas

Tabla 4.16 Test de diferencia de medias: Índice integral de RSE y reputación corporativa

\section{IMÁGENES}

Imagen 1.1. Esquema de la estructura de la tesis. 18

Imagen 2.1. Mapa de la literatura desplegado en temas y subtemas..... 23

Imagen 2.2. Mapa de la literatura con principales autores 24

Imagen 2.1: Nube de palabras más frecuentes en relación a las variables abordadas . 60 Imagen 2.2: Nube de palabras más frecuentes en relación a las metodologías..... 61 Imagen 2.3: Nube de palabras más frecuentes en los hallazgos de las investigaciones 62 Imagen 2.3. Nube de palabras: Dimensiones de la RSE abordadas por los autores ...... 81 Imagen 3.1. Pasos propuestos para el desarrollo de la metodología para la medición integral de RSE

Imagen 3.1: Modelo explicativo: Desempeño económico y reputación corporativa y su relación con la RSE. 114

Imagen 4.2. Árbol de clasificación. RSE: desempeño económico y reputación corporativa 144 


\section{GRÁFICOS}

Gráfico 4.1. Valor medio del indicador global de RSE para los sectores con mayor

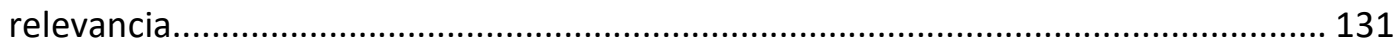




\section{CAPÍTULO 1: INTRODUCCIÓN}

En este capítulo se formula el problema que da origen a la investigación: la falta de conocimiento del nivel de implementación de prácticas de Responsabilidad Social Empresaria (RSE) en las empresas argentinas. Haciendo énfasis en que "lo que no se mide no se administra", se plantea el desarrollo de una metodología para la medición de la implementación de prácticas de RSE, que posibilitará no sólo medir dichas prácticas dentro de las empresas argentinas, sino también analizar la relación de las mismas con la rentabilidad y reputación corporativa. Se establece el objetivo general y los objetivos específicos de la investigación, así como algunas hipótesis. Luego, se detallan las metodologías abordadas para el cumplimiento de cada uno de los objetivos específicos. Por último, se menciona el aporte que realiza la investigación en los planos teóricos y prácticos.

\subsection{Formulación del problema}

Ética y moral constituyen dos términos etimológicamente homónimos, con raíces en el griego (ethos) y en el latín (more) respectivamente, y que significan morada/costumbre.

La ética nace con Aristóteles y su inquietud en responder a la pregunta: ¿de qué manera es necesario que un hombre viva su vida? Con el correr del tiempo, se transformó en una rama de la filosofía ligada a la razón y a la crítica, que como disciplina práctica tiene por finalidad la reconstrucción de la estructura argumentativa racional de la moralidad. A su vez, la moralidad es entendida como un código privativo de conductas seguido por los miembros de una sociedad. Es decir que la ética es la rama de la filosofía que se encarga del estudio de la moral o de las morales. Como tal, enfrenta el desafío de aplicar los argumentos práctico-racionales a la vida social, tanto en el nivel individual -o sea respecto de las decisiones personales- como a nivel de 
desarrollo de los sistemas sociales, pasando por las organizaciones y en particular, las organizaciones empresariales, en lo que refiere a la toma de decisiones de política estratégica de negocios, como así también en cuanto a su responsabilidad empresaria (Solari, 2002).

En el contexto de la globalización, las empresas son protagonistas de muchos de los males que las sociedades padecen, con lo cual se hace imperativo e ineludible día a día exigir a los entes empresariales comportamientos socialmente responsables. Por otro lado, este tema está despertando hace ya varios años el interés y la preocupación de importantes organismos internacionales e instituciones del ámbito académico.

En el mundo globalizado, el mayor esfuerzo de las empresas está orientado a solventar los estragos realizados por sus actividades, incorporando en la cultura organizacional y en las estrategias de negocios la dimensión social, movilizando a su vez competencias y recursos disponibles de la empresa -principalmente financiando proyectos educativos, formativos, medioambientales, de salud, para apoyar y mejorar las comunidades donde se establecen. Además, la permanencia de las compañías en los mercados globales requiere una visión empresarial ética y de mayor solidaridad con las necesidades del entorno. Para tal efecto, se incorporan principios éticos que fusionen la relación entre la empresa y la sociedad, principios que expresan qué se debe y qué no se debe hacer en función de construir una sociedad mejor (Hernández \& Bonomie, 2010).

En este mismo sentido, cabe agregar que la gestión empresarial avanza utilizando conceptos, herramental y prácticas en función de criterios que pueden estar condicionados por la presión internacional, la globalización de los negocios, y la competencia comercial-que requiere no sólo calidad y eficiencia sino altos estándares éticos, por lo menos desde la enunciación (Gorrochategui N, 2012).

Si bien el tema sobre RSE ha sido ampliamente estudiado, no existen investigaciones cuyo eje de análisis sean las prácticas de RSE que están implementando las empresas argentinas, ni tampoco que indaguen si las mencionadas prácticas guardan algún tipo de relación con la rentabilidad y la reputación corporativa. La ausencia de 
conocimiento sobre el comportamiento de las empresas argentinas respecto de esta temática se considera de interés y constituye un desafío que implica reflexionar acerca de un problema organizacional de actualidad, ya que proporcionaría información novedosa que es clave para la gestión actual.

El planteo general del problema de la investigación genera un conjunto de interrogantes que pueden agruparse en dos categorías: 1) implementación y medición de prácticas de RSE de las empresas argentinas, y 2) relación entre la implementación de prácticas de RSE con el desempeño económico y la reputación corporativa.

Es preciso aclarar que en la investigación se considera la implementación de prácticas de RSE como la instrumentación de acciones tendientes a ejecutar políticas, programas y/o actividades de RSE. A su vez, cuando se considera la RSE desde el punto de vista integral es que se están contemplando cada una de sus dimensiones: social, medioambiental y económica.

Por otra parte, se buscará analizar si es que existe relación entre las prácticas de RSE y el desempeño económico y la reputación corporativa, entendiendo el desempeño económico utilizando como medida proxy la rentabilidad y, en el caso de la reputación corporativa, información de fuente secundaria proveniente del Monitor Empresarial de Reputación Corporativa (MERCO).

Respecto del primer punto, se procurará responder los siguientes interrogantes: ¿cuál es el nivel de implementación de prácticas de RSE en las empresas argentinas?, ¿la implementación de prácticas de RSE presenta diferencias significativas según la dimensión?, ¿la implementación de prácticas de RSE varía según el tamaño de las empresas?

Por otra parte, en relación al segundo punto, interesa conocer: ¿cuál es la relación entre la implementación de RSE y el desempeño económico?, ¿cuál es la relación entre la implementación de RSE y la reputación corporativa?

\subsection{Formulación de objetivos e hipótesis}

El objetivo general de la presente investigación consiste en: 
- Desarrollar una metodología integral para la medición de prácticas de RSE.

Los objetivos específicos son los siguientes:

4. Identificar indicadores relevantes para la medición integral de prácticas de RSE.

5. Diseñar la metodología para la medición integral de prácticas de RSE.

6. Validarla metodología para determinar el nivel de aplicación de prácticas de RSE en las empresas argentinas.

Por lo expuesto, es posible enunciar algunas hipótesis iniciales de esta investigación:

- Las empresas que aplican prácticas de RSE lo hacen en todas sus dimensiones (económica, social y medioambiental), es decir que consideran la RSE en su sentido amplio.

- Cuanto mayor sea el tamaño de la empresa, mayor será la implementación integral de prácticas de RSE.

- Cuanto mayor sea la implementación integral de prácticas de RSE, mejor será el desempeño económico y la reputación de la empresa.

\subsection{Metodología}

\subsubsection{Tipo de investigación}

En una primera parte, la investigación tiene un carácter exploratorio y cualitativo. El carácter exploratorio queda explicitado a partir del propósito de examinar un tema de investigación poco estudiado, que permitirá a su vez cumplir con el objetivo central de la investigación: “Diseñar la metodología para la medición integral de prácticas de RSE". Es a través de este primer análisis exploratorio que se presenta en el marco 
teórico que luego se podrán operacionalizar las variables propuestas para el diseño de la metodología, de allí es menester aclarar la razón de la gran extensión del mismo y de la utilización del análisis de contenido.

Luego, para el diseño y validación de la metodología desarrollada, se efectúa un análisis de tipo cuantitativo, y el estudio en este caso se torna descriptivo puesto que mide los conceptos involucrados. De esta manera, se mide cada una de las variables propuestas para detallar cómo es y cómo se manifiesta el fenómeno de interés.

\subsubsection{Población objeto de la validación}

La población objeto de la validación son las 37 empresas argentinas adheridas a la Global Reporting Initiative (GRI) que cotizan en la Comisión Nacional de Valores (CNV), durante el período 2012-2016. Las razones que llevaron a elegir esta población son la disponibilidad de la información y la homogeneidad de los datos a tratar. Por lo tanto, las fuentes utilizadas para la recolección de datos son secundarias, ya que el estudio se centró en la recopilación de las memorias de sostenibilidad y los estados contables presentados por las empresas. Del total de las 37 empresas, se recopilaron y analizaron 95 memorias de sostenibilidad y 61 estados contables.

La utilización de las memorias de sostenibilidad de la GRI radicó principalmente en la comparabilidad inter e intraempresas en los distintos años analizados, así como en la exhaustividad, gracias a la cantidad y precisión de indicadores que propone el mencionado organismo. Lo mismo ocurre con la información contenida en los estados contables, que mantienen una homogeneidad que permite la comparación de indicadores de desempeño económico en distintos años y para distintas empresas.

\subsubsection{Metodologías y técnicas aplicadas}

Para dar respuesta a los objetivos específicos se aplicaron las siguientes metodologías:

- Objetivo 1: "Identificar indicadores relevantes para la medición integral de prácticas de RSE". El análisis de contenido fue el método más apropiado para llevar a cabo esta tarea ya que permitió analizar las palabras y frases que han 
abordado los autores y clasificarlas en categorías más simples, con la finalidad de descubrir patrones o tendencias en función de los objetivos de investigación planteados. Además, este análisis posibilitó determinar la frecuencia de las variables, dimensiones e indicadores abordados, así como las metodologías desarrolladas (Capítulo 2). Este análisis fue fundamental para contar con la información necesaria para el cumplimiento del objetivo 2, de allí la importante extensión del capítulo concerniente al marco teórico.

- Objetivo 2: "Diseñar la metodología para la medición integral de prácticas de RSE". Para dar cumplimiento a este objetivo, se realizó la operacionalización de las variables y el posterior procedimiento a seguir para el desarrollo de la metodología (Capítulo 3), para lo cual fueron contempladas las conclusiones que surgieron mediante el cumplimiento del objetivo 1.

- Objetivo 3: "Validarla metodología para determinar el nivel de aplicación de prácticas de RSE en las empresas argentinas". En este caso, se aplicó la metodología para la medición integral de prácticas de RSE, propuesta en el Capítulo 3. Para determinar si las diferencias entre el grado de aplicación de RSE por dimensión era significativamente distinta se efectuó un análisis de correlación. Por otra parte, para indagar la relación entre el grado de aplicación de RSE y el tamaño de las empresas, se aplicó un test de "Diferencia de medias para muestras independientes". También, se desarrolló un modelo de regresión lineal para analizar la relación entre el nivel de aplicación de prácticas de RSE con la reputación corporativa y el desempeño económico. Para dar más robustez a los resultados del análisis de regresión se aplicó como metodología alternativa la técnica de "árboles de decisión" y pruebas Chi-2 de Pearson (Capítulo 4).

Cabe destacar, que las operaciones que se han realizado para el tratamiento de la metodología propuesta se describen con mayor nivel de detalle al interior de cada capítulo. 


\subsection{Aportes}

El aporte que realiza la investigación radica en la generación de evidencia acerca de las prácticas de RSE a nivel integral y por dimensión de las empresas argentinas. Adicionalmente, se generó información sobre el nivel de aplicación de RSE en relación con el desempeño económico y la reputación corporativa.

Esta contribución tiene repercusión tanto por su relevancia social e implicaciones prácticas, como por su valor teórico y utilidad metodológica.

La investigación tiene relevancia social e implicaciones prácticas, puesto que cubre una necesidad insatisfecha de las empresas argentinas, originada en la falta de estudios acerca de la evolución de las prácticas de RSE en aquellas empresas que la aplican, así como también si las mencionadas prácticas varían según la dimensión de RSE o el tamaño de la organización. También, la investigación brindará información acerca de la relación entre el nivel de prácticas de RSE con la rentabilidad económica y con la reputación corporativa de la población objeto de estudio. Esta información será útil para la gestión de las empresas argentinas, tanto para aquellas que llevan a cabo estas prácticas en la actualidad, como también para las que están evaluando incorporarlas.

La investigación aporta valor teórico, debido a que el tema tiene poco desarrollo conceptual, y, por lo tanto, esta reflexión sobre el comportamiento respecto a las prácticas de RSE de las empresas argentinas es una contribución a la disciplina administración.

Por último, tiene utilidad metodológica puesto que crea un instrumento para la recolección y análisis de datos referentes a prácticas de RSE y sugiere cómo estudiar adecuadamente las mismas.

En la siguiente imagen se resume la estructura de la tesis según el desarrollo temático en cada uno de los capítulos. 
Imagen 1.1. Esquema de la estructura de la tesis

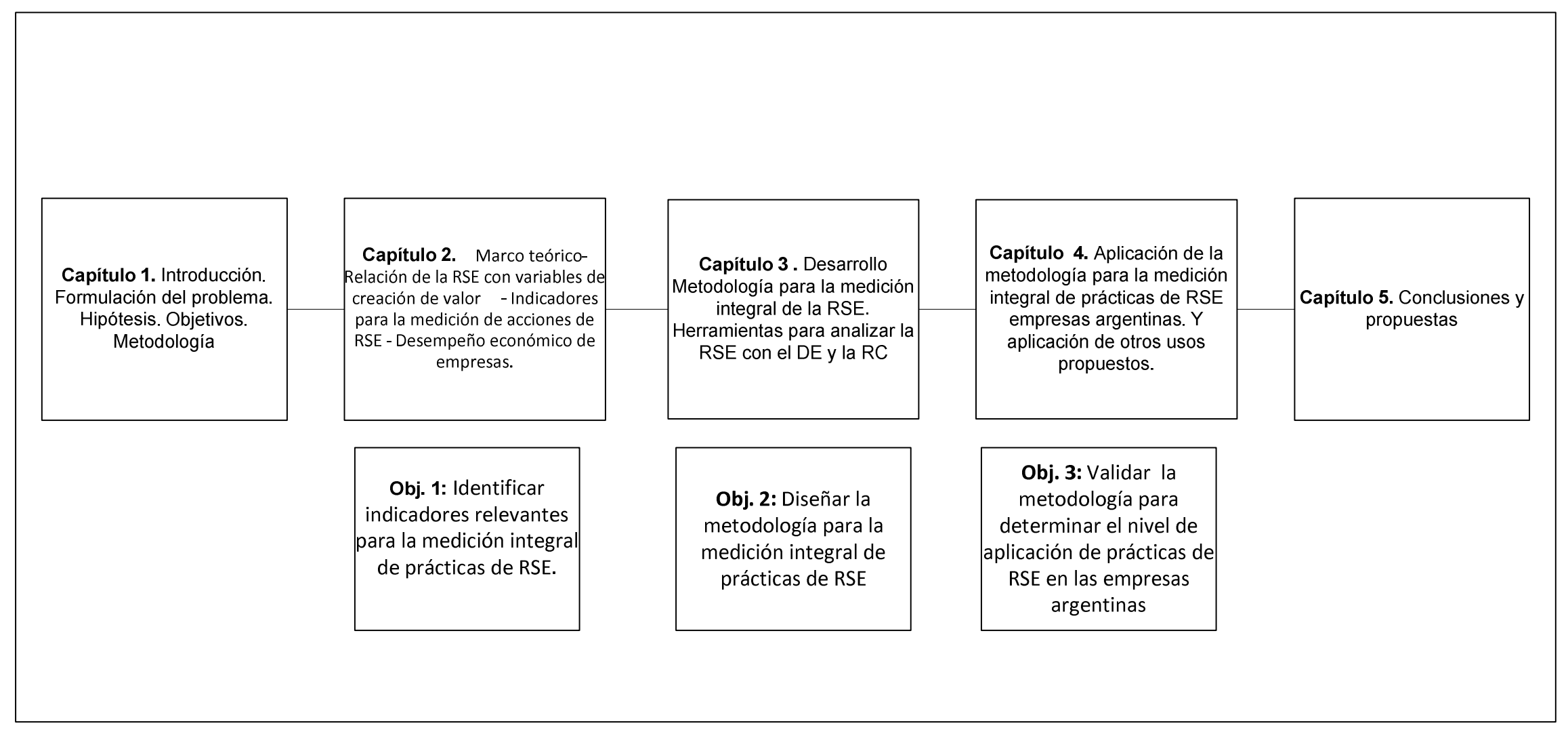

Fuente: elaboración propia. 


\section{CAPITULO 2: MARCO TEÓRICO}

En el siguiente capítulo se presenta el marco teórico de la investigación, cuya síntesis mediante un esquema de mapeo se presenta en primer lugar. De esta manera, el marco teórico se divide en 3 componentes:

1. Modelos para medir los efectos de la RSE sobre variables de creación de valor en las empresas.

2. Indicadores para la medición de prácticas de RSE.

3. Indicadores de performance financiera y de desempeño económico.

Este capítulo es fundamental ya que posibilita reconstruir y recuperar avances epistemológicos, teóricos y metodológicos sobre la temática, y presentando diversas posturas. Es por esa razón que se recurrió al análisis de artículos científicos como fuente de información. Es preciso resaltar que este análisis no se agotó con la compilación y sistematización de evidencias logradas por la investigación previa, sino que trasciende a la misma mediante la reflexión. Es así como se busca establecer lo ignorado y lo conocido del fenómeno, los límites y posibilidades de dicho conocimiento, de manera de poder identificar indicadores relevantes para la medición integral de prácticas de RSE, que posibiliten el desarrollo de la metodología, tal como lo estipula el objetivo central de esta tesis.

\subsection{Introducción}

En los últimos años ha proliferado la literatura sobre la Responsabilidad Social Empresaria (RSE), ya sea describiendo actuaciones, argumentando sobre su necesidad y/o presentando modos de entender la misma, por lo que se han propuesto numerosas definiciones o descripciones (Carné, D. M., 2007).

Al momento de definir qué se entiende por RSE no hay un consenso generalizado, desde distintos ámbitos se han generado definiciones, todas a ser tenidas en cuenta por sus respectivos impactos. Es por tal razón que, brevemente, se enunciarán algunos 
aportes a la definición de RSE efectuados desde las organizaciones de fomento de prácticas de RSE, así como desde el ámbito académico.

En primer lugar es de destacar el papel que ocupa el Pacto Global (Naciones Unidas):

“El objetivo del Pacto Mundial es promover el diálogo social para la creación de una ciudadanía corporativa global, que permita conciliar los intereses empresarios con los valores y el mandato de Naciones Unidas demandados por la sociedad civil, los sindicatos y los gobiernos. Estos valores se traducen en principios universales relacionados con la defensa de los derechos humanos, de los estándares laborales, del medio ambiente y de la lucha contra la corrupción. La iniciativa aspira a que las empresas adhieran a ellos voluntariamente y a que, en forma paulatina, los incorporen a la gestión de los negocios, para que penetren en su cultura organizacional y se conviertan en una guía para vincularse con los diferentes grupos de interés" (Liarte-Vejrup, 2015) .

También es importante mencionar la actuación del Instituto ETHOS: se trata de una asociación de empresas, sin fines de lucro, creada con la misión de movilizar, sensibilizar y ayudar a las empresas a gestionar sus negocios de forma socialmente responsable. El Instituto ETHOS sostiene:

"La responsabilidad social empresarial es la forma de gestión definida a partir de la relación ética y transparente de la empresa con todos los grupos con los cuales ella está relacionada y por el establecimiento de objetivos empresariales compatibles con el desarrollo social sostenible, conservando recursos ambientales y culturales para las futuras generaciones, respetando la diversidad y fomentando la reducción de las desigualdades sociales" (citado por Gorrochategui, 2012).

En la Argentina, el Instituto Argentino de Responsabilidad Social Empresaria (IARSE), fue creado a mediados del año 2002 con la misión de "promover y difundir el concepto y la práctica de la Responsabilidad Social Empresaria (RSE) para impulsar el desarrollo sustentable de Argentina, trabajando junto a las empresas a través de redes de información, intercambio de experiencias y colaboración mutua". 
EI IARSE parte de concebir a la RSE como:

“Modelo de gestión que contempla los impactos económicos, ambientales, éticos y sociales derivados de la actividad empresarial, el IARSE crea valor para las empresas y la sociedad trabajando junto al mundo de los negocios, generando herramientas de gestión y mecanismos de información e intercambio de experiencias. Promueve, además, la colaboración mutua entre las empresas que han decidido hacer de su conducta responsable un valor a partir del cual contribuir a la construcción de una sociedad más justa y sustentable" (IARSE, 2014).

Por otra parte, en el ámbito académico distintos autores han investigado sobre el tema y dado definición al concepto de RSE.

Si bien hay diversas definiciones es de destacar la manera en que Izquierdo (2004) la define como: "la libre voluntad de la empresa de aportar el mayor valor posible a sus diferentes grupos de interés". De allí se desprenden las siguientes ideas:

- Ante todo, se trata de una voluntad no obligada por imperativo legal. Si bien la RSE bien entendida exige un escrupuloso cumplimiento de la ley, las buenas prácticas a que da lugar deben rebasar las exigencias legales (si no, estaríamos ante la simple responsabilidad legal).

- En segundo lugar, esa voluntad de aportación de valor a cada stakeholder está condicionada por la paralela voluntad de tratar con criterio similar a los restantes. Con lo cual, sólo es posible entender adecuadamente la RSE desde una perspectiva global y presidida por el reiterado principio de equilibrio.

- Se trata de un principio que conduce a una tercera implicación: esa atención mesurada a todos los grupos de interés supone tomar en consideración todas las dimensiones de la actividad de la empresa.

Es importante aclarar que cuando se pretende crear "valor" para cada stakeholder, se asume la postura de Argandoña(2011), quien considera que el concepto de valor va 
más allá del valor extrínseco de naturaleza económica para incluir otros tipos de valores que los stakeholders también necesitan, como ser: valores extrínsecos inmateriales que proporciona la empresa (por ejemplo, algún tipo de formación), valores intrínsecos psicológicos (como la satisfacción por el trabajo realizado) y valores intrínsecos operativos (como podría ser la adquisición de conocimiento o capacidades).

A continuación, para organizar y edificar el marco teórico, se utilizó el "método de mapeo" propuesto por Hernández Sampieri y Méndez (2009). Este método implica elaborar un mapa conceptual y tomarlo como base para profundizar en la revisión de la literatura y el desarrollo del marco teórico. Como todo mapa conceptual, su claridad y estructura dependen de que sean seleccionados los términos adecuados, lo que a su vez se relaciona con un planteo inicial preciso.

De esta manera, se puede observar en la Imagen 2.1 y la Imagen 2.2 que el marco teórico presenta 3 grandes componentes:

1- Modelos para medir los efectos de la RSE sobre variables de creación de valor en las empresas.

2- Indicadores para la medición de prácticas de RSE.

3- Indicadores de performance financiera y de desempeño económico. 
Imagen 2.1. Mapa de la literatura desplegado en temas y subtemas

MARCO TEÓRICO: METODOLOGÍA PARA LA MEDICIÓN DE PRÁCTICAS DE RSE

Modelos para medir los efectos de la RSE sobre variables de creación de valor en las empresas

- 22 investigaciones académicas

- 8 países de diferentes contextos -Abordaje de la RSE

- Medidas abordadas

-Variables analizadas

-Metodologías aplicadas

Relación entre indicadores de RSE y otras variables de creación de valor

Conclusiones: abordar la RSE multidimensionalmente, posibilidad de relacionar la RSE con otras variables, uso de herramientas estadísticas.

Indicadores para la medición de prácticas de RSE

* Desarrollados por la academia (20 investigaciones, 11 países distintos) -Dimensiones abordadas por los indicadores

- Tipo de indicadores

- Forma de relevamiento

* Indicadores desarrollados por el GRI, relación con ODS

Conclusiones: utilización de indicadores GRI, desarrollo de indicadores cuantitativos integrales y por dimensión
Indicadores de performance financiera y de desempeño económico

- Tipos de indicadores financieros y no financieros

- Clasificación de medidas de performance financiera

- Medidas de rentabilidad

Conclusiones: Importancia de analizar la relación entre RSE con la rentabilidad y reputación corporativa

Fuente: elaboración propia. 
Imagen 2.2. Mapa de la literatura con principales autores

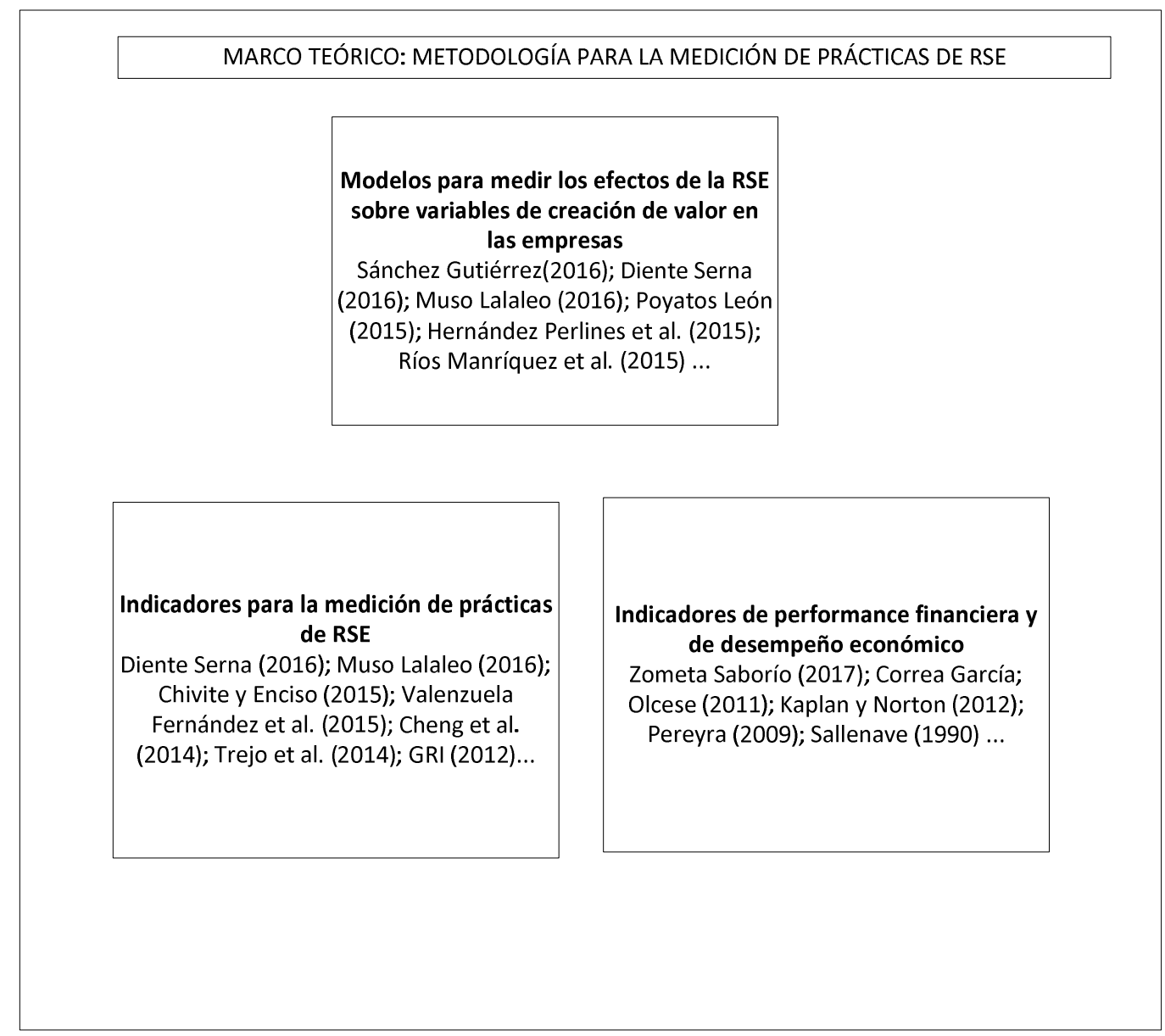

Fuente: elaboración propia.

Teniendo en cuenta la magnitud y diversidad de bibliografía analizada, se profundizó cada uno de los componentes en distintas secciones de este capítulo.

\subsection{Modelos para medir los efectos de la RSE sobre las variables de creación de valor en las empresas}

\subsubsection{Procedimiento utilizado}

En este apartado se exponen 22 investigaciones académicas que han abordado los efectos que se producen al interior de las organizaciones ante la aplicación de prácticas de Responsabilidad Social Empresaria (RSE), realizadas durante el período 2008-2016 en 8 países de diferentes contextos: España, México, Estados Unidos, Canadá, Chile, Colombia, Ecuador y Pakistán. Debido a la cantidad de investigaciones 
sobre el tema, así como la diversidad de variables y metodologías abordadas por las mismas, se requiere un método bien organizado de clasificación y categorización que permita el análisis posterior de los datos. El análisis de contenido parece ser un método apropiado para llevar a cabo esta tarea, ya que permite analizar las palabras y frases que han abordado los autores y clasificarlas en categorías más simples con la finalidad de descubrir patrones o tendencias en función de los objetivos de investigación planteados. Además, este análisis posibilita determinar la frecuencia de mención de determinadas palabras, las asociaciones entre ellas, o las similitudes y diferencias entre diferentes grupos de comentarios.

El estudio realizado consta de una primera fase donde se confeccionó una tabla resumen de las investigaciones analizadas que contempló:

- Abordaje de la RSE: integral, a través de dimensiones o ambas.

- Medidas utilizadas: contables, financieras, de percepción.

- Variables consideradas para el análisis.

- Metodología aplicada.

- Relación presente entre la RSE y otras variables.

\subsubsection{Investigaciones académicas que han abordado los efectos que se producen al interior de las organizaciones ante la aplicación de prácticas de RSE}

\section{Olaf, Weber (Canadá, 2008)}

En el marco de la Global Reporting Initiative (GRI) analizaron una muestra de 100 empresas de 19 países distintos durante el período 2002-2004, su trabajo se centró en responder los siguientes interrogantes:

- ¿Cuál es la relación entre el desempeño no financiero (ambiental, social, gobierno) y el desempeño financiero de las empresas? 
- ¿Cuál es la relación entre los impulsores de sostenibilidad y el desempeño financiero?

Para el análisis, se consideró la sostenibilidad corporativa desde los distintos aspectos que la componen, tales como el desempeño ambiental, social, económico y de gobernabilidad y a su vez, se abordaron distintos impulsores de las mismas considerando los indicadores del GRI.

Por otra parte, para cuantificar el desempeño financiero se utilizaron las siguientes medidas contables: resultado antes de intereses, impuestos y amortizaciones (EBITDA), resultados sobre el activo (ROA) y resultado sobre el patrimonio neto (ROE). Para medir la RSE, se analizaron los indicadores GRI y se generaron variables para las siguientes dimensiones: Performance Económica, Performance Medioambiental, Performance Social y Gobierno Corporativo.

En cuanto a la metodología, para analizar las relaciones entre los impulsores y los indicadores de resultado, se utilizó el análisis de regresión lineal múltiple. Las variables independientes fueron los indicadores del GRI y la variable dependiente fue el impacto sobre el desarrollo sostenible medido por los respectivos indicadores de resultados. Cabe aclarar que cada dimensión fue analizada por separado.

Para el análisis de la relación entre desempeño de sostenibilidad y desempeño financiero, se utilizó la regresión logística binaria. La hipótesis fue que los impulsores influyen positivamente en los indicadores de resultados, lo que influye positivamente en los indicadores financieros de una empresa.

La presente investigación demostró que los aspectos ambientales, sociales y económicos están en efecto correlacionados con el buen desempeño. Sin embargo, este resultado no se aplicó en el ámbito del gobierno corporativo. En conjunto, estos resultados sugieren que las empresas que han implementado políticas, estrategias y operaciones ambientales, económicas o sociales, contribuyen a las áreas de desarrollo sostenible correspondientes al disminuir sus impactos ambientales negativos. Con respecto a la segunda pregunta al inicio de la investigación, se dejó en evidencia 
relaciones significativas entre el desempeño de la sostenibilidad y el desempeño financiero.

\section{Longinos Marín Rives \&Alicia Rubio Bañón (España, 2008)}

En su trabajo plantearon las siguientes hipótesis:

- H1: La RSE influye de forma directa y positiva sobre la Estrategia Competitiva (EC).

- H2: El Grado de Rivalidad Competitivo (GRC) modera el efecto de la RSE sobre la EC. Este efecto será mayor si el GRC es alto, y será menor si el GRC es bajo.

Para llevar a cabo la investigación desarrollaron un cuestionario que fue enviado a 500 empresas de la región de Murcia (España), del cual se obtuvo una muestra válida definitiva de 144 respuestas.

Para medir los conceptos se utilizaron escalas procedentes de la literatura en organización de empresas, suficientemente testadas en el ámbito científico, todas ellas tipo Likert de 5 puntos. La metodología planteada presentó la ventaja de utilizar las dimensiones de RSE económica, legal, ética y discrecional. El Éxito Competitivo (EC) se midió utilizando la escala multidimensional propuesta en el modelo de Quinn y Rohrbaugh (1983), incluyendo variables cuantitativas y cualitativas, así como el uso de fuentes subjetivas. Por otra parte, el grado de rivalidad competitiva (GRC) se midió siguiendo el procedimiento utilizado por Garrigós y Camisón (2001), gracias a la utilización de una variable discreta en la que se le pregunta al gerente que califique bajo una de las posibilidades las características sobre su sector.

En cuanto a la metodología propuesta se realizó un análisis factorial confirmatorio (CFA). Para la realización del CFA se optó por el método de estimación de Máxima Verosimilitud Robusto (MVR). Cabe destacar que, gracias al CFA, fue posible evaluar de forma simultánea la multidimensionalidad y la fiabilidad de la medida de cada constructo y dimensión. 
Los resultados del contraste de las hipótesis afirman que la RSE como recurso competitivo tiene más impacto sobre el éxito competitivo en aquellos sectores que ya tienen un alto grado de rivalidad competitiva, ya que es justamente en ese caso cuando es más difícil obtener ventajas. No obstante, cuando la rivalidad competitiva es baja, las empresas que operan en el mercado explotarán otras ventajas derivadas de sus marcas, su tecnología o sus costes, entre otros, pasando en este caso la RSE a tener un efecto menor, aunque siga siendo un efecto significativo.

\section{María José Charlo Molina \& Ismael Moya Clemente (España, 2010)}

Contrastaron la hipótesis de si las empresas incluidas en el FTSE4Good IBEX presentaban un comportamiento diferente a sus semejantes en los índices IBEX, y si este efecto podía ser atribuible a la identificación de estas empresas con aspectos éticos y socialmente responsables. Por lo tanto, la muestra contempló empresas que se podían incluir en uno u otro grupo y que eran comparables entre sí. Para ello, se consideraron en la investigación como empresas socialmente responsables a aquellas que formaban parte del índice de sostenibilidad español, el índice FTSE4Good IBEX. Los criterios de inclusión se basaron en la exigencia del cumplimiento de un conjunto de estándares sociales, medioambientales y de gobierno corporativo. Se trató, por lo tanto, de analizar en qué medida dichos filtros podrían ser la causa de resultados financieros distintos a otras empresas que no contaban con estas prácticas de RSE. EI total de la muestra estuvo conformado por 87 empresas de las que 32 se consideraron socialmente responsables.

Respecto a la metodología utilizada por los autores, el análisis del comportamiento financiero de las empresas socialmente responsables se realizó mediante la elaboración de una base de datos de corte transversal. Las variables obtenidas a partir de datos de los mercados financieros se refirieron al período comprendido entre noviembre 2007 y noviembre 2008. El resto de las variables del estudio requirió información contable, para la cual se utilizó el ejercicio 2007. De este modo, la base de datos se conformó en base a las siguientes variables:

- Coeficiente Alfa: indica el exceso de rentabilidad sobre el riesgo asociado a un valor concreto, debido a sus propias características, en relación con el conjunto 
del mercado. Se utiliza para la evaluación de un título, comparando su rendimiento con el de un índice bursátil de referencia.

- Coeficiente Beta: mide el riesgo sistemático de la rentabilidad de un título en relación a la variación de la rentabilidad del mercado. Si la beta del título es mayor que 1 , tiene una volatilidad superior a la del mercado y se denomina agresivo ya que subirá y bajará más que el índice representativo del mercado. $\mathrm{Si}$, por el contrario, la beta es menor que 1 se le denomina defensivo y amortiguará los movimientos del mercado.

- Volatilidad: refleja los cambios bruscos en los precios de los distintos valores en función de diferentes variables económicas. Se calcula como la desviación típica anualizada de la tasa de variación del precio de un activo a lo largo de un período de tiempo.

- Rentabilidad financiera (ROE): relaciona el beneficio neto con los recursos propios implicados en su obtención. Se trata de la rentabilidad final que obtienen los propietarios de la empresa y por lo tanto una medida del coste de oportunidad de invertir en la misma.

- Beneficio por acción: es el cociente entre el beneficio neto de una empresa y el número de acciones. Está directamente relacionado con la rentabilidad (y por lo tanto con la cotización) de las acciones, siendo una medida más fiable que el dividendo por acción.

- Precio valor contable: este cociente guarda relación con diversos aspectos de la empresa, tales como el coste de capital, crecimiento, creación de valor, etc. Valores mayores de la unidad se consideran positivos y proporcionan una visión favorable sobre las expectativas de la empresa, reflejadas en la estimación que realiza el mercado de las mismas. 
Con el fin de contrastar la hipótesis de partida y verificar si existían diferencias significativas entre los dos grupos de empresas consideradas, teniendo en cuenta las variables descritas anteriormente, los autores crearon una variable dicotómica que tomó el valor 0 para las empresas que no formaban parte del FTSE4Good del (Índice Bursátil Español (IBEX) y el valor 1 para aquellas que se consideraron socialmente responsables. La metodología utilizada fue el análisis de varianza (ANOVA) de un factor, verificando la hipótesis de la igualdad de las medias de las variables financieras para cada grupo.

De los resultados obtenidos, se comprueba que las acciones de las empresas socialmente responsables obtienen una rentabilidad superior para un mismo riesgo sistemático, respecto a las empresas que no reúnen estos requisitos, el denominado "alfa ético", lo que representaría un aliciente para los inversores. También, se han detectado diferencias significativas en cuanto a su sensibilidad ante las oscilaciones del mercado, siendo mayor la prima de mercado en el caso de las empresas que pertenecen al índice sostenible. De todas formas, el valor promedio del coeficiente beta de las empresas con buenas prácticas fue inferior a 1 y pueden considerarse como títulos defensivos que amortiguarían las caídas bursátiles. Por lo que respecta al resto de las variables, la volatilidad es inferior en la cotización de las empresas socialmente responsables, si bien no existen diferencias significativas entre ambos grupos. Algo similar ocurre con la rentabilidad financiera y el precio valor contable; siendo ambas superiores en las empresas pertenecientes al FTSE4Good IBEX, no se confirma esta diferencia a nivel estadístico. Lo mismo se puede afirmar en el caso del beneficio por acción, aunque el valor de esta variable es mayor en las empresas no incluidas en el índice. De esta manera, la investigación confirmó que las empresas con buenas prácticas son tan rentables como el resto, e incluso en los mercados financieros pueden ofrecer una prima adicional.

\section{María del Mar Alonso-Almeida, et al. (México, 2010)}

Realizaron una investigación en la cual uno de los objetivos fue el de contribuir a extender el conocimiento del impacto de la RSE en las empresas desde el punto de vista financiero (sin prescindir del resto de los involucrados en las empresas, los grupos 
de interés). Para cumplir con el objetivo, seleccionaron una muestra formada por empresas que habían mantenido y renovado anualmente el distintivo de ESR (Cemefi) y, además, que cotizaban en la Bolsa Mexicana de Valores (BMV). En total, la muestra estuvo conformada por 19 empresas que representaban el 15\% de las empresas que cotizaban en la BMV y sólo el $5 \%$ de las empresas que eran responsables socialmente de acuerdo con el distintivo de ESR.

En cuanto a la metodología utilizada por Alonso-Almeida, M., et al. (2010), estos autores trabajaron con datos de panel para series de tiempo de corte transversal, ya que contaban con información de 19 empresas de la Bolsa Mexicana de Valores (BMV) para el período de 2001 al 2009.De esta manera, se plantearon distintos modelos estadísticos de regresión contemplando distintas variables dependientes obtenidas a partir de información contable: rendimiento sobre activos (ROA), rendimiento sobre capital (ROE), las utilidades por acción (UPA) y el crecimiento de las utilidades. En todos los casos las variables independientes fueron: "RSE" para definirla se utilizó una dummy en donde 1 refleja que la empresa tiene el distintivo de RSE otorgado en un año por Cemefi y 0 que no lo tiene; una variable de control que suponía el tamaño de la empresa medido como el logaritmo de los activos y otra variable más que medía el riesgo de la empresa a través del endeudamiento de la empresa (P/A).

Respecto a los resultados de la investigación, estos muestran los efectos positivos que en la empresa que cotizan en bolsa tiene el distintivo de RSE, puesto que resulta significativo su impacto, especialmente en las variables de desempeño financiero de valor de mercado. Según Alonso-Almeida et al. (2010) el hecho que sea precisamente en las variables de desempeño financiero de valor de mercado, sugiere que cuando se obtiene el distintivo, éste actúa como un anuncio al mercado de que la empresa está contribuyendo a mejorar su entorno, satisfacer las expectativas de sus grupos de interés e incrementar la riqueza en su comunidad. Por lo tanto, los inversionistas estarían considerando que esta empresa se esfuerza por tener un futuro sostenible y premian esta actividad con rendimientos anormales. La investigación puso de manifiesto también que las empresas con el distintivo tienen una más alta capitalización, con lo que probablemente estén en buena disposición para conseguir financiación externa que les permita desarrollar sus planes de desarrollo futuro. 


\section{Dylan Minor \& John Morgan (Estados Unidos, 2011)}

Realizaron un estudio que relacionó la reputación y la RSE para todas las empresas S\&P 500 durante el período 1991-2006.

En cuanto a la metodología propuesta por estos autores la misma consistió en un análisis de serie de tiempo que estudió la relación entre el precio de las acciones (utilizada como variable proxy para determinar la reputación de las empresas) y el índice de RSE seleccionado. Para esto último, se utilizó la medición realizada por MSCI KLD 400 Social Index, índice a través del cual se le asigna una puntuación (del 1 al 4) a cada una de las dimensiones de la RSE.

El principal hallazgo fue que la respuesta a los precios de las acciones, ante un evento adverso para la empresa, es significativamente menor en el caso de empresas involucradas con la RSE.

\section{Aldo Olcese (España, 2011)}

Examinó la evolución y tendencia de las recomendaciones e indicadores de RSE propuestas por la Real Academia de Ciencias Económicas y Financieras (RACEF) para cada una de las distintas áreas: gobierno, estrategia y estructura, sistemas, personas y operaciones en países en desarrollo. En la investigación, se analizaron los resultados obtenidos para los diferentes indicadores, se presentaron buenas prácticas destacadas y se identificaron las empresas con mejor puntuación. Por otra parte, se analizó la percepción de los directivos de las empresas estudiadas sobre la importancia de los distintos componentes y atributos del marco de creación de valor integral de la RSE.

Respecto a la muestra, se valoraron 33 sociedades españolas cotizantes en el IBEX35, durante el período 2007-2009.

La metodología utilizada por Olcese (2011) para dar respuesta a los objetivos consistió en una revisión exhaustiva de la literatura especializada. Luego, tomando en consideración las 44 recomendaciones y los 120 indicadores de RSE propuestos por la Real Academia de Ciencias Económicas y Financieras (RACEF), se elaboró un cuestionario, con el fin de llevar a cabo el relevamiento de la percepción de los 
directivos de las 33 firmas que conformaron la muestra. Cabe mencionar que siempre que fue posible, las respuestas al cuestionario fueron contrastadas con la información enviada por la propia empresa o publicada en su memoria de RSE o página web corporativa.

De esta manera, la investigación, en lugar de analizar la influencia de la RSE sobre las tradicionales medidas financieras de las empresas, se centró en estudiar las relaciones entre los elementos de la RSE y las variables intermedias que intervienen en el proceso de creación de valor: imagen de marca, gestión del riesgo, eficiencia laboral, posición competitiva, eficiencia operativa, oportunidades de crecimiento, capacidad innovadora y costo de capital.

A partir de los resultados obtenidos, se concluyó que existe una percepción claramente favorable sobre la importancia de la RSE en la creación de valor, demostrando que hay una asunción e interiorización clara por parte de los directivos y responsables de la RSE sobre los beneficios que proporciona la integración de los principios de la RSE en la gestión y estrategia de la empresa.

Por último, es importante destacar que el estudio concluye que los atributos derivados de la RSE que aportan mayor valor son, según las opiniones recogidas, la reputación, la gestión del riesgo y la eficiencia laboral. Por otra parte, perciben como menos decisivo el impacto de la RSE sobre factores generadores de ingresos como la posición competitiva, las oportunidades de crecimiento y la capacidad innovadora. Por lo tanto, la RSE es vista más como una necesidad que como una oportunidad.

\section{Martha Álvarez \&Ronald Vargas (Colombia, 2011)}

Para determinar cuáles son los beneficios que obtienen las empresas al incorporar la RSE en sus objetivos corporativos, los autores efectuaron una búsqueda y análisis bibliográfico en textos que referenciaran el tema, partiendo de analizar la RSE desde las dimensiones interna y externa planteadas en el Libro Verde. Así mismo, analizaron los informes sociales y de sostenibilidad presentados por las grandes empresas manufactureras del Área Metropolitana del Valle de Aburrá (Colombia), complementándose con encuestas efectuadas a algunos funcionarios de estas 
empresas encargados del manejo del tema de la RSE, así como consultas realizadas a algunos expertos en el tema.

La población que se seleccionó fueron las grandes empresas manufactureras del Área Metropolitana del Valle de Aburrá, las cuales fueron tomadas de la base de datos de CONFECÁMARAS, donde están inscriptas dichas empresas. Según esta base de datos, en el Área Metropolitana del Valle de Aburrá existían en ese momento 262 empresas, las cuales estaban incluidas en 23 subsectores que pertenecían a la industria manufacturera. La muestra se eligió según un criterio intencional, de acuerdo con la representatividad en el medio y al tamaño de las empresas, arrojando una muestra de 55 empresas con el fin de obtener resultados más efectivos. Lo primero que se hizo con las empresas seleccionadas fue efectuar un rastreo por sus páginas web con el fin de encontrar información que se publicara y que tuviera relación con el tema de la RSE. En esta primera parte, se encontró información de 12 empresas. Luego, se continuó con un rastreo telefónico con el fin de indagar si se trabaja el tema y conseguir una entrevista para realizar una encuesta o enviarla vía e-mail para que fuera contestada.

El trabajo luego del análisis bibliográfico y relevamiento concluye que los beneficios que tienen las empresas en general al incorporar la RSE en sus objetivos corporativos son los siguientes:

Dimensión Interna:

- Trabajadores: reducción de costos de operación; aumento del rendimiento financiero y económico de la empresa; capacidad de atraer y retener a un personal de calidad; disminución de ausencias y tardanzas del personal; mayor productividad del personal y la empresa; identificación total del personal con la empresa; y mejoramiento de la cultura organizacional.

- Medio Ambiente: reducción de los costos de producción, a través de control de desechos y eficiencia en el uso de la energía; mejor calidad de productos y condiciones favorables en el proceso de manufacturación; aumento de la reputación e imagen de la marca; y mayor innovación y competitividad hacia la 
creación y diseño de nuevos productos, servicios y procesos ambientales conscientes.

\section{Dimensión Externa:}

- Sociedad: respaldo de las instancias gubernamentales; confiabilidad y respaldo de los mercados financieros e inversionistas; atracciones de nuevos consumidores e inversionistas; y mejores relaciones comunitarias.

- Mercado: diferenciación y distinción de marca en el mercado; atracción y retención de nuevos consumidores; fortalecimiento de la lealtad del consumidor hacia la marca del producto o servicio; aumento de las ventas; mejor imagen ante los empleados, clientes, proveedores y accionistas; incremento del valor de la empresa; y oportunidad de nuevos negocios.

- Derechos Humanos: cumplimiento y respeto de leyes nacionales e internacionales; promoción de los estándares laborales para la realización de negocios transparentes y justos; disminución o eliminación de sanciones comerciales, campañas negativas y boicots; aumento en la productividad, rendimiento y retención del personal; satisfacción de las preocupaciones sociales del consumidor y mejoramiento de bienestar en la comunidad donde se opera.

\section{Nadeem Iqbal et al. (Pakistán, 2012)}

Analizaron 156 empresas cotizantes en la bolsa de Karachi (Pakistán), para el período 2010-2011. Se plantearon las siguientes hipótesis:

- H1: Un mayor desempeño socialmente responsable incrementa el valor de mercado de las acciones.

- H2: El desempeño financiero interviene en el desempeño socialmente responsable y en el valor de mercado de la acción. 
- H3: Un mayor desempeño socialmente responsable incrementa el nivel de endeudamiento de la firma.

- H4: El desempeño financiero interviene en el desempeño socialmente responsable y en el nivel de deuda de la empresa.

En cuanto a las variables seleccionadas para el análisis, los autores seleccionaron las siguientes medidas contables: ROA (rendimiento sobre activos), ROE (rendimiento sobre patrimonio neto), D/E (nivel de endeudamiento) y como variable de control el sector. Por otra parte, para medir la RSE utilizaron un índice ponderado que contempló: gobierno corporativo, principios de ética empresarial, cumplimiento ambiental, cumplimiento social, divulgación ambiental y social, la integridad del producto, las donaciones e inversiones corporativas en la comunidad, diálogo con las partes, seguridad en la cadena de ejecución financiera y la oferta.

En cuanto a la metodología utilizada, los autores efectuaron análisis de correlación entre pares de variables, así como distintas regresiones lineales para dar respuesta a las hipótesis planteadas.

Los resultados del estudio, en contraposición con todas las otras investigaciones analizadas, concluyeron que el desempeño social de las empresas (RSE) no tiene ningún efecto sobre el rendimiento financiero y que la RSE tiene efecto negativo en el valor de mercado de la acción, pero no tiene relación con el apalancamiento de la firma, de manera significativa.

\section{Harmony Palmer (Estados Unidos, 2012)}

En esta investigación se establecen como hipótesis:

- H1: un mejor desempeño en la RSE se relaciona con el crecimiento en el margen bruto de ventas

- H2: un mejor desempeño en la RSE se relaciona con el crecimiento en las ventas. 
Respecto a la muestra seleccionada en esta investigación, ésta estuvo conformada por 333 empresas incluidas en el S\&P 500.

En cuanto a la metodología, se llevaron a cabo en primer lugar para cada hipótesis un análisis de correlación entre las variables.

Para determinar qué empresas se consideraban socialmente responsables se utilizó el índice $\mathrm{MSCl}$ Index. Luego, para dar respuesta a la $\mathrm{H} 1$, se realizó un modelo de regresión cuya variable independiente fue la RSE y la variable dependiente el nivel de ventas. Cabe mencionar que la variable ventas se midió de dos maneras: ventas/cantidad de empleados y ventas/activo. Por otra parte, para dar respuesta a la H2, también se llevó a cabo un análisis de regresión, en el cual la variable independiente fue la RSE y la dependiente el margen de ventas. En ambos casos, se utilizaron como variables de control el tamaño, el riesgo y la industria.

Respecto a los resultados, se concluyó por una parte que un mejor desempeño en RSE genera un aumento en el margen bruto de ventas. Este resultado sugiere según Palmer, H (2012) que algunos clientes están dispuestos a pagar un precio más alto por los productos y/o servicios de empresas con programas de RSE efectivos. Muchas firmas acompañan aumentos en las inversiones de RSE con aumentos en su precio de productos/servicios. Ellos hacen esto para cubrir el costo de los gastos y creen que los consumidores encontrarán más valor en los programas de RSE que el costo de adición del producto. Por lo tanto, los ejecutivos pueden ser consolados por la evidencia de que algunos clientes aceptarán la prima si la empresa se involucra en iniciativas de RSE.

Por otra parte, no se demuestra la $\mathrm{H} 2$, es decir lo que indica que los aumentos en el desempeño de la RSE conducen a una disminución de las ventas. Los resultados indican entonces que algunas personas están menos dispuestas a comprar el producto y/o servicio de las empresas con mayor RSE y, por lo tanto las empresas pueden experimentar una disminución en la base de clientes. Como se ha explicado anteriormente, la aplicación de muchos programas de RSE va acompañada de un aumento de los precios de los productos/servicios. Por lo tanto, este resultado indica que menos personas están dispuestas a aceptar la prima. Esto sugiere que algunos 
consumidores o creen que el aumento en el costo de la prima supera el beneficio de los programas o no apoyan las causas de la RSE. Suponiendo que los aumentos en las inversiones en RSE lleven a aumentos en la performance de la RSE, estos resultados indican que los aumentos en las inversiones en RSE realmente disminuyen, no aumentan, las ventas.

\section{Juan Rositas Martínez, et al. (México, 2012)}

Estos autores se plantearon la pregunta de si la responsabilidad social empresarial tiene una relación de asociación positiva con la efectividad organizacional. Encuestaron a 133 directivos de pequeñas, medianas y grandes empresas del área metropolitana de Monterrey.

Los autores elaboraron un cuestionario, preguntando sobre distintos indicadores a los que debían asignársele un puntaje. El instrumento presentó la limitación de que los resultados correspondían a percepciones, tanto de las prácticas de RSE, como de la efectividad organizacional.

En cuanto a la metodología, se desarrolló una prueba Chi2 de Pearson y se calculó el coeficiente de contingencia. Como resultados se evidenció relación positiva entre la RSE y la efectividad organizacional.

\section{Manuel Larrán Jorge et al. (España, 2013)}

Analizando las Pymes, en su trabajo estudiaron la relación que en el ámbito de estas empresas mantienen el desarrollo de prácticas de RSE y el rendimiento competitivo.

De esta manera, plantearon un modelo cuyas hipótesis fueron:

- H1: El desarrollo de prácticas de RSE permite a las pymes mejorar su rendimiento competitivo.

- H2: Las mejoras relacionales (con los grupos de interés) ejercen una influencia mediadora en la relación que mantienen el desarrollo de prácticas de RSE y el rendimiento competitivo. 
Para la investigación se seleccionaron aleatoriamente empresas en base al listado SABI de empresas de la región de Murcia. De las empresas listadas, se realizó una selección en base a una frecuencia elegida al azar y a partir de una tabla de números aleatorios. No obstante, se establecieron los siguientes criterios de selección: empresas con 20 o más trabajadores, empresas en función del sector y rama de actividad. Para ello, con el fin de asegurar la representatividad de la muestra, se fijaron unas cuotas mínimas en base al número de empresas pertenecientes a las distintas ramas de actividad empresarial de la región. La muestra analizada fue de 481 empresas.

La información sobre las variables necesarias para el estudio fue recabada a través de un cuestionario dirigido a los gerentes de la empresa, o bien a los mandos intermedios responsables del área de responsabilidad social.

En cuanto a la metodología aplicada por Jorge et al. (2013), la misma consistió en una modelización de ecuaciones estructurales y análisis factorial con la intención de identificar posibles agrupaciones de variables con significado común. A su vez, realizada la adecuación para efectuar el análisis factorial exploratorio, se aplicó el método de factorización denominado análisis de componentes principales.

Este estudio permitió demostrar que la incorporación a la gestión organizativa de las PyMEs de prácticas relacionadas con la RSE contribuye a mejorar los resultados, corroborándose la existencia de una relación causal positiva y significativa entre el nivel de prácticas de RSE y el rendimiento competitivo, ya sea a través de una relación causal directa o mediante el impacto que tales prácticas pueden tener en la relación con los distintos grupos de interés.

\section{Dolores Gallardo Vázquez\& Isabel Sánchez-Hernández (España, 2013)}

Plantearon como hipótesis de su trabajo que las organizaciones que se orientan a la RSE consiguen mayores rendimientos e innovan más, consiguiendo un mayor éxito competitivo.

De esta manera establecieron como hipótesis: 
- Una mayor orientación a la responsabilidad social (RS) supondrá un mayor éxito competitivo;

- Una mayor orientación a la RS supondrá una mayor performance;

- Una mayor orientación a la RS supondrá un mayor nivel de innovación;

- Un mayor performance supondrá un mayor éxito competitivo;

- Un mayor nivel de innovación supondrá un mayor éxito competitivo.

En la investigación se analizó una muestra representativa de la realidad del tejido regional, la cual estuvo conformada por 777 empresas de Extremadura (España). El trabajo de campo se basó en llamadas telefónicas a los responsables de las empresas durante el mes de mayo de 2010. El índice de participación fue de un 11,07\% y correspondió al porcentaje de empresas en las que se ha localizado un interlocutor válido que ha accedido a participar en el estudio. Para la consecución de las 777 encuestas objetivo fue necesario que se contactaran con 7.022 empresas.

Como instrumento de relevamiento elaboraron un cuestionario a partir de las medidas diseñadas para cada constructo basándose en la literatura previa, con escalas Likert de 10 puntos donde el directivo tenía que posicionarse según sus percepciones entre "totalmente en desacuerdo" o "totalmente de acuerdo" con relación a las cuestiones de RS y entre "muy por debajo de la competencia" y "muy por encima de la competencia" en el resto de las variables del modelo. En cuanto a la metodología aplicada por los autores, la mencionada escala fue testeada mediante la aplicación de un modelo de ecuaciones estructurales basado en la metodología de Partial Least Squares (PLS), relacionando los cuatro constructos determinantes para la empresa ya mencionados: la orientación a la RS, la innovación, el éxito competitivo y la performance.

Como resultados, se puede mencionar que la validación del modelo recoge las vinculaciones planteadas de manera empírica, es decir la relación positiva entre RSE y la innovación, el éxito competitivo y la performance. 
Isabel González Ramos, et al. (España, 2014)

Centraron su trabajo en el sector de las energías renovables en España, trataron de superar las limitaciones existentes en otros trabajos previos aportando una nueva escala de medida para la RSE e incorporando la reputación corporativa como una variable mediadora en dicha relación.

A partir de una revisión de la literatura previa, construyeron una serie de escalas multiítem para medir tres dimensiones de la RSE, la reputación corporativa y los resultados económicos. Cada uno de los ítems se estableció en base a una escala Likert (1 "importancia concedida muy baja" y 5 "importancia concedida muy alta"). El trabajo siguió una perspectiva de elaboración del constructo de la RSE a partir de las dimensiones más aceptadas por la literatura (medioambiental, económica y social).

Por otra parte, también a través de escala de tipo Likert, se indagó sobre la reputación corporativa y los resultados económicos. Se trabajó con una variable de control: el tamaño, definido como el logaritmo natural de la cantidad de empleados.

En cuanto a la población y muestra seleccionada, el trabajo se llevó a cabo en empresas relacionadas con la actividad de generación de energías renovables. El número total de empresas que pasaron a formar parte de la población fue de 726 . El relevamiento se realizó entre septiembre y diciembre de 2012 a través de un cuestionario online a directivos de empresa o unidad de negocio y se recogieron datos referentes a los años 2010, 2011 y 2012. Tras contacto y seguimiento telefónico, se recogieron 76 cuestionarios válidos, que representó el 10.47 \% de tasa de respuesta.

Por otra parte, la metodología que se aplicó fue un modelo de ecuaciones estructurales (SEM). Concretamente, la técnica utilizada ha sido PLS (mínimos cuadrados parciales).

Como resultados de la investigación de González Ramos et al. (2014) se puede destacar que al introducir la reputación corporativa en el análisis, la relación directa entre la RSC y los resultados económicos deja de ser significativa como consecuencia del efecto mediador total que ejerce la reputación corporativa entre ambas variables. Observando los resultados se demuestra la existencia de una estrecha relación entre la 
RSE y la reputación corporativa; y entre esta última y los resultados económicos, por lo que se acepta la hipótesis de mediación total.

\section{Beiting Cheng et al. (Estados Unidos, 2014)}

Analizaron 2439 empresas cotizantes utilizando datos de Thompson Reuters ASSET4, para el período 2002-2009. En su investigación, plantearon como hipótesis que una mayor performance en RSE está relacionada con mayor acceso al financiamiento. Para medir la restricción de capital de las empresas, los investigadores utilizaron el índice KZ (desarrollado por Kaplan and Zingales, 1997), el mismo consiste en una combinación lineal de cinco índices contables: a) flujo de caja en relación al capital total, b) relación valor de mercado/libro, c) deuda en relación al capital total, d) dividendos en relación al capital total, y e) participación de efectivo en el capital. A su vez para dar mayor robustez a este indicador se calcularon otros indicadores, tales como SA Index basado en Hadlock and Pierce (2010) y el WW Index basado en Whitted and Wu (2006).

Por otra parte, para medir el desempeño de las empresas respecto a la RSE, se utilizó el índice de Thompson Reuters ASSET4 que mide el desempeño de las empresas en tres dimensiones ("pilares") de la RSE: la gobernabilidad social, ambiental y empresaria. Respecto a la metodología, se aplicó análisis de correlación, así como se definieron modelos de regresión, cuya variable dependiente fueron los índices de restricción de capital KZ, SA Index y WW Index, mientras que las variables independientes el índice de RSE, así como algunas variables de control, tales como tamaño, país, industria y año.

El trabajo evidenció que las empresas con mejor desempeño en RSE poseen más bajas restricciones de capital.

\section{María Peana Chivite \& Vicente Enciso (España, 2015)}

Analizando empresas españolas, en su artículo los autores se centraron principalmente en la creación de valor para el accionista, vía cuenta de resultados. De forma complementaria, se analizó si los informes de RSE suponían un aumento en la transparencia de las empresas; esto estaría en línea con la creación de valor para el 
accionista o inversor. Para ello, el análisis se centró en la actividad de 122 empresas españolas cotizadas en el período comprendido entre los años 2000 y 2009.

En cuanto a la metodología utilizada por los autores, utilizaron regresiones lineales (método empírico-analítico principalmente). En cuanto a las variables dependientes, las mismas fueron: el beneficio neto de la empresa y la rentabilidad económica (ROA), medida como cociente entre el beneficio neto y el activo. Como variable explicativa principal a analizar se introdujo la RSE.

Para medir la variable RSE, se utilizó el índice de revelación o de divulgación de RSE, el mismo toma los ocho índices siguientes: el Pacto mundial, las normas AA1000AS, SA8000, la inclusión en The Dow Jones Sustainability Indexes (DJSI), el EFQM, el Global Reporting Initiative (GRI), el FTSE4 Good y la mención e Informes de RSE presentados por las empresas.

Respecto de la primera hipótesis, se concluyó que la RSE afecta positivamente a la cuenta de resultados al ser significativa la variable RSE. Los resultados reflejaron una relación positiva entre la aplicación de medidas de RSE y la cuenta de resultados. Esto nos lleva a reforzar las afirmaciones sobre la creación de valor que supone para la empresa la aplicación de medidas de RSE, no solo por el valor añadido, en cuanto a la mejora social o medio ambiental que pueda suponer, sino porque las empresas que aplican RSE son más rentables. Finalmente y respecto al contraste de la segunda hipótesis marcada, en cuanto a si los informes de RSE suponen un incremento en la transparencia, los autores concluyen que la aplicación y publicación de las medidas de RSE supone una mayor rentabilidad y más transparencia para las empresas, por lo tanto se puede hablar de un valor añadido nada despreciable.

\section{Leslier Valenzuela Fernández, et al. (Chile, 2015)}

Analizaron empresas chilenas; la muestra estuvo conformada por 55 empresas no financieras que habían cotizado en la Bolsa de Comercio de Santiago para el período 2007-2012.

Los autores plantearon el siguiente modelo: la RSE (social, ética, medioambiental y colaboradores) influye en la Reputación Corporativa y esta última en el Desempeño 
Financiero. Para medir el desempeño financiero se utilizó la base de datos Datastream que provee información financiera confiable acerca de la empresa (crecimiento de ventas, market to book y rendimiento anual de las acciones). Por otra parte, para medir la RSE, se utilizaron las Memorias Anuales, sitios web, medios de comunicación y redes sociales para cada empresa. Con toda la información recabada se llevó a cabo una revisión que se basó en un análisis de contenidos que tuvo como objetivo recolectar y ordenar la información para así describir y caracterizar las distintas acciones estratégicas en el ámbito de la RSE que implementan las empresas.

Las variables explicativas fueron el resultado del análisis de contenido, los autores se centraron en la identificación de las distintas dimensiones por las cuales las empresas habían emitido información voluntaria acerca de prácticas en RSE.

En cuanto a la metodología desarrollada, además del análisis de contenido, se llevó a cabo un análisis de regresión (utilizando datos de panel), cuyas variables dependientes fueron las financieras (crecimiento de ventas, market to book y rendimiento anual de las acciones) y para las variables explicativas, se definieron: una variable (4DIM) dicotómica que toma el valor 1 si la empresa ha divulgado información en las cuatro dimensiones propuestas en su conjunto, "DSOCIAL" variable dicotómica que toma el valor 1 si la empresa ha divulgado información voluntaria desde una perspectiva social, "ETICA" variable dicotómica que toma el valor 1 si la empresa ha divulgado información voluntaria desde una perspectiva ética, "DSOCIAL" variable dicotómica que toma el valor 1 si la empresa ha divulgado información voluntaria desde una perspectiva social, "DAMB" variable dicotómica que toma el valor 1 si la empresa ha divulgado información voluntaria desde una perspectiva ambiental, "DCOLAB" es una variable dicotómica que toma el valor 1 si la empresa ha divulgado información voluntaria desde una perspectiva de colaboradores y "DREDES" una variable dicotómica que toma el valor 1 si la empresa ha divulgado información voluntaria a través de redes sociales. Luego se plantearon algunas otras variables independientes tales como: el logaritmo natural del total de activos, ROA (rentabilidad sobre los activos), el apalancamiento financiero medido como el nivel de deuda sobre patrimonio, los gastos de capital sobre las ventas, el porcentaje de participación del 
principal accionista y la tasa de pago de dividendos. A su vez, fueron controladas todas las estimaciones por efectos sectoriales y temporales.

También se utilizaron pruebas no paramétricas de Kruskal-Wallis para las dimensiones de estudio.

Los resultados dejaron de manifiesto que la implementación de las cuatro dimensiones en su conjunto, al igual que la dimensión ética y social, influye positivamente sobre el desempeño financiero.

\section{Martha Ríos Manríquez, et al. (México, 2015)}

Analizaron en el año 2013 a 296 empresas mexicanas; los sujetos objeto de la investigación fueron los dueños de las empresas, o en su caso, el máximo directivo. Para ello, se diseñó un instrumento a escala Likert. Se midieron las siguientes dimensiones:

- Desempeño empresarial: resultados cuantitativos y cualitativos obtenidos por una organización en un tiempo determinado.

- Comportamiento ético: conjunto de principios que guían la toma de decisiones del personal de la organización.

- Calidad Laboral: ambiente de trabajo favorable, estimulante, seguro, creativo, no discriminatorio y participativo en donde todos sus miembros interactúan a partir de bases justas de integridad y respeto que propician su desarrollo humano y profesional.

En cuanto a la metodología definda por estos autores, la investigación fue cuantitativa de tipo correlacional, ya que se buscó analizar la relación que existe entre el comportamiento ético y el desempeño empresarial, y entre calidad laboral y el desempeño laboral, con el desempeño empresarial. Se utilizaron tablas de frecuencia, pruebas chi2.

La investigación demuestra que existe una relación positiva y significativa entre el comportamiento ético y el desempeño empresarial, y entre la calidad laboral y el desempeño empresarial. 


\section{Felipe Hernández Perlines \& Juan Pablo Infante Hernández (España, 2015)}

Los autores analizaron las Micro, Pequeñas y Medianas Empresas (Mipymes) y realizaron una investigación en la que plantearon las siguientes hipótesis:

- H1: La adopción de medidas de RSE en todas sus dimensiones tiene una influencia positiva en el rendimiento económico de la Mipyme.

- H2: La adopción de medidas de RSE en su dimensión económica tiene una influencia positiva en el rendimiento económico de la Mipyme.

- H3: La adopción de medidas de RSE en su dimensión social tiene una influencia positiva en el rendimiento económico de la Mipyme.

- H4: La adopción de medidas de RSE en su dimensión medioambiental tiene una influencia positiva en el rendimiento económico de la Mipyme.

Los datos sobre las medidas de RSE se obtuvieron de los informes de sostenibilidad que habían sido elaborados bajo la iniciativa del ICO (Instituto de Crédito Oficial) y de la Caja Navarra (CAN). Dichos informes fueron realizados bajo los estándares internacionales del Global Reporting Initiative (GRI), en su versión G3. Los informes obtenidos correspondían a los años 2009 y 2010 y ascendieron a 2.098 memorias de sostenibilidad.

Para los datos económicos, utilizaron la base de datos SABI. Como no se disponía de datos económicos de todas las empresas que habían confeccionado informe de sostenibilidad, se realizó un cruce de datos, resultando un total de 278 Mipymes sobre las que se poseía toda la información precisa para la realización de la investigación.

Por otra parte, en el trabajo se optó por la utilización de medidas económicofinancieras para medir el rendimiento económico. Las variables independientes fueron: ingresos de explotación, resultados del ejercicio, total del activo y fondos propios. Los anteriores valores les permitieron medir el nivel de eficiencia interna de la empresa a nivel de negocio. 
Para alcanzar el objetivo del presente trabajo, se utilizó la técnica PLS (mínimos cuadrados parciales), la justificación de esta elección está motivada por la naturaleza exploratoria del trabajo, debido a que se utilizaron escalas no validadas por otros autores. Siendo esta técnica menos rígida respecto a requisitos mínimos sobre tamaño de la muestra, es adecuada para estimar parámetros en modelos complejos.

Una vez finalizado el análisis, se pudo afirmar la existencia de una correlación positiva entre la RSE y los rendimientos económicos. En el presente trabajo se habían planteado dos objetivos: el primero era determinar el tipo de influencia conjunta de las tres dimensiones de la RSE (económica, social y medioambiental) en los rendimientos económicos, y el segundo, determinar el tipo de influencia por separado de cada una de las dimensiones de la RSE en los rendimientos económicos. Dichos objetivos han quedado cumplidos, ya que los modelos planteados muestran una influencia positiva de la RSE en los rendimientos económicos de las Mipymes, tanto de forma agregada como de forma individual.

\section{Juan Ángel Poyatos León (España, 2015)}

En su trabajo planteó como objetivo analizar las relaciones entre la RSE y la performance financiera de empresas europeas, buscando una posible relación causal entre ambas dimensiones.

Cabe destacar que para llevar a cabo la investigación, se introdujo un desfase temporal de tres años al medir la relación entre la RSE y los resultados financieros de las empresas (debido a que diversos autores afirman que el impacto de la RSE en el rendimiento es a medio plazo) y separando el análisis entre empresas de sectores cuyo comportamiento (desde un punto de vista RSE) es homogéneo o heterogéneo (puesto que a su vez, numerosos autores indican que el sector es una variable moderadora muy importante).

Respecto a la población objeto del estudio, el análisis se llevó a cabo sobre empresas con base europea recogidas en la base de datos de EIRIS, buscando especialmente relaciones de causalidad entre la RSE y los resultados financieros de las empresas analizadas. Los datos de las variables económico-financieras fueron recogidos de la 
base de datos Amadeus. Cabe aclarar que la misma es una reconocida base de datos de información financiera comparable que recopila datos de más de 19 millones de empresas en toda Europa, ampliamente utilizada como herramienta de investigación de organizaciones empresariales, así como para efectuar análisis.

La base de datos dispone de información de 9 años (2003 a 2011), lo cual es un horizonte temporal bastante amplio, además de disponer de información muy actualizada (el momento de la adquisición de la base de datos fue 2012). Respecto al número de empresas analizadas, solo se contaba de información de 449 de ellas para todos los años, siendo 526 empresas las que se repetían desde el año 2003 hasta el 2010.

El análisis de la investigación se centró en la dimensión "Grupos de Interés", para determinar si existía o no relación causal entre la dimensión Grupos de Interés y los resultados financieros de las empresas analizadas. Para hacerlo, se planteó un Sistema de Ecuaciones Estructurales (SEM). Se determinó de esta manera, si los factores de la dimensión Grupos de Interés, mantenían una relación causal con la performance financiera de empresas de los sectores homogéneos y heterogéneos, manteniendo el desfase temporal de 3 años.

Respecto a la limitación de unir empresas de sectores dispares, se crearon dos grupos de empresas para llevar a cabo el análisis y para determinar si realmente ése era un elemento determinante o no. Se agruparon a las empresas provenientes de sectores cuyo comportamiento era homogéneo (desde un punto de vista de RSE) y empresas cuyo comportamiento era heterogéneo (esta clasificación se obtuvo a través de diversas tablas de contingencia de las empresas que contiene la base de datos de EIRIS). Esté paréntesis puede ser una nota al pie de página. En concreto, los sectores calificados como homogéneos fueron Banks, Technology Hardware \& Software, Construction \& Materials, y Oil, Gas \& Electricity (204 empresas). Por otro lado, los sectores calificados como heterogéneos fueron Media, General Industrial \& Engineering, y Real State \& Investment (156 empresas).

En cuanto a las variables seleccionadas para medir el desempeño económicofinanciero, las mismas fueron: resultados antes de impuestos, flujo de caja, margen de 
beneficio, ROE, solvencia, ingresos netos, número de empleados, total de activos, nivel de capitalización de mercado, ingresos operativos (facturación).

Al final de este análisis, se llegó a la conclusión de que al vincular las variables que miden el comportamiento socialmente responsable de las empresas analizadas (tanto de sectoreshomogéneos como heterogéneos) con las variables económico-financieras seleccionadas de las mismas empresas, no se producía ninguna correlación (positiva o negativa), al no ser significativo el resultado alcanzado. Estos resultados se repiten tanto teniendo en cuenta o no el desfasaje temporal de 3 años.

A su vez, al analizar los grupos de interés, solamente uno de los factores: Grupo de interés Empleados, con un nivel de significación del 95\%, afecta de manera positiva los rendimientos de las empresas procedentes de los sectores homogéneos analizados. El resto de los factores de los Grupos de Interés no afectan los rendimientos.

\section{Jessica Muso Lalaleo (Ecuador, 2016)}

Realizó una investigación cuyo objetivo fue analizar la influencia de la responsabilidad social empresarial en la imagen corporativa y rendimiento financiero de las Pymes para conocer los factores causales de la mejora en la gestión social. Es así como en el trabajo se establecieron las siguientes hipótesis:

- H1: La RSE influye positivamente en la imagen corporativa de las Pymes.

- H2: La RSE influye positivamente en el rendimiento financiero de las Pymes.

La presente investigación consideró como unidad de estudio a miembros de CERES, también a empresas escogidas al azar dentro de la revista Ekos, cuyos resultados económicos se encuentran publicados en la superintendencia de compañías de Ecuador. De esta manera, la población está constituida por 52 empresas distribuidas en 5 sectores. Al seleccionar las empresas se consideró incluir aquellas medianas y grandes, debido a que son este tipo de empresas las que disponen de memorias de responsabilidad social y estados financieros publicados en los organismos de control y en sus páginas web empresariales. 
Para la investigación se utilizó información de fuentes primarias: una lista de verificación en las páginas web de las distintas empresas subdivida en 5 dimensiones (social, ética, ambiental, colaboración y redes). Posteriormente, se aplicaron parámetros de medición que se encuentre entre rangos de 0 y 1 , donde se valoraron los ítems bajo una calificación dicotómica, de forma que un determinado ítem se valoró con un "1" si se disponía de la información, y con " 0 ", en caso contrario. Por otro lado, se obtuvo información financiera publicada en la Superintendencia de Compañías (empresas comerciales), la Superintendencia de Bancos y Seguros (bancos) así como, de la Superintendencia de Economía Popular y Solidaria (cooperativas), a partir de la cual se procedió a elaborar una base de datos de las cifras económicas de los últimos 2 años (2014 y 2015). Cabe aclarar que la verificación se llevó a cabo a partir de los meses de febrero y mayo del 2016.

En este sentido, se procedió a realizar para cada dimensión analizada un subíndice, definido mediante el cociente entre la sumatoria del número del total de ítems identificados y el número total de ítems que constituyen el subíndice. Luego, para expresar de manera general la variable de responsabilidad social, se consideró el valor de cada uno de los subíndices calculados para cada dimensión, dividido la cantidad de subíndices.

Por otro lado, para determinar la variable imagen corporativa, se consideró el incremento en las ventas.

Finalmente, para conocer la relación del Rendimiento Financiero se consideraron las siguientes variables: rendimiento sobre activos (ROA), liquidez, rentabilidad sobre ventas, endeudamiento.

De la investigación de Muso Lalaleo (2016), se puede destacar que la imagen corporativa está correlacionada con las actividades de ética (p-valor 0.01), colaboración ( $p$-valor 0.038 ) y redes ( $p$-valor 0.031). De esta manera, se ha verificado la primera hipótesis ya que el análisis demostró que las pymes que realizaban actividades de responsabilidad social en estas dimensiones tenían un efecto positivo en su imagen corporativa. Por otra parte, para verificar la segunda hipótesis se analizaron varios indicadores financieros; y se llegó al resultado de que las actividades 
de RSE en las Pymes específicamente en ética ( $p$-valor 0.038) influían en la rentabilidad sobre el activo y al mismo tiempo en la rentabilidad sobre ventas ( $p$-valor 0.003 ). De igual manera, las actividades de colaboración de empleados ( $p$-valor 0.042) y redes ( $p$ valor 0.015) también se correlacionaban con la rentabilidad sobre las ventas. Esto quiere decir que la hipótesis 2 se ha verificado, permitiendo concluir que las actividades de responsabilidad social tienen un efecto positivo en la rentabilidad de las Pymes.

\section{Sonia Diente Serna (España, 2016)}

Su investigación tuvo como objetivo analizar la vinculación entre rendimiento financiero y las actuaciones de RSE.

La muestra y parte de la información requerida fue obtenida de la base de datos Amadeus, la cual contiene información económico-financiera de entidades ubicadas en Europa. Para la elección de las empresas de la muestra, se acotaron en primer lugar aquellas que tuvieran su domicilio social en la provincia de Valladolid (España). A continuación, se procedió a seleccionar solamente las entidades que, en el momento de la búsqueda, figuraban como activas y presentaban información económicofinanciera individual. Una vez realizada la búsqueda el recuento de empresas ascendió a 1.737, de las cuales 26 fueron descartadas por contener información incorrecta o repetida, quedando una primera muestra integrada por un total de 1.711 empresas. Posteriormente, y en función de los objetivos planteados en el estudio, un aspecto esencial era saber si las empresas que conformaban la muestra poseían página web que permitiese evidenciar si suministran información de las actuaciones de RSE que realizan. Para ello, se procedió a la búsqueda de la página web de cada una de estas entidades, encontrándose que 940 no disponían de web corporativa. Por lo tanto, más de la mitad de las empresas de la muestra inicial (54,93\%) no tenía página web, motivo por el cual fueron eliminadas de la muestra. En consecuencia, la muestra definitiva empleada en el estudio se compuso de 771 empresas activas ubicadas en la provincia de Valladolid. Por otra parte, con el objetivo de que se obtuviera de cada una de las empresas información de todos los indicadores de rendimiento financiero, se 
eliminaron las empresas que no incorporaban información en alguno de los ratios, quedando la muestra reducida para realizar este análisis a 627 empresas.

Las tres dimensiones de RSE analizadas fueron: económica, social y recursos humanos. Para la generación del indicador se le dio el mismo peso relativo a cada dimensión, de tal forma que el mayor valor que pudo alcanzar el indicador que midió el grado de actuaciones de RSE fue de 3. Es decir, cuando una empresa tuvo un grado de actuaciones de RSE correspondiente a3, indicaba que proporcionaba información sobre acciones medioambientales, de recursos humanos y enfocados a la sociedad.

De esta manera, para construir el indicador del grado de actuaciones de RSE, se consultó la página web de cada una de las empresas de la muestra y se comprobó si incluía información que estuviera relacionada con alguna de estas tres dimensiones.

Para abordar los rendimientos económico-financieros se utilizaron los siguientes indicadores: la rentabilidad financiera, la rentabilidad económica y el margen de beneficios neto.

Con el fin de analizar si en las empresas de la muestra se podía establecer una vinculación entre el rendimiento empresarial y el grado de actuaciones de RSE, se procedió a recopilar información económico-financiera de estas entidades en la base de datos Amadeus. Los datos más actualizados y que proporcionaban información de un mayor número de empresas de la muestra correspondieron al ejercicio económico 2014.

Por último, la investigación de Diente Serna (2016) dejó en evidencia que el promedio de los indicadores de rendimiento es superior en las empresas que realizan actuaciones de RSE que en las que no las realizan. Asimismo, se ha observado que las firmas que han llevado a cabo prácticas en los tres ámbitos son las que han logrado mayores rendimientos financieros, siendo muy superiores a los de las entidades que no han comunicado ninguna práctica sostenible.

\section{José Sánchez Gutiérrez (México, 2016)}

Esta investigación estableció como propuesta principal que la Responsabilidad Social impacta positivamente en la ventaja competitiva de la empresa, pero que esta última 
no sólo se explica mediante la RSE, sino también por la reducción de costos, el desempeño tecnológico y el desempeño financiero

Para dar respuesta al objetivo planteado, se aplicó un cuestionario en 450 empresas manufactureras ubicadas en la ciudad de Guadalajara, México en el 2012.Se usó el muestreo simple aleatorio sobre un universo de 2847 empresas. El estudio originalmente buscaba explicar la relación entre la Responsabilidad Social y la ventaja competitiva en las empresas analizadas. Debido a que la alta gerencia es quien tiene información sobre la temática y mucha es confidencial, se procedió a la aplicación de un estudio de percepción, de esta manera se relevó una encuesta a los directivos de las empresas. Las preguntas estaban encaminadas a medir la intensidad o el grado de sentimiento respecto a una variable, aplicándose para esto una escala Likert.

Los cuestionarios, toda vez que fueron respondidos, permitieron usar ecuaciones estructurales para un análisis e interpretación preliminar. La fiabilidad y validez se evaluó a través del Análisis Factorial Confirmatorio (AFC).

Sánchez Gutiérrez (2016) demostró a través de su investigación que, según la percepción de los directivos, es clara la relación entre el desempeño financiero, la disminución de los costos y el desempeño tecnológico con la ventaja competitiva. A su vez, de esta misma forma, los directivos vincularon la RSE con la ventaja competitiva. Sin embargo, perciben que la RSE está desvinculada del desempeño tanto financiero como tecnológico y consideran que la RSE aumenta los costos.

\subsubsection{Metodología abordada para el análisis bibliográfico}

En primer lugar, se expondrá en la Tabla 2.1 un resumen de los autores mencionados en el apartado anterior que permite sintetizar varios aspectos: el abordaje de la RSE, las medidas abordadas, las variables analizadas, las metodologías y las relaciones que se presentan entre la RSE y otras variables. Sobre este resumen posteriormente se aplicará el análisis de contenido. 
Tabla 2.1 Síntesis Análisis Bibliográfico

\begin{tabular}{|c|c|c|c|c|c|c|c|c|c|}
\hline \multirow[b]{2}{*}{ Autores } & \multicolumn{3}{|c|}{ Abordaje de RSE } & \multicolumn{3}{|c|}{ Medidas analizadas } & \multirow[b]{2}{*}{ Variables analizadas } & \multirow[b]{2}{*}{ Metodología } & \multirow[b]{2}{*}{ Relación } \\
\hline & Integral & Dimensiones & Ambas & Contables & Financieras & Percepción & & & \\
\hline $\begin{array}{l}\text { Weber, etal } \\
\text { (2008) }\end{array}$ & & $\begin{array}{c}\text { Económica } \\
\text { Medioambiental } \\
\text { Social } \\
\text { Gobierno corporativo }\end{array}$ & & $\mathrm{x}$ & & & $\begin{array}{c}\text { EBITDA } \\
\text { ROA } \\
\text { ROE } \\
\text { Indicadores del GRI }\end{array}$ & $\begin{array}{l}\text { Análisis de Regresión Lineal } \\
\text { Múltiple }\end{array}$ & $\begin{array}{l}\text { Aspectos ambientales, } \\
\text { sociales y económicas } \\
\text { están correlacionadas con } \\
\text { el buen desempeño }\end{array}$ \\
\hline $\begin{array}{l}\text { Rives, L. M., \& } \\
\text { Bañón, (2008) }\end{array}$ & & $\begin{array}{l}\text { Económica, legal, ética y } \\
\text { discrecional }\end{array}$ & & & & $\mathrm{x}$ & $\begin{array}{c}\text { Percepción sobre: } \\
\text { dimensiones de RSE } \\
\text { (económica, legal, ética y } \\
\text { discrecional), éxito } \\
\text { competitivo y rivalidad } \\
\text { competitiva }\end{array}$ & $\begin{array}{c}\text { Análisis factorial } \\
\text { confirmatorio - método de } \\
\text { Estimación de Máxima } \\
\text { Verosimilitud Robusto } \\
\text { (MVR) }\end{array}$ & $\begin{array}{c}\text { La RSE como recurso } \\
\text { competitivo tiene más } \\
\text { impacto sobre el éxito } \\
\text { competitivo en aquellos } \\
\text { sectores que ya tienen un } \\
\text { alto grado de rivalidad } \\
\text { competitiva } \\
\end{array}$ \\
\hline $\begin{array}{l}\text { Charlo Molina \& } \\
\text { Moya Clemente } \\
\text { (2010) }\end{array}$ & $\begin{array}{l}\text { Índice de sostenibilidad } \\
\text { FTSE4Good IBEX }\end{array}$ & & & $\mathrm{x}$ & $\mathrm{x}$ & & $\begin{array}{c}\text { Coeficiente alfa (exceso } \\
\text { de rentabilidad sobre el } \\
\text { riesgo) } \\
\text { Beta } \\
\text { Volatilidad } \\
\text { ROE } \\
\text { Beneficio por acción } \\
\text { Precio valor contable }\end{array}$ & $\begin{array}{l}\text { Análisis de varianza } \\
\text { (ANOVA) de un factor }\end{array}$ & $\begin{array}{l}\text { Empresas con buenas } \\
\text { prácticas son tan rentables } \\
\text { como las otras, y pueden } \\
\text { ofrecer una prima adicional } \\
\text { en los mercados financieros }\end{array}$ \\
\hline $\begin{array}{l}\text { Alonso-Almeida, } \\
\text { et al. (2010) }\end{array}$ & Distintivo de ESR (Cemefi) & & & $\mathrm{x}$ & $\mathrm{x}$ & & $\begin{array}{c}\text { ROA } \\
\text { ROE } \\
\text { UPA y el crecimiento de } \\
\text { las utilidades. } \\
\text { Variables de control } \\
\text { logaritmo de los activos y } \\
\text { endeudamiento de la } \\
\text { empresa (P/A) }\end{array}$ & $\begin{array}{c}\text { Análisis de Regresión Lineal } \\
\text { Múltiple }\end{array}$ & $\begin{array}{l}\text { Los resultados obtenidos } \\
\text { muestran que existe una } \\
\text { relación positiva entre el } \\
\text { desempeño financiero y la } \\
\text { obtención de dicho } \\
\text { distintivo en las variables } \\
\text { financieras ROE y ROA, en } \\
\text { las utilidades por acción } \\
\text { (UPA) y en el ratio de } \\
\text { precio entre valor de libros } \\
\text { (P/VL) }\end{array}$ \\
\hline
\end{tabular}




\begin{tabular}{|c|c|c|c|c|c|c|c|c|c|}
\hline \multirow[b]{2}{*}{ Autores } & \multicolumn{3}{|c|}{ Abordaje de RSE } & \multicolumn{3}{|c|}{ Medidas analizadas } & \multirow[b]{2}{*}{ Variables analizadas } & \multirow[b]{2}{*}{ Metodología } & \multirow[b]{2}{*}{ Relación } \\
\hline & Integral & Dimensiones & Ambas & Contables & Financieras & Percepción & & & \\
\hline $\begin{array}{l}\text { Minor \& Morgan } \\
\quad(2011)\end{array}$ & MSCI KLD 400 Social Index & & & & 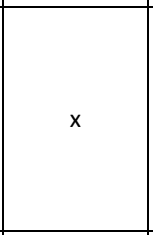 & & Precio de las acciones & $\begin{array}{l}\text { Serie de tiempo } \\
\text { (correlación entre } \\
\text { variables) }\end{array}$ & $\begin{array}{l}\text { La baja de los precios de } \\
\text { las acciones, ante un } \\
\text { evento adverso para la } \\
\text { empresa, es } \\
\text { significativamente menor } \\
\text { en el caso de empresas } \\
\text { socialmente responsables }\end{array}$ \\
\hline Olcese, (2011) & $x$ & & & & & $x$ & $\begin{array}{c}\text { Variables intermedias que } \\
\text { intervienen en el proceso } \\
\text { de creación de valor: } \\
\text { imagen de marca, gestión } \\
\text { del riesgo, eficiencia } \\
\text { laboral, posición } \\
\text { competitiva, eficiencia } \\
\text { operativa, oportunidades } \\
\text { de crecimiento, capacidad } \\
\text { innovadora y costo de } \\
\text { capital. } \\
\end{array}$ & Tablas de frecuencias & $\begin{array}{l}\text { Percepción claramente } \\
\text { favorable sobre la } \\
\text { importancia de la RSE en la } \\
\text { creación de valor }\end{array}$ \\
\hline $\begin{array}{c}\text { Álvarez \& Vargas } \\
\text { (2011) }\end{array}$ & $x$ & & & & & $\mathrm{x}$ & $\begin{array}{l}\text { Beneficios sobre los } \\
\text { trabajadores; } \\
\text { medioambiente, } \\
\text { sociedad, mercado }\end{array}$ & $\begin{array}{l}\text { Tablas de frecuencia } \\
\text { Análisis de contenido }\end{array}$ & $\begin{array}{c}\text { Relación positiva entre RSE } \\
\text { y los trabajadores, } \\
\text { medioambiente y sociedad }\end{array}$ \\
\hline Iqbal et al. (2012) & Índice ponderado & $\begin{array}{c}\text { Índice ponderado que } \\
\text { contemple las dimensiones } \\
\text { de la RSE }\end{array}$ & $x$ & $x$ & & & $\begin{array}{l}\text { ROA } \\
\text { ROE } \\
\text { D/E } \\
\text { Sector }\end{array}$ & $\begin{array}{l}\text { Correlación } \\
\text { Regresiones lineales }\end{array}$ & $\begin{array}{l}\text { El desempeño social de las } \\
\text { empresas (RSE) no tiene } \\
\text { ningún efecto sobre el } \\
\text { rendimiento financiero y la } \\
\text { RSE tiene efecto negativo } \\
\text { en el valor de mercado de } \\
\text { la acción, pero no tiene } \\
\text { relación con el } \\
\text { apalancamiento de la firma } \\
\text { de manera significativa. }\end{array}$ \\
\hline
\end{tabular}




\begin{tabular}{|c|c|c|c|c|c|c|c|c|c|}
\hline \multirow[b]{2}{*}{ Autores } & \multicolumn{3}{|c|}{ Abordaje de RSE } & \multicolumn{3}{|c|}{ Medidas analizadas } & \multirow[b]{2}{*}{ Variables analizadas } & \multirow[b]{2}{*}{ Metodología } & \multirow[b]{2}{*}{ Relación } \\
\hline & Integral & Dimensiones & Ambas & Contables & Financieras & Percepción & & & \\
\hline Palmer(2012) & índice MSCI Index & & & $\mathrm{x}$ & & & $\begin{array}{c}\text { Ventas/cantidad de } \\
\text { empleados y ventas/activo } \\
\text { margen de ventas } \\
\text { Variables de control: } \\
\text { tamaño, el riesgo y la } \\
\text { industria }\end{array}$ & Análisis de regresión & $\begin{array}{c}\text { Mejor desempeño en RSE } \\
\text { genera un aumento en el } \\
\text { margen bruto de ventas y } \\
\text { conduce a una disminución } \\
\text { de las ventas }\end{array}$ \\
\hline $\begin{array}{l}\text { Martinez et al. } \\
\quad(2012)\end{array}$ & $\mathrm{x}$ & & & & & $\mathrm{x}$ & $\begin{array}{l}\text { Percepción sobre: RSE y } \\
\text { efectividad organizacional }\end{array}$ & $\begin{array}{c}\text { Pruebas Chi2 y Coeficiente } \\
\text { de contingencia }\end{array}$ & $\begin{array}{l}\text { Relación positiva entre RSE } \\
\text { y efectividad organizacional }\end{array}$ \\
\hline $\begin{array}{l}\text { Larrán Jorge, } \\
\text { Madueño\& } \\
\text { Martínez } \\
\text { (2013) }\end{array}$ & & $\begin{array}{c}\text { Medioambiente, } \\
\text { empleados, sociedad y } \\
\text { clientes. }\end{array}$ & & & & $\mathrm{x}$ & $\begin{array}{l}\text { Percepción de los } \\
\text { empresarios }\end{array}$ & $\begin{array}{l}\text { Modelización de ecuaciones } \\
\text { estructurales, análisis } \\
\text { factorial con la intención de } \\
\text { identificar posibles } \\
\text { agrupaciones de variables } \\
\text { con significado común. } \\
\text { Análisis de componentes } \\
\text { principales }\end{array}$ & $\begin{array}{l}\text { Existencia de una relación } \\
\text { causal positiva y } \\
\text { significativa entre el nivel } \\
\text { de prácticas de RSE y el } \\
\text { performance competitivo, } \\
\text { ya sea a través de una } \\
\text { relación causal directa o } \\
\text { mediante el impacto que } \\
\text { tales prácticas puede tener } \\
\text { en la relación con los } \\
\text { distintos grupos de interés }\end{array}$ \\
\hline $\begin{array}{l}\text { Gallardo } \\
\text { Vázquez et al. } \\
\text { (2013) }\end{array}$ & $x$ & $\begin{array}{c}\text { Social } \\
\text { Económica } \\
\text { Ambiental }\end{array}$ & $\mathrm{x}$ & & & $\mathrm{x}$ & $\begin{array}{l}\text { Éxito competitivo } \\
\text { Performance } \\
\text { Innovación }\end{array}$ & Análisis estructurado & $\begin{array}{l}\text { Relación positiva entre la } \\
\text { RSE con: la innovación, el } \\
\text { éxito competitivo y el } \\
\text { rendimiento }\end{array}$ \\
\hline $\begin{array}{l}\text { González } \\
\text { Ramos et al. } \\
\text { (2014) }\end{array}$ & $\mathrm{x}$ & $\begin{array}{c}\text { Social } \\
\text { Económica } \\
\text { Ambiental }\end{array}$ & $\mathrm{x}$ & & & $\mathrm{x}$ & $\begin{array}{c}\text { Reputación } \\
\text { Resultados Económicos } \\
\text { Variable control: tamaño }\end{array}$ & Análisis estructurado & $\begin{array}{l}\text { Relación positiva de la RSE } \\
\text { con la reputación y los } \\
\text { resultados económicos }\end{array}$ \\
\hline
\end{tabular}




\begin{tabular}{|c|c|c|c|c|c|c|c|c|c|}
\hline \multirow[b]{2}{*}{ Autores } & \multicolumn{3}{|c|}{ Abordaje de RSE } & \multicolumn{3}{|c|}{ Medidas analizadas } & \multirow[b]{2}{*}{ Variables analizadas } & \multirow[b]{2}{*}{ Metodología } & \multirow[b]{2}{*}{ Relación } \\
\hline & Integral & Dimensiones & Ambas & Contables & Financieras & Percepción & & & \\
\hline $\begin{array}{l}\text { Cheng et al. } \\
\text { (2014) }\end{array}$ & $\begin{array}{c}\text { Índice Thompson Reuters } \\
\text { ASSET4 }\end{array}$ & & & $x$ & $x$ & & $\begin{array}{c}\text { Restricción de capital } \\
\text { medido a través de índices } \\
\text { (KZ, SA index y WW index ) } \\
\text { Variables control: tamaño, } \\
\text { país, industria y año }\end{array}$ & $\begin{array}{l}\text { Análisis de correlación y } \\
\text { análisis de regresión }\end{array}$ & $\begin{array}{c}\text { Empresas con mejor } \\
\text { desempeño en RSE poseen } \\
\text { más bajas restricciones de } \\
\text { capital }\end{array}$ \\
\hline $\begin{array}{l}\text { Chivite \& } \\
\text { Enciso(2015) }\end{array}$ & $\begin{array}{l}\text { Índice de revelación o de } \\
\text { divulgación de RSC }\end{array}$ & & & $x$ & & & $\begin{array}{l}\text { Beneficio neto de la } \\
\text { empresa } \\
\text { Rentabilidad económica } \\
\text { ROA }\end{array}$ & Análisis de regresión & $\begin{array}{l}\text { Relación positiva entre la } \\
\text { aplicación de medidas de } \\
\text { RSE y la cuenta de } \\
\text { resultados }\end{array}$ \\
\hline $\begin{array}{l}\text { Valenzuela } \\
\text { Fernández et } \\
\text { al. (2015) }\end{array}$ & & $\begin{array}{c}\text { Ética } \\
\text { Ambiental } \\
\text { Social } \\
\text { Divulgación información }\end{array}$ & & $x$ & & & $\begin{array}{c}\text { Logaritmo natural activos } \\
\text { ROA } \\
\text { Gatos de capital/ventas } \\
\% \text { de participación del } \\
\text { principal accionista } \\
\text { Tasa de pago de dividendos }\end{array}$ & $\begin{array}{l}\text { Análisis de contenido para } \\
\text { definir dimensiones de RSE } \\
\text { Análisis de regresión } \\
\text { Pruebas no paramétricas de } \\
\text { Kruskal-Wallis }\end{array}$ & $\begin{array}{l}\text { La implementación de las } \\
\text { cuatro dimensiones en su } \\
\text { conjunto, al igual que la } \\
\text { dimensión ética y social, } \\
\text { influye positivamente sobre } \\
\text { el desempeño financiero }\end{array}$ \\
\hline $\begin{array}{c}\text { Ríos } \\
\text { Manríquez et } \\
\text { al. (2015) }\end{array}$ & & $\begin{array}{l}\text { Desempeño empresarial } \\
\text { Comportamiento ético } \\
\text { Calidad Laboral }\end{array}$ & & & & $x$ & $\begin{array}{l}\text { Resultados cuantitativos y } \\
\text { cualitativos }\end{array}$ & $\begin{array}{l}\text { Tablas de frecuencia, } \\
\text { pruebas chi2. Análisis de } \\
\text { Correlación }\end{array}$ & $\begin{array}{c}\text { Relación positiva y } \\
\text { significativa entre el } \\
\text { comportamiento ético y el } \\
\text { desempeño empresarial, y } \\
\text { entre la calidad laboral y el } \\
\text { desempeño empresarial }\end{array}$ \\
\hline $\begin{array}{l}\text { Hernández } \\
\text { Perlines \& } \\
\text { Infante } \\
\text { Hernández } \\
\text { (2015) }\end{array}$ & $x$ & $\begin{array}{c}\text { Económica } \\
\text { Social } \\
\text { Medioambiental }\end{array}$ & $\mathrm{x}$ & $x$ & & & $\begin{array}{l}\text { Ingresos de explotación, } \\
\text { resultados del ejercicio, } \\
\text { total del activo y total de } \\
\text { fondos propios }\end{array}$ & Análisis estructurado & $\begin{array}{l}\text { Una vez finalizado el análisis } \\
\text { se puede afirmar la } \\
\text { existencia de una } \\
\text { correlación positiva entre la } \\
\text { RSE y los resultados } \\
\text { económicos }\end{array}$ \\
\hline
\end{tabular}

Fuente: elaboración propia. 


\begin{tabular}{|c|c|c|c|c|c|c|c|c|c|}
\hline \multirow[b]{2}{*}{ Autores } & \multicolumn{3}{|c|}{ Abordaje de RSE } & \multicolumn{3}{|c|}{ Medidas analizadas } & \multirow[b]{2}{*}{ Variables analizadas } & \multirow[b]{2}{*}{ Metodología } & \multirow[b]{2}{*}{ Relación } \\
\hline & Integral & Dimensiones & Ambas & Contables & Financieras & Percepción & & & \\
\hline $\begin{array}{l}\text { Poyatos } \\
\text { León(2015) }\end{array}$ & $x$ & $\begin{array}{l}\text { Gestión, empleados, } \\
\text { Clientes/Proveedores y } \\
\text { Comunidad }\end{array}$ & $\mathrm{x}$ & & & & $\begin{array}{l}\text { Resultados antes de } \\
\text { impuestos, flujo de caja, } \\
\text { margen de beneficio, ROE, } \\
\text { solvencia, ingresos netos, } \\
\text { número de empleados, } \\
\text { total de activos, nivel de } \\
\text { capitalización de mercado, } \\
\text { ingresos operativos } \\
\text { (facturación) }\end{array}$ & $\begin{array}{l}\text { Tablas frecuencia } \\
\text { Correlación } \\
\text { Análisis factorial } \\
\text { Análisis estructurado }\end{array}$ & $\begin{array}{l}\text { RSE (grupo de interés } \\
\text { empleados) relacionado } \\
\text { positivamente con } \\
\text { rendimiento } \\
\text { Variables comportamiento } \\
\text { social no relacionado con } \\
\text { variables económicas- } \\
\text { financieras }\end{array}$ \\
\hline $\begin{array}{l}\text { Muso Lalaleo } \\
\quad(2016)\end{array}$ & $\mathrm{x}$ & $\begin{array}{l}\text { Social } \\
\text { Económica } \\
\text { Ambiental } \\
\text { Colaboración } \\
\text { Redes }\end{array}$ & $\mathrm{x}$ & $\mathrm{x}$ & & & $\begin{array}{c}\text { Crecimiento de ventas } \\
\text { (Imagen Corporativa) } \\
\text { ROA, Liquidez, Rentabilidad } \\
\text { sobre ventas, } \\
\text { Endeudamiento }\end{array}$ & Correlación & $\begin{array}{l}\text { RSE relación positiva con } \\
\text { imagen corporativa y } \\
\text { Rendimiento financiero }\end{array}$ \\
\hline $\begin{array}{l}\text { Diente Serna } \\
\quad(2016)\end{array}$ & $x$ & $\begin{array}{c}\text { Ambiental } \\
\text { Sociedad } \\
\text { Recursos Humanos }\end{array}$ & $\mathrm{x}$ & $\mathrm{x}$ & & & $\begin{array}{c}\text { ROA } \\
\text { ROE } \\
\text { Margen de beneficio neto } \\
\text { Variables control: tamaño, } \\
\text { sector, forma jurídica, } \\
\text { antigüedad en el sector }\end{array}$ & Tablas de frecuencia & $\begin{array}{c}\text { Relación positiva entre RSE } \\
\text { y rendimiento }\end{array}$ \\
\hline $\begin{array}{l}\text { Sánchez } \\
\text { Gutiérrez } \\
\text { (2016) }\end{array}$ & $x$ & & & & & $x$ & Ventaja Competitiva & $\begin{array}{l}\text { Análisis estructurado } \\
\text { Análisis factorial } \\
\text { confirmatorio }\end{array}$ & $\begin{array}{l}\text { Relación positiva entre RSE } \\
\text { y Ventaja Competitiva } \\
\text { RSE desvinculada con } \\
\text { desempeño financiero } \\
\text { RSE aumenta costos }\end{array}$ \\
\hline
\end{tabular}

Fuente: elaboración propia. 


\subsubsection{Principales resultados del análisis de contenido}

En primer lugar, en cuanto a la frecuencia con que los autores abordaron la temática (Tabla 2.2), el 45,5\% lo hizo de manera integral (a través de distintos índices que contemplan la RSE en su conjunto), el 22,7\% analizando distintas dimensiones de RSE por separado y un $31,8 \%$ lo hizo contemplando ambas opciones, es decir, no sólo un abordaje que discriminó cada dimensión, sino haciéndolo también de manera integral.

Tabla 2.2: Abordaje de la RSE por los autores

\begin{tabular}{|l|l|l|}
\hline Abordaje de RSE & Cantidad & Porcentaje \\
\hline Integral & 10 & 45,5 \\
\hline Dimensiones & 5 & 22,7 \\
\hline Ambas & 7 & 31,8 \\
\hline Total & 22 & 100,0 \\
\hline
\end{tabular}

Fuente: elaboración propia.

En cuanto a las medidas analizadas por los autores (Tabla 2.3), el 45,5\% abordó la relación de la RSE con medidas de percepción de los empresarios, luego el 36,4\% relacionó medidas contables con la RSE, el 13,6\% combinó medidas contables y financieras y por último sólo un autor $(4,5 \%)$ consideró relevante relacionar medidas financieras con las prácticas de RSE.

Tabla 2.3: Medidas analizadas por los autores

\begin{tabular}{|l|l|l|}
\hline Medidas analizadas & Cantidad & Porcentaje \\
\hline Contables & 8 & 36,4 \\
\hline Financieras & 1 & 4,5 \\
\hline Contables y financieras & 3 & 13,6 \\
\hline Percepción & 10 & 45,5 \\
\hline Total & 22 & 100,0 \\
\hline
\end{tabular}

Fuente: elaboración propia.

Respecto a las variables abordadas por los autores, se observa en la Imagen 2.1 (Nube de palabras más frecuentes en relación a las variables abordadas) como se destacan las variables contables de la rentabilidad sobre activos (ROA), la rentabilidad sobre el 
patrimonio neto (ROE), luego el endeudamiento, el éxito competitivo y la percepción sobre la RSE. El resto de las variables, si bien en la mayoría de los casos están relacionadas de alguna manera con las mencionadas anteriormente, han tenido frecuencia menor a $1 \%$.

Imagen 2.1: Nube de palabras más frecuentes en relación a las variables abordadas

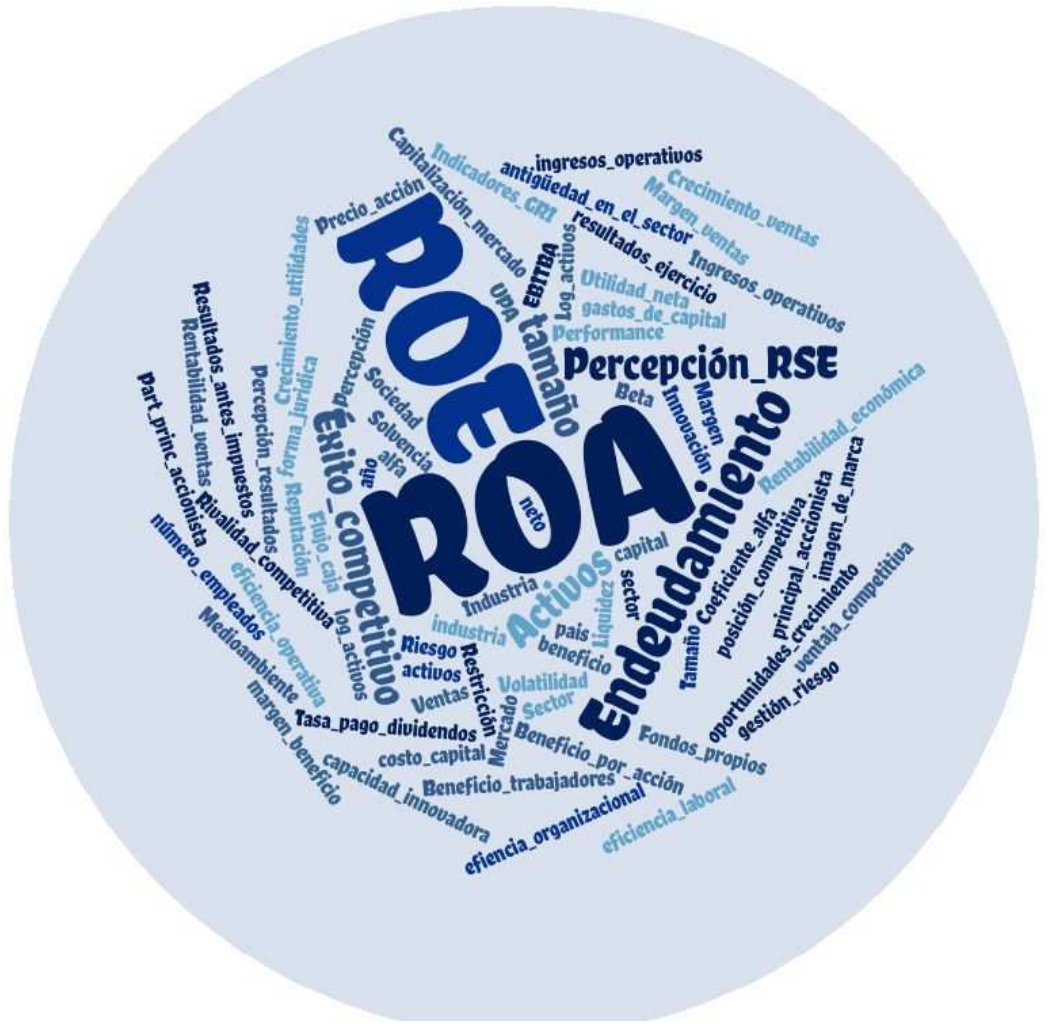

Fuente: elaboración propia.

En cuanto a las metodologías desarrolladas, se observa en la Imagen 2.2 (Nube de palabras más frecuentes en relación a las metodologías) como se destacan las de tipo cuantitativas, destacándose fundamentalmente la aplicación del análisis de regresión lineal, análisis de correlación, ecuaciones estructurales y análisis factorial confirmatorio. 
Imagen 2.2: Nube de palabras más frecuentes en relación a las metodologías

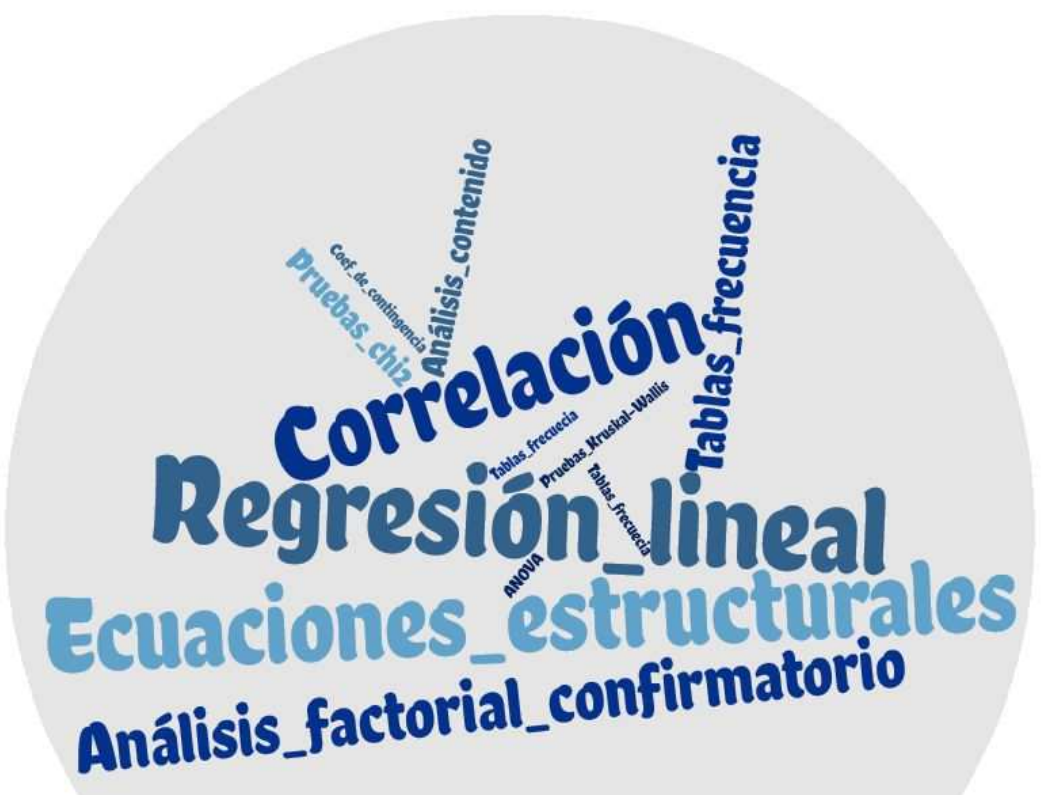

Fuente: elaboración propia.

Por último, se observan en la Imagen 2.3 (nube de palabras más frecuentes en relación a los hallazgos de las investigaciones) cómo queda en evidencia que los principales hallazgos están asociados a una relación entre la RSE y la rentabilidad (Alonso-Almeida et al. (2010); Charlo Molina \& Moya Clemente (2010); Chivite \& Enciso (2015); Valenzuela Fernández et al. (2015); Muso Lalaleo (2016) entre otros autores), así como la relación positiva entre la RSE y el desempeño empresario (Weber et al. (2008); Ríos Manríquez et al. (2015); Palmer (2012)). Por otra parte, también se destaca la relación positiva entre RSE y éxito competitivo (Rives \& Bañón (2008); Larrán Jorge, et al. (2013); Gallardo Vázquez et al. (2013). El resto de las relaciones que se demostraron 
entre RSE y otras variables han sido demostradas sólo por trabajos de investigación particulares.

Imagen 2.3: Nube de palabras más frecuentes en los hallazgos de las investigaciones

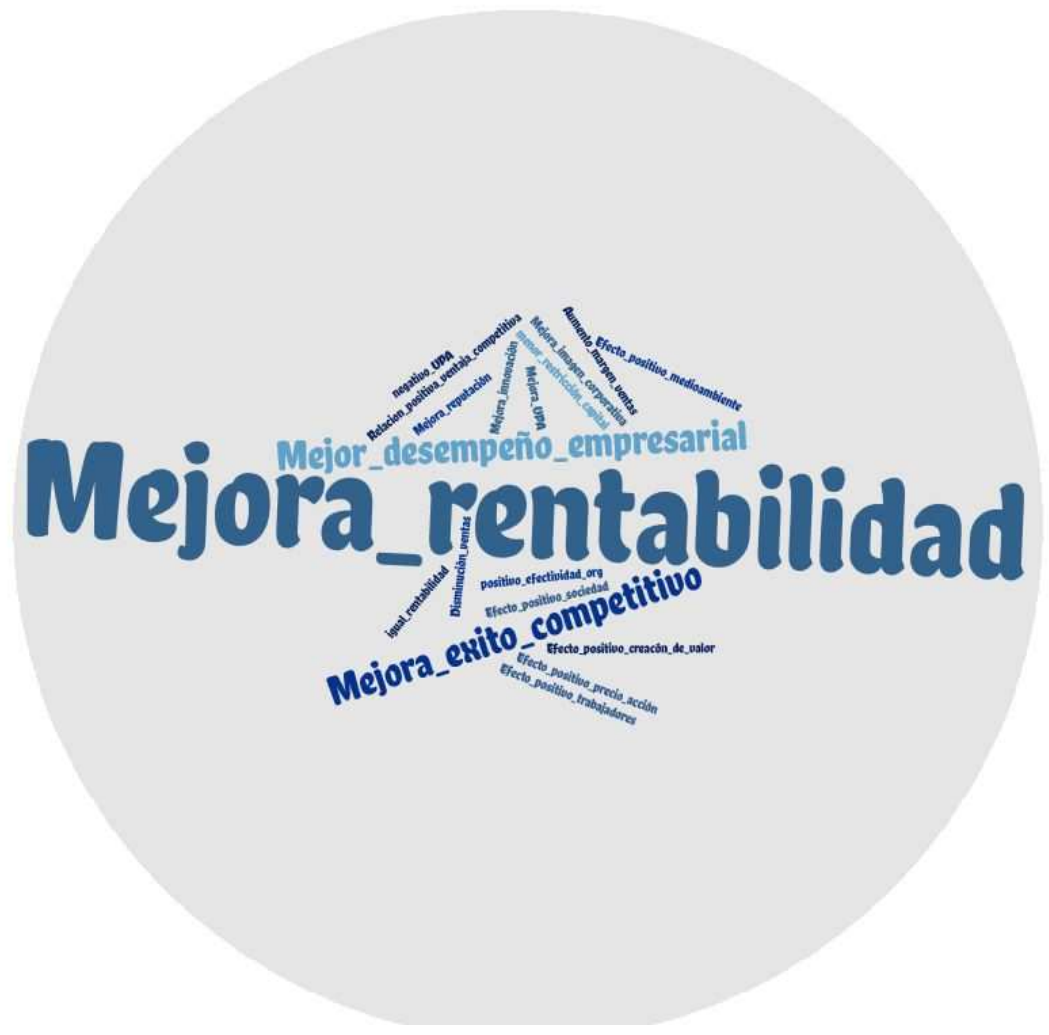

Fuente: elaboración propia.

\subsubsection{Principales conclusiones del análisis bibliográfico}

Como principales resultados se puede mencionar:

- Que las variables más abordadas por los autores han sido las medidas de percepción y las contables (fundamentalmente las variables ROA y ROE).

- En cuanto a las metodologías aplicadas, en casi la totalidad de las investigaciones se han aplicado métodos cuantitativos estadísticos, 
destacándose fundamentalmente: el análisis de regresión lineal, el análisis de correlación, así como el análisis de ecuaciones estructurales.

- A su vez, se concluye que en la mayor parte de las investigaciones se verifican resultados positivos que se generan en las organizaciones ante la aplicación de prácticas de RSE. La única relación negativa que se observa es el caso de un estudio que concluye que las prácticas de RSE aumentarían los costos, por lo que si se trasladará esto al precio del producto, podría bajar el nivel de ventas. Entre las relaciones positivas demostradas quedó en evidencia una relación positiva entre RSE y rentabilidad, seguido de una relación positiva entre RSE y desempeño empresarial, así como la RSE y el éxito competitivo.

- Si bien existe una tendencia a confirmar el impacto positivo de la RSE sobre los resultados económicos de las empresas, es preciso considerar algunas limitaciones metodológicas, que se detallan a continuación.

a) La gran variabilidad de medidas utilizadas, de esta manera: las financieras enfatizan al accionista como principal grupo de interés, por lo tanto, responden a estímulos externos a la empresa; las medidas contables están relacionadas con la eficiencia de la empresa y dependen de la asignación de recursos y decisiones y capacidades de quienes gestionan la empresa; y, en cambio, por último las medidas de percepción están basadas en apreciaciones subjetivas de los empresarios.

En cuanto a las medidas contables, se analizaron con más frecuencia la ROA y ROE, y con menos frecuencia otras variables como el EBITDA, margen de ventas, el endeudamiento y la liquidez.

Del análisis pueden formularse algunas proposiciones como:

- Cuanto mayor sea el margen de ventas, mayor será la ROA.

- En el caso de presencia de apalancamiento positivo, cuanto mayor sea la ROA y mayor sea el endeudamiento, tanto mayor será la ROE.

- Las empresas que más desarrollan prácticas de RSE tienden a obtener mayor ROA. 
Como medidas de percepción del empresario o de una valoración externa a la empresa, distintas investigaciones contemplaron: la ventaja competitiva, el éxito competitivo, la rivalidad competitiva, la imagen y reputación corporativa.

Al respecto pueden ser enunciadas las siguientes proposiciones:

- Las empresas que más desarrollan y consolidan su ventaja competitiva tienen un mayor éxito competitivo.

- Cuanto mayor sea el éxito competitivo de una empresa, tanto mayor será su imagen y reputación corporativa.

- Las empresas que más desarrollan prácticas de RSE mejoran su reputación corporativa.

b) Otra limitación a considerar es que las investigaciones fueron realizadas sobre diversas empresas y contextos, por lo cual esto podría relativizar los resultados y no hacerlos comparables, fundamentalmente porque en pocas investigaciones se trabajó con variables de control como tamaño, tipo de industria y país.

Ante esta situación, se genera el interrogante respecto a qué sucede con empresas de otros países con otros contextos como la Argentina. Esto deja en evidencia la falta de información sobre el tema por parte de los decisores organizacionales, de allí la importancia de la concientización de los empresarios sobre la vinculación no sólo de las medidas contables y financieras tradicionales entre sí, sino de la medición integral de las prácticas de RSE y su posterior vinculación de éstas con medidas de creación de valor.

\subsubsection{Consideraciones para el desarrollo de la metodología de medición integral de la RSE}

A partir de este primer análisis, se pueden comenzar a sintetizar algunas consideraciones que se deberán tener en cuenta para el desarrollo de la metodología de medición integral de la RSE. 
Cualquier intento de medir un concepto como la RSE debe contemplar su característica multidimensional, de allí que se deberán generar indicadores de RSE tanto por dimensiones como de manera integral.

Respecto al tipo de relevamiento de las prácticas de RSE llevadas a cabo por las empresas, muchas de las investigaciones han obtenido esta información mediante el relevamiento de encuestas. Dado que se trata de medidas de percepción, las respuestas están basadas en apreciaciones subjetivas de los empresarios, y es por ello que, para disminuir la subjetividad es aconsejable obtener información de estas prácticas mediante otro mecanismo -como podría ser el relevamiento de memorias de sustentabilidad (GRI). Este aspecto será profundizado en el punto 2.3.

También, se observó cómo las distintas investigaciones en mayor o menor medida han recurrido a la estadística para dar mayor solidez a los resultados. En este sentido, en esta tesis se aplicará una metodología apoyada en herramientas estadísticas siempre que sea posible para lograr mayor objetividad y dar mayor robustez a las conclusiones a las que se arribe.

Por último, este primer análisis dejó en evidencia no sólo la importancia del desarrollo de una metodología para la medición de prácticas de RSE, sino también su posterior vinculación con medidas de creación de valor, tanto contables (ROA, ROE, utilidad neta, margen bruto) como de percepción (reputación corporativa, Imagen, éxito competitivo). Por tal razón, esta tesis no se limitará al desarrollo y aplicación de una metodología para la medición integral de prácticas de RSE, sino que se analizará también la vinculación entre RSE con el desempeño económico y la reputación corporativa.

\subsection{Indicadores para la medición de prácticas de RSE}

Teniendo en cuenta que la problemática ha sido abordada tanto por académicos como por iniciativas específicas (como ser: la Global Reporting Iniciativie (GRI) y el Pacto Global) en esta investigación se abordaron ambos ámbitos en distintos apartados. 
En una primera parte, se realizó una revisión bibliográfica sobre los indicadores utilizados por la academia para la medición de las prácticas de RSE. Luego, se llevó a cabo un análisis de los indicadores propuestos por el GRI, contemplando el abordaje en cada caso para la medición de la RSE y su relación con los 10 objetivos de desarrollo del Pacto Global (2010). Finalmente, se analizó la relación de los indicadores propuestos por el GRI y su relación con los Objetivos de Desarrollo Sostenibles (ODS).

\subsubsection{Definición de indicadores}

Es importante conceptualizar la definición de "indicador". Según el Banco Interamericano de Desarrollo (BID, 2016), se puede afirmar que los indicadores vienen de los conceptos que los investigadores y gerentes de las políticas están tratando de medir. Las teorías son construcciones de conceptos interrelacionados que, en el paradigma neopositivista del conocimiento, deben hacerse "observables". Para lograr esto último, es necesario operacionalizar esos conceptos en dimensiones; y esas dimensiones se dividirán en variables, las cuales, en su momento, serán medidas con indicadores. Estadísticamente, las variables pueden clasificarse en cualitativas o cuantitativas (continuas o discretas), puesto que las características de estas variables son distintas, también lo son su escala de medición. EI BID (2016), propone los siguientes tipos de variables:

- Dato (escala) nominal: observaciones que pueden sólo ser clasificadas y contadas.

- Dato (escala) ordinal: observaciones clasificadas y contadas en un orden específico. Por ejemplo, sabemos que regular es mejor que mala, y que buena es mejor que regular. Sin embargo, no podemos afirmar cuán mejor es una buena colaboración que una regular. 
- Dato (escala) de intervalo: observaciones clasificadas en una escala ordinal, pero los intervalos entre las observaciones se expresan en unidades fijas y cuantificables.

- Dato (escala) de razón: los datos tienen un orden definido, existe una distancia numérica específica entre dos cantidades y la división de dos cantidades tiene sentido.

Como ya se mencionó, los procedimientos estadísticos varían de acuerdo a las escalas de medición en que pueden ser expresados los datos, y es por eso que la anterior clasificación cobra sentido.

Por otra parte, los datos por sí solos no constituyen, un indicador; son listas de características de poblaciones; "cuentas" o "magnitudes" que difícilmente se utilizan tal como se presentan inicialmente. Los indicadores son, en general, la relación entre dos o más variables (BID, 2016). Estadísticamente se utilizan distintas medidas para la construcción de indicadores, entre ellos: la media, razones, proporciones y tasas.

Es importante mencionar el aporte de Strandberg (2010), citado por Salgado Cabrera \& González Navarro (2014), según este autor los indicadores deben cumplir con tres requisitos:

- En primer lugar, el indicador debe ser fiable, es decir, ofrecer las mismas posibles respuestas cuando se aplica más de una vez.

- En segundo lugar, el indicador debe ser comparable, o sea, debe poder compararse a través del tiempo y entre distintas empresas, ofreciendo un resultado homogéneo, que facilite la creación de un ranking, por ejemplo, de RSE entre empresas dentro de un mismo sector.

- Por último, un indicador debe ser válido, es decir, debe ser capaz de medir aquello para lo que fue construido, la práctica de RSE que busca medir. 


\subsubsection{Indicadores desarrollados desde la academia para medir el desempeño en prácticas de RSE}

A continuación, se presenta una revisión bibliográfica de autores que desde la academia han abordado de distintas maneras y en distintos contextos la medición de las prácticas de RSE. Los mismos se presentan en orden cronológico.

Prado et al. (2004)

Los autores plantean que la medición del desempeño es un componente esencial para la toma de decisiones que tiene que estar presente en cada una de las categorías propuestas sobre RSE. Por lo tanto, es preciso medir para identificar las áreas que requieren atención, hacer comparaciones y desarrollar planes de mejora. Establecen seis categorías a analizar: transparencia, valores y prácticas anti-corrupción; colaboradores; públicos de interés clave (clientes, proveedores y comunidad); medio ambiente; fortalecimiento institucional; y sostenibilidad económica.

A su vez, definen indicadores Tipo 1 y Tipo 2. Los indicadores Tipo 1 están diseñados para que la empresa evalúe su desempeño a lo largo del tiempo y como método de registro de información necesaria para toma de decisiones. Los indicadores Tipo 2 le permitirán a la empresa ubicarse en uno de los cuatro niveles o estadios de la RSE y obtener su posición relativa con respecto al óptimo. De esta manera, mencionan una serie de indicadores contemplando ambos niveles. Así, por ejemplo: para la categoría "Públicos de interés clave: Comunidad", fue creada la Sub-categoría "Inversiones, donaciones y participación en proyectos sociales", luego el indicador Tipo 1 fue definido como: ¿La empresa lleva a cabo programas o proyectos sociales en forma individual o a través de alianzas?, posibles respuestas: si o no; y el indicador Tipo 2, en función de la selección de una de las siguientes opciones:

- $\quad$ No realiza donaciones ni participa en proyectos sociales;

- Realiza donaciones y participa en proyectos sociales de modo ocasional, cuenta con un programa de acción social formal y recursos asignados que le permiten llevar a cabo proyectos sociales en forma permanente; ó 
- En adición a lo anterior, mantiene alianzas con otras organizaciones a fin de maximizar su impacto social.

\section{Vílchez et al. (2009)}

Según los autores, la medida de sostenibilidad de una organización es básica para su subsistencia en el mercado, debiéndose valorar su evolución y estableciendo objetivos y metas cuantificables. De esta manera, luego de un análisis de exploración exhaustivo de distintas propuestas de medición de RSE, proponen una serie de indicadores para las siguientes dimensiones: económica (8 indicadores), social (17 indicadores), ambiental (9 indicadores) y producto (9 indicadores). En la mayoría de los casos, los indicadores son cuantitativos y surgen de la medición del desempeño de la empresa. Por ejemplo, para la dimensión ambiental, establecieron los siguientes indicadores:

- Energías no renovables utilizadas

- Energía total consumida por tonelada de producto terminado

- Consumo total de agua por tonelada de producto terminado

- Cantidad de emisiones por tonelada de producto terminado (CO2,COV, SO2, NO2)

- Cantidad de residuos generados por tonelada de producto terminado

- Cantidad de residuos valorizados

- \% de materias primas recicladas o reutilizadas por tonelada de producto terminado

- \% de productos fabricados en centros de certificación ambiental ISO 14001, EMAS o equivalente

- \% proveedores con certificación ambiental ISO 14001, EMAS o equivalente

\section{Vintró Sánchez et al. (2009)}

La idea principal del trabajo consistió en medir el grado de desarrollo en términos de RSE, por parte de la empresa, de manera periódica. Para ello, consideraron que es preciso disponer de un sistema de indicadores que informen acerca del grado de 
consecución en cada una de las principales esferas en las que se basa la RSE, puesto que por el momento no existe un indicador consolidado.

Aunque los sistemas de medida propuestos por distintos organismos son aplicables para cualquier empresa, en algunos casos los datos necesarios podrían ser difíciles de obtener o incluso, el número de criterios ser excesivo en relación con el tamaño de la empresa. Es por tal motivo que, centrándose en la medida del grado de RSE, principalmente de pequeñas y medianas empresas (PYMES), los autores establecen que podría ser más conveniente un tablero de comando más operativo y simplificado. En este contexto, y tomando como punto de partida los fundamentos de la integración de sistemas, se proponen un sistema de indicadores de RSE formulado en base a las sinergias existentes con las disciplinas de calidad, medioambiente y seguridad y salud laboral, que aporte facilidad y agilidad en su utilización.

Puesto que la mayoría de las empresas tienen implantados sistemas de gestión de calidad, medioambiente, seguridad y salud laboral, o incluso tienen implantado un sistema integrado de gestión, la información que habitualmente recogen (con alguna modificación) podría ser la fuente de datos para el sistema de indicadores de RSE propuesto. Es por este motivo que los autores consideran que un sistema de indicadores de RSE, basado en los pilares de la integración de sistemas, puede ser de gran utilidad para el tejido empresarial.

De esta manera, los autores establecieron tres grupos de criterios: medioambiente, calidad y seguridad de RSE, y diseñaron un tablero de comando compuesto por tres indicadores secundarios (RSE-Calidad, RSE-Medioambiente y RSE-Seguridad) divididos en sub-áreas, y un indicador principal que reporta un valor global de RSE. Los indicadores establecidos por los autores son cuantitativos y en la mayoría de los casos definidos como proporciones, por ejemplo, para el caso: "Fomento de proyectos sociales", el indicador que se propone es: "Beneficios destinados a proyectos sociales/Resultado del ejercicio antes de descontar las inversiones sociales". 


\section{Instituto Centroamericano de Administración Empresarial (INCAE, 2010)}

El Manual de Indicadores de Responsabilidad Social Empresarial desarrollado por el INCAE Business School es una herramienta de autodiagnóstico dirigida a revisar la gestión de la empresa que comprende una conducta socialmente responsable.

El Modelo de RSE propuesto comprende ocho categorías que a su vez están ubicadas en dos dimensiones generales: interna y externa. La dimensión interna se refiere a las prácticas enfocadas hacia el interior de las empresas, dentro de la misma se encuentran las siguientes categorías: Cumplimiento de Leyes, Ética y Transparencia, Desarrollo de Capital Humano y Mitigación de Impactos Negativos. Respecto a la dimensión externa: Beneficios de Colaboradores, Proyección a las Familias, Proyección a las Comunidades y Proyección a nivel Nacional o Regional.

El modelo está estructurado en ocho categorías, cada una de las cuales incluye a su vez varias sub-categorías. Paralelamente para cada sub-categoría se ha diseñado un grupo de métricas específicas. Por ejemplo, el vértice "Cumplimiento de las Leyes" está compuesto por seis sub-categorías en total; a modo de ejemplo, una de estas subcategorías es "Cumplimiento de la Legislación Laboral", la cual a su vez incluye un grupo de indicadores cualitativos con preguntas cerradas de respuesta Si o No.

\section{Perera (2011)}

Los autores diseñaron un tablero de comando de gestión de sustentabilidad que reúne un conjunto de indicadores que conforman un alcance "ideal" de acuerdo con la realidad y posibilidades de cada empresa, decidiendo qué aspectos se monitorearán y cómo. Los indicadores se agruparon, por las siguientes dimensiones: "Definición y seguimiento de políticas de responsabilidad social", "Valor agregado generado y distribuido", "Indicadores de generación del valor agregado" e "Indicadores de distribución del valor agregado".

\section{Iqbal et al. (2012)}

Para medir la RSE, utilizaron las siguientes dimensiones: "Gobierno corporativo", "Principios de ética empresarial", "Cumplimiento ambiental", "Cumplimiento social", "Divulgación ambiental y social", "Integridad del producto", "Donaciones e inversiones 
corporativas en la comunidad y diálogo con las partes", "Desempeño financiero" y "Seguridad de la cadena de suministro". A su vez, a cada dimensión se le asignó un valor entre 1 y 5 (dónde 5 es el máximo valor).

\section{Martínez et al. (2012)}

Los autores elaboraron un cuestionario preguntando sobre distintos indicadores desarrollados para la medición de prácticas de RSE. Las preguntas fueron diseñadas para que se le asigne un puntaje (del 1 al 6). El instrumento presentó la limitación, al igual que en alguna de las anteriores investigaciones, de que los resultados correspondían a percepciones, tanto de las prácticas de RSE, como de la efectividad organizacional. De esta manera, para la medición del desempeño en RSE mediante el cuestionario se solicitó opinión sobre los siguientes aspectos:

- Nuestras acciones de cultura medio/ambiental, eco-eficiencia, seguridad, desarrollo de la comunidad nos generan preferencias en nuestros clientes/ consumidores.

- En nuestra organización contribuimos a la formación y desarrollo de las competencias laborales de nuestros trabajadores.

- Contribuimos al desarrollo de la comunidad en la que mi empresa está presente.

- Una de nuestras prioridades es la generación de valor no solo para nuestros clientes, sino también para las personas que invierten en mi empresa.

Como ya se mencionó, se solicitó que los mismos sean evaluados con una escala de seis puntos: "siempre y en toda la organización", "la mayoría de las veces y en gran parte de la organización", "con frecuencia intermedia", "algunas veces" y "pocas veces y nunca".

\section{Salgado Cabrera \& González Navarro (2014)}

Los mencionados autores, dada la relevancia de la industria salmonicultora chilena en el crecimiento y desarrollo económico de la región de Los Lagos y del país en general, llevaron a cabo la construcción de un índice de RSE para este sector en los ámbitos laborales, ambientales y en relación con la comunidad local (las cuales podrían 
considerarse como "dimensiones"). Luego, para cada una de las dimensiones construyeron 11 indicadores y los corroboraron mediante la aplicación a dos empresas salmonicultoras. Para cada uno de los 11 indicadores se asignó valor de 0 o 1, según el comportamiento observado en cada empresa, donde 1 denota la presencia y 0 la ausencia de la práctica analizada.

\section{Gallardo Vázquez (2013)}

La RSE fue considerada por estos autores, como un constructo de segundo orden de naturaleza reflexiva, donde los indicadores dimensión social, dimensión económica y dimensión medioambiental son a su vez variables no observables, reflejadas en indicadores primarios. Para relevar el desempeño de prácticas de RSE, elaboraron un cuestionario basándose en la literatura previa, con escalas Likert de 10 puntos donde el directivo tenía que posicionarse según sus percepciones entre: "0 (totalmente en desacuerdo)" o "10 (totalmente de acuerdo)" con relación a las cuestiones de RSE.

\section{González Ramos et al. (2014)}

A partir de una revisión de la literatura, construyeron una serie de escalas multi-ítem para medir tres dimensiones de la RSE (medioambiental, económica y social). Cada uno de los ítems se estableció en base a una escala Likert (1 "Importancia concedida muy baja" y 5 "importancia concedida muy alta"), para la medición de cada dimensión, llevaron a cabo un relevamiento de encuestas a directivos de empresas y se recogieron datos referentes a los años 2010 a 2012.

\section{Valenzuela Fernández et al. (2015)}

Para medir la RSE, utilizaron las Memorias Anuales, sitios web, medios de comunicación y redes sociales para cada empresa. Con toda la información recabada se llevó a cabo una revisión que se basó en un análisis de contenidos cuyo objetivo fue recolectar y ordenar la información para así describir y caracterizar las distintas acciones estratégicas en el ámbito de la RSE que implementaban las empresas.

De esta manera, los autores definieron las siguientes dimensiones: "4DIM" dicotómica que tomó el valor 1 si la empresa había divulgado información en las cuatro dimensiones propuestas en su conjunto, "DSOCIAL" variable dicotómica que tomó el 
valor 1 si la empresa había divulgado información voluntaria desde una perspectiva social, "ÉTICA" variable dicotómica que tomó el valor 1 si la empresa había divulgado información voluntaria desde una perspectiva ética, "DAMB" variable dicotómica que tomó el valor 1 si la empresa había divulgado información voluntaria desde una perspectiva ambiental y "DCOLAB" variable dicotómica que tomó el valor 1 si la empresa había divulgado información voluntaria desde una perspectiva de colaboradores. Adicionalmente, generaron la variable "DREDES" una variable dicotómica que tomó el valor 1 si la empresa había divulgado información voluntaria a través de redes sociales.

\section{Muso Lalaleo (2016)}

Para la investigación, la autora, utilizó información que surgió de la verificación en las páginas web de las distintas empresas subdivida en 5 dimensiones: social, ética, ambiental, colaboración y redes. Posteriormente, aplicó parámetros de medición, donde se valoró los ítems bajo una calificación dicotómica, de forma que un determinado ítem se valorara con un " 1 " si se disponía de la información, y con " 0 ", en caso contrario. En este sentido, procedió a realizar para cada dimensión analizada un subíndice, definido mediante el cociente entre la sumatoria del número de ítems identificados y el número total de ítems que constituyen el subíndice. Luego, para expresar de manera general la variable de RSE, consideró el valor de cada uno de los subíndices calculados para cada dimensión, dividido la cantidad de subíndices.

\section{Diente Serna (2016)}

Las tres dimensiones de RSE analizadas fueron: económica, social y recursos humanos. Para la generación del indicador se le otorgó el mismo peso relativo a cada dimensión, de tal forma que el mayor valor que pudo alcanzar el indicador que midió el grado de actuaciones de RSE fue de 3. De esta manera, para construir el indicador del grado de actuaciones de RSE se consultó la página web de cada una de las empresas de la muestra y se comprobó si incluían información que estuviera relacionada con alguna de estas tres dimensiones. Por lo tanto, cuando una empresa tuvo un grado de actuaciones de RSE de 3 indicaba que proporcionaba información sobre acciones medioambientales, de recursos humanos y enfocadas a la sociedad. 
Algunos otros autores en sus trabajos para medir el desempeño en prácticas de RSE han utilizado indicadores o índices propuesto por otros organismos:

- Weber et al. (2008) para el análisis de las prácticas de RSE no generan sus propios indicadores, sino que consideraron la sostenibilidad corporativa desde los distintos aspectos que la componen, tales como el desempeño ambiental, social, económico y de gobernabilidad, abordando los distintos impulsores de estas dimensiones considerando los indicadores del GRI.

- Trejo et al. (2014) proponen una serie de indicadores que contemplan los modelos Alianza por la Responsabilidad Social Empresarial, México, 2013 (AliaRSE) (2013) y KPMG (2008).De esta manera, establecen indicadores que contemplan las siguientes dimensiones: Calidad de vida en la empresa, Ética empresarial, Vinculación y compromiso con la comunidad y su desarrollo, Cuidado y preservación del ambiente, Consideraciones económicas, Reputación o Marca, Innovación y Aprendizaje, Motivación al empleado, Administración o Reducción del riesgo, Relaciones estrechas con los proveedores, Acceso a capital o Incremento de valor a los participantes, Mejora en la posición de Mercado, Mejora en la relación con el Estado y Ahorro en costos.

- Olcese (2011) para dar respuesta a los objetivos de su investigación y analizar el desempeño en prácticas de RSE, tomó en consideración las 44 recomendaciones y los 120 indicadores de RSE propuestos por la Real Academia de Ciencias Económicas y Financieras (RACEF).

- Álvarez y Vargas (2011) para analizar el desempeño socialmente responsable de las empresas, realizaron un relevamiento cuyo cuestionario contempló lo planteado, tanto para la dimensión interna como la externa en el Libro Verde.

- También Palmer (2012), para determinar qué empresas se consideraban socialmente responsables, utilizó el índice Morgan Stanley Capital International (MSCl Index).

- Cheng et al. (2014), para medir el desempeño de las empresas respecto a la RSE, utilizaron el índice de Thompson Reuters ASSET4 que mide el desempeño 
de las empresas en tres dimensiones ("pilares") de la RSE: la gobernabilidad social, ambiental y empresaria.

- Chivite \& Enciso (2015), para medir la RSE, utilizaron el índice de revelación o de divulgación de RSE, el cual consideró los ocho siguientes índices: el Pacto mundial, las normas AA1000AS, SA8000, la inclusión en The Dow Jones Sustainability Indexes (DJSI), el EFQM, y el Global Reporting Initiative (GRI), el FTSE4 Good y la mención e Informes de RSE presentados por las empresas.

\subsubsection{Metodología para el análisis de indicadores de RSE}

Debido a la cantidad de investigaciones sobre la temática, así como la diversidad de variables y metodologías abordadas por las mismas, la técnica seleccionada fue: "El análisis de contenido", la misma posibilitó el análisis de la frecuencia de mención de determinadas palabras, las asociaciones entre ellas, o las similitudes y diferencias entre diferentes grupos de comentarios.

Los artículos que conformaron el análisis fueron seleccionados siguiendo los siguientes pasos: en primer lugar, se seleccionaron las bases de datos internacionales para encontrar las revistas, artículos y estudios más adecuados. Las bases escogidas fueron: "Biblioteca Electrónica de Ciencia y Tecnología” (Ministerio de Educación de la Nación, Argentina), "La Referencia" (La Red Federada de Repositorios Institucionales de Publicaciones Científicas) y "Google Académico". La segunda decisión se basó en la selección de las palabras clave. Se seleccionaron: "indicadores de RSE" así como "medición de RSE". En tercer lugar, se seleccionó el intervalo de tiempo. El período seleccionado fue de 2004 a 2016 con el objetivo de analizar los artículos más recientes.

\subsubsection{Principales resultados del análisis de indicadores propuestos por la academia}

En primer lugar, se presenta la Tabla 2.3, en la cual se resume la bibliografía analizada según el origen de los indicadores: si fueron desarrollados por los mismos autores o si 
utilizaron propuestas desarrolladas por otros organismos. Como se puede observar, se analizaron 20 investigaciones realizadas durante el período 2004-2016 en diversos países, entre las que se destacan: 7 de España, 3 de México, 2 de Chile, 2 de Costa Rica y 2 de Estados Unidos.

Por otra parte, del análisis de la Tabla 2.3, se observa que de los 20 artículos, 13 abordaron la medición de las prácticas de RSE a través de indicadores desarrollados en el marco de su propia investigación y 7 abordaron la temática a través de indicadores desarrollados por otros, entre los que podemos mencionar la GRI, la Real Academia de Ciencias Económicas y Financieras (RACEF), Thompson Reuters ASSET4 y la Alianza por la Responsabilidad Social Empresarial México (AliaRSE).

Tabla 2.3. Resumen del análisis bibliográfico según origen de los indicadores propuestos

\begin{tabular}{|l|l|l|l|l|}
\hline \multicolumn{1}{|c|}{ Autores } & Año & País & $\begin{array}{c}\text { ¿Utilizan } \\
\text { indicadores } \\
\text { desarrollados } \\
\text { por algún } \\
\text { organismo? }\end{array}$ & $\begin{array}{l}\text { En caso afirmativo, } \\
\text { ¿Cuál/Cuáles? }\end{array}$ \\
\hline Prado et al. & 2004 & Costa Rica & NO & No aplica \\
\hline Weber et al. & 2008 & Canadá & SI & GRI \\
\hline
\end{tabular}




\begin{tabular}{|c|c|c|c|c|}
\hline Vílchez et al. & 2009 & España & NO & No aplica \\
\hline Vintró Sánchez et al. & 2009 & España & NO & No aplica \\
\hline INCAE Business School & 2010 & Costa Rica & NO & No aplica \\
\hline Perera & 2011 & Uruguay & NO & No aplica \\
\hline Olcese & 2011 & España & $\mathrm{SI}$ & RACEF \\
\hline Álvarez \& Vargas & 2011 & España & $\mathrm{SI}$ & Libro Verde \\
\hline Iqbal et al. & 2012 & Pakistán & NO & No aplica \\
\hline Martinez et al. & 2012 & México & NO & No aplica \\
\hline Palmer & 2012 & \begin{tabular}{|l|} 
Estados \\
Unidos \\
\end{tabular} & $\mathrm{SI}$ & Índice MSCI Index \\
\hline Gallardo Vázquez & 2013 & España & NO & No aplica \\
\hline Salgado Cabrera \& González Navarro & 2013 & Chile & NO & No aplica \\
\hline González Ramoset al. & 2014 & España & NO & No aplica \\
\hline Trejoet al. & 2014 & México & $\mathrm{SI}$ & $\begin{array}{l}\text { AliaRSE (2013) } \\
\text { KPMG (2008) }\end{array}$ \\
\hline Cheng et al. & 2014 & \begin{tabular}{|l|} 
Estados \\
Unidos \\
\end{tabular} & $\mathrm{SI}$ & Thompson Reuters ASSET4 \\
\hline Valenzuela Fernández et al. & 2015 & Chile & NO & No aplica \\
\hline Chivite\& Enciso & 2015 & México & SI & $\begin{array}{l}\text { AA1000AS } \\
\text { SA8000 } \\
\text { Dow Jones Sustainability Indexes } \\
\text { (DJSI) } \\
\text { EFQM } \\
\text { GRI } \\
\text { FTSE4 Good }\end{array}$ \\
\hline Muso Lalaleo & 2016 & Ecuador & NO & No aplica \\
\hline Diente Serna & 2016 & España & NO & No aplica \\
\hline
\end{tabular}

Fuente: elaboración propia

En la Tabla 2.4 se presenta un resumen de los autores que generaron una metodología propia para la medición de la RSE, que incluye: dimensiones abordadas, modo de relevamiento y tipo de indicadores desarrollados.

Tabla 2.4. Resumen análisis bibliográfico: dimensiones abordadas, relevamiento y tipo de indicadores

\begin{tabular}{|l|c|c|l|l|l|l|}
\hline \multicolumn{1}{|c|}{ Autores } & Año & País & \multicolumn{1}{|c|}{ Dimensiones abordadas } & $\begin{array}{c}\text { Forma de } \\
\text { relevamient } \\
\text { o datos }\end{array}$ & $\begin{array}{c}\text { Tipo de } \\
\text { indicadores }\end{array}$ & Valores \\
\hline Prado et al. & 2004 & Costa Rica & $\begin{array}{l}\text { Transparencia, valores y prácticas anti- } \\
\text { corrupción } \\
\text { Colaboradores } \\
\text { Público de interés } \\
\text { Medio ambiente } \\
\text { Fortalecimiento institucional } \\
\text { Sostenibilidad económica }\end{array}$ & $\begin{array}{l}\text { Cualitativos } \\
\text { (Categóricos) }\end{array}$ & $\begin{array}{l}\text { Dicotómica } \\
\text { (SI/NO) }\end{array}$ \\
\hline
\end{tabular}




\begin{tabular}{|c|c|c|c|c|c|c|}
\hline Vílchez et al. & 2009 & España & $\begin{array}{l}\text { Económica } \\
\text { Social } \\
\text { Ambiental } \\
\text { Producto }\end{array}$ & Encuestas & Cuantitativos & $\begin{array}{l}\text { Recuentos } \\
\text { Proporciones }\end{array}$ \\
\hline $\begin{array}{l}\text { Vintró Sánchez et } \\
\text { al. }\end{array}$ & 2009 & España & $\begin{array}{l}\text { Medioambiental } \\
\text { Calidad } \\
\text { Seguridad }\end{array}$ & Encuestas & Cuantitativos & Proporciones \\
\hline $\begin{array}{l}\text { INCAE Business } \\
\text { School }\end{array}$ & 2010 & Costa Rica & $\begin{array}{l}\text { Cumplimiento de Leyes, Ética \& } \\
\text { Transparencia } \\
\text { Desarrollo de Capital Humano } \\
\text { Mitigación de Impactos Negativos. } \\
\text { Beneficios de Colaboradores } \\
\text { Proyección a las Familias } \\
\text { Proyección a las Comunidades } \\
\text { Proyección a nivel Nacional o Regional. }\end{array}$ & Encuestas & $\begin{array}{l}\text { Cualitativos } \\
\text { (Categóricos) }\end{array}$ & $\begin{array}{l}\text { Dicotómica } \\
\text { (SI/NO) }\end{array}$ \\
\hline Perera & 2011 & Uruguay & $\begin{array}{l}\text { Definición y seguimiento de políticas } \\
\text { de responsabilidad social } \\
\text { Valor agregado generado y distribuido } \\
\text { Indicadores de generación del valor } \\
\text { agregado } \\
\text { Indicadores de distribución del valor } \\
\text { agregado }\end{array}$ & \begin{tabular}{|l|} 
Propone \\
para que el \\
monitoreo lo \\
haga la \\
propia \\
empresa
\end{tabular} & Cuali-Cuanti & $\begin{array}{l}\text { Recuentos } \\
\text { Proporciones } \\
\text { Descripciones }\end{array}$ \\
\hline lqbal et al. & 2012 & Pakistán & $\begin{array}{l}\text { Gobierno corporativo } \\
\text { Principios de ética empresarial } \\
\text { Cumplimiento ambiental } \\
\text { Cumplimiento social } \\
\text { Divulgación ambiental y social } \\
\text { Integridad del producto } \\
\text { Donaciones e inversiones corporativas } \\
\text { en la comunidad y diálogo con las } \\
\text { partes } \\
\text { Desempeño financiero } \\
\text { Seguridad de la cadena de suministro }\end{array}$ & \begin{tabular}{|l|} 
Lectura de \\
reportes y \\
web de la \\
empresa
\end{tabular} & Cuantitativos & $\begin{array}{l}\text { Escala likert } \\
\text { de } 1 \text { a } 5\end{array}$ \\
\hline Martinez et al. & 2012 & México & $\begin{array}{l}\text { Ambiental } \\
\text { Seguridad } \\
\text { Comunidad } \\
\text { Clientes } \\
\text { Trabajadores }\end{array}$ & Encuestas & Cuantitativos & $\begin{array}{l}\text { Escala likert } \\
\text { de } 1 \text { a } 6\end{array}$ \\
\hline Gallardo Vázquez & 2013 & España & $\begin{array}{l}\text { Social } \\
\text { Económica } \\
\text { Medioambiental }\end{array}$ & Encuestas & Cuantitativos & $\begin{array}{l}\text { Likert de de } 0 \\
\text { a } 10 \text {, donde } \\
0: \\
\text { "totalmente } \\
\text { en } \\
\text { desacuerdo" } \\
\text { o "10: } \\
\text { totalmente } \\
\text { de acuerdo" } \\
\end{array}$ \\
\hline
\end{tabular}

\section{Continúa}

Tabla 2.4. Resumen análisis bibliográfico: dimensiones abordadas, relevamiento y tipo de indicadores

\begin{tabular}{|c|c|c|c|c|c|c|}
\hline Autores & Año & País & Dimensiones abordadas & $\begin{array}{c}\text { Forma de } \\
\text { relevamient } \\
\text { o datos }\end{array}$ & $\begin{array}{c}\text { Tipo de } \\
\text { indicadores }\end{array}$ & Valores \\
\hline
\end{tabular}




\begin{tabular}{|c|c|c|c|c|c|c|}
\hline Salgado \& González & 2014 & Chile & $\begin{array}{l}\text { Laboral } \\
\text { Ambiental } \\
\text { Comunidad Local }\end{array}$ & Encuestas & $\begin{array}{l}\text { Cualitativos } \\
\text { (Categóricos) }\end{array}$ & $\begin{array}{l}\text { Dicotómica } \\
(0 / 1), \text { dónde } 1 \\
\text { denota } \\
\text { presencia y } 0 \\
\text { ausencia }\end{array}$ \\
\hline González Ramoset al. & 2014 & España & $\begin{array}{l}\text { Medioambiental } \\
\text { Económica } \\
\text { Social }\end{array}$ & Encuestas & Cuantitativos & $\begin{array}{l}\text { Likert: } 1 \\
\text { "Importancia } \\
\text { concedida muy } \\
\text { baja" y } 5 \\
\text { "importancia } \\
\text { concedida muy } \\
\text { alta" }\end{array}$ \\
\hline $\begin{array}{l}\text { Valenzuela Fernández } \\
\text { et al. }\end{array}$ & 2015 & Chile & $\begin{array}{l}\text { Social } \\
\text { Ética } \\
\text { Ambiental } \\
\text { Colaboradores } \\
\text { Redes Sociales }\end{array}$ & $\begin{array}{l}\text { Lectura de } \\
\text { reportes y } \\
\text { web de la } \\
\text { empresa }\end{array}$ & $\begin{array}{l}\text { Cualitativos } \\
\text { (Categóricos) }\end{array}$ & $\begin{array}{l}\text { Valor } 0 / 1 \text {, el } \\
\text { valor } 1 \text { si la } \\
\text { empresa ha } \\
\text { divulgado } \\
\text { información de } \\
\text { esa perspectiva }\end{array}$ \\
\hline Muso Lalaleo & 2016 & Ecuador & $\begin{array}{l}\text { Social } \\
\text { Ética } \\
\text { Ambiental } \\
\text { Colaboración } \\
\text { Redes }\end{array}$ & $\begin{array}{l}\text { Lectura de } \\
\text { reportes y } \\
\text { web de la } \\
\text { empresa }\end{array}$ & $\begin{array}{l}\text { Cualitativos } \\
\text { (Categóricos) }\end{array}$ & $\begin{array}{l}\text { Valor } 0 / 1 \text {, el } \\
\text { valor } 1 \mathrm{si} \mathrm{la} \\
\text { empresa ha } \\
\text { divulgado } \\
\text { información de } \\
\text { esa perspectiva }\end{array}$ \\
\hline Diente Serna & 2016 & España & $\begin{array}{l}\text { Económica } \\
\text { Social } \\
\text { Recursos Humanos }\end{array}$ & \begin{tabular}{|l} 
Análisis \\
página web
\end{tabular} & $\begin{array}{l}\text { Cualitativos } \\
\text { (Categóricos) }\end{array}$ & $\begin{array}{l}\text { Valor } 0 / 1 \text {, el } \\
\text { valor } 1 \text { si la } \\
\text { empresa ha } \\
\text { divulgado } \\
\text { información de } \\
\text { esa perspectiva }\end{array}$ \\
\hline
\end{tabular}

Fuente: elaboración propia 
Imagen 2.3. Nube de palabras: Dimensiones de la RSE abordadas por los autores

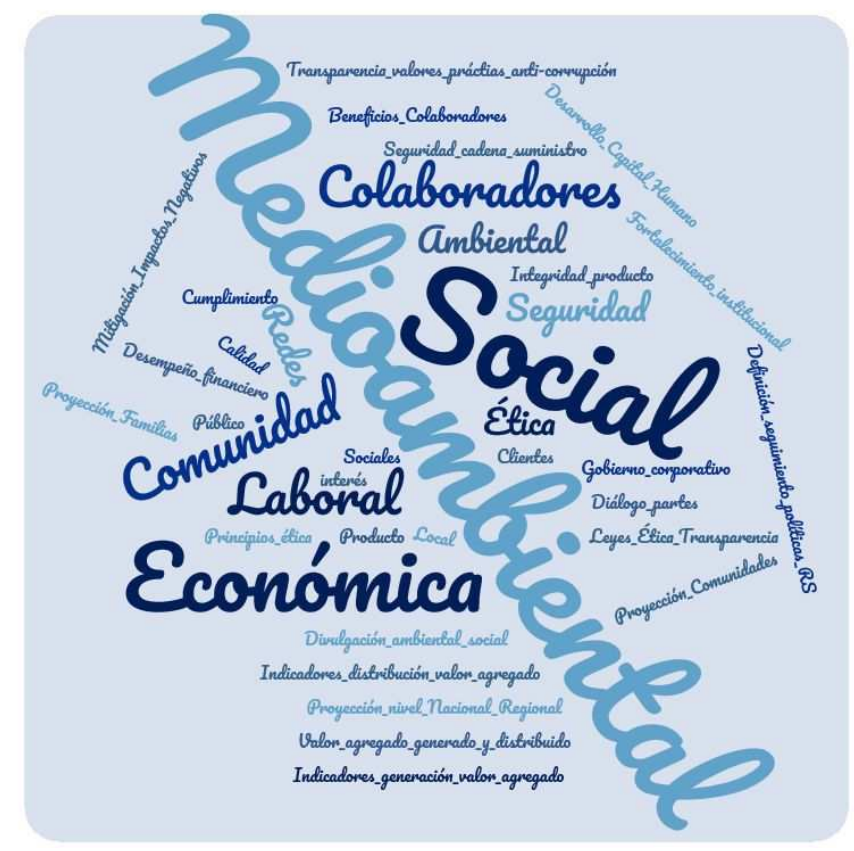

Fuente: elaboración propia.

Como se puede observar del análisis de la Tabla 2.4 y en la Imagen 2.3, los académicos han abordado el análisis de medición de las prácticas de la RSE desde distintas dimensiones, entre las que se destacan la Medioambiental, la Social y la Económica. Por otra parte, en la mayoría de los trabajos (aproximadamente en el 60\%) se llevaron a cabo relevamientos primarios mediante encuestas para la obtención de los datos y posterior cálculo de los indicadores, mientras que en el 30\% restante se obtuvieron los datos de las páginas web y/o reportes de sustentabilidad publicados por las empresas.

En cuanto a los indicadores, aproximadamente el $46 \%$ era del tipo categórico, con respuestas posibles: Si o No, ante presencia o ausencia de cierta práctica de RSE. Luego, un $30 \%$ de las investigaciones presentan indicadores donde se analiza el desempeño de las prácticas de RSE a través de una escala de Likert, y sólo un $24 \%$ de las investigaciones presentan indicadores más complejos que impliquen mayores cálculos como proporciones, que permitan analizar cuantitativamente el desempeño de las prácticas de RSE, así como su variación cuantitativa en el tiempo. 


\subsubsection{Indicadores desarrollados por la Global Reporting Initiative (GRI)}

A finales de la década de los 90, si bien para la elaboración de memorias financieras de las organizaciones existían una serie de directrices internacionalmente aceptadas, no ocurría lo mismo a la hora de constatar los aspectos económicos, medioambientales y sociales de dichas organizaciones. Algunas de ellas, desde contextos distintos propusieron un conjunto de sistemas de cuantificación y directrices para llevarlo a cabo, concentrándose en cuestiones concretas del ámbito económico, medioambiental o social.

En este contexto de falta de sistemas de medición de aspectos como los ambientales y sociales, una coalición liderada por CERES (Coalición para las Economías Medioambientalmente Responsables) y PNUMA (Programa de las Naciones Unidas para el Medio Ambiente) decidieron asumir esta tarea y buscar una solución mediante un proceso intensivo de consultas a empresas, ONGs, expertos y otras instituciones internacionales dedicadas a cuestiones sociales y medioambientales. Partiendo de esta iniciativa, se elaboró la primera versión de la Guía de la Global Reporting Initiative en el año 2000. Ello fue posible gracias a la participación y la dedicación de un gran número de personas y de organizaciones comprometidas en defender la sostenibilidad, la transparencia y la rendición de cuentas. El fruto de esos esfuerzos fue que la GRI se convirtió en una organización independiente en el año 2002. Se constituyó con la misión de "que el proceso de elaboración de memorias de sostenibilidad llegara a ser tan habitual como el de los informes financieros" (GRI, 2012).

En primer lugar, es de destacar que, según la GRI, la elaboración de memorias de sostenibilidad ayuda a las organizaciones a marcarse objetivos, medir el desempeño y gestionar el cambio con el propósito de que sus operaciones sean más sostenibles. Las memorias de sostenibilidad contienen información sobre la incidencia de las organizaciones, ya sea esta positiva o negativa, en el medio ambiente, la sociedad y la economía. Son estas memorias de sostenibilidad las que contienen los indicadores para el seguimiento de las prácticas de RSE. Otro aporte sustancial de las memorias de sostenibilidad se origina al acordar a nivel internacional los contenidos y los sistemas 
de medida, puesto que esto favorece la accesibilidad y la comparabilidad de la información, y por consiguiente, mejora la calidad de la información para que los grupos de interés tomen las decisiones pertinentes (GRI, 2013).

Es así como el marco para la elaboración de Memorias de Sostenibilidad de la GRI se creó para facilitar un "lenguaje común" que pudiera ser aplicado por todo tipo de organizaciones y se ha redactado con referencia a un gran número de acuerdos y normas internacionales. De esta manera, la Guía para la elaboración de memorias de sostenibilidad G3 de GRI remite a leyes y normas generalmente aceptadas. Entre ellas:

- Artículo 15 de la Declaración de los Principios de la Cumbre de Río de Janeiro sobre Medio Ambiente y Desarrollo.

- Declaración Universal de los Derechos Humanos de las Naciones Unidas y sus Protocolos.

- $\quad$ Convención de las Naciones Unidas: Pacto Internacional de Derechos Civiles y Políticos.

- Convención de las Naciones Unidas: Pacto Internacional de Derechos económicos, sociales y culturales.

- Declaración de la OIT relativa a los principios y derechos fundamentales en el trabajo, 1998.

- Declaración y Programa de Acción de Viena.

- Declaración tripartita de principios sobre las empresas multinacionales y la política social de la OIT.

- $\quad$ Líneas directrices de la OCDE para empresas multinacionales.

- $\quad$ Principios de la Iniciativa del Pacto Mundial (Pacto Global).

Por otra parte, al momento de elaborar las Memorias según la Guía G3, se le permite a las empresas que elijan el nivel en el que quieren hacer la memoria (desde C, para los principiantes, hasta A+ para los más experimentados), lo que refleja los diferentes 
grados de utilización del Marco de la GRI. De esta manera, la versión G3 de la Guía de la GRI introduce una tabla con los Niveles de Aplicación del proceso de elaboración de memorias de GRI (Tabla 2.5).

Tabla 2.5. Niveles de Aplicación del proceso de elaboración de memorias de GRI G3

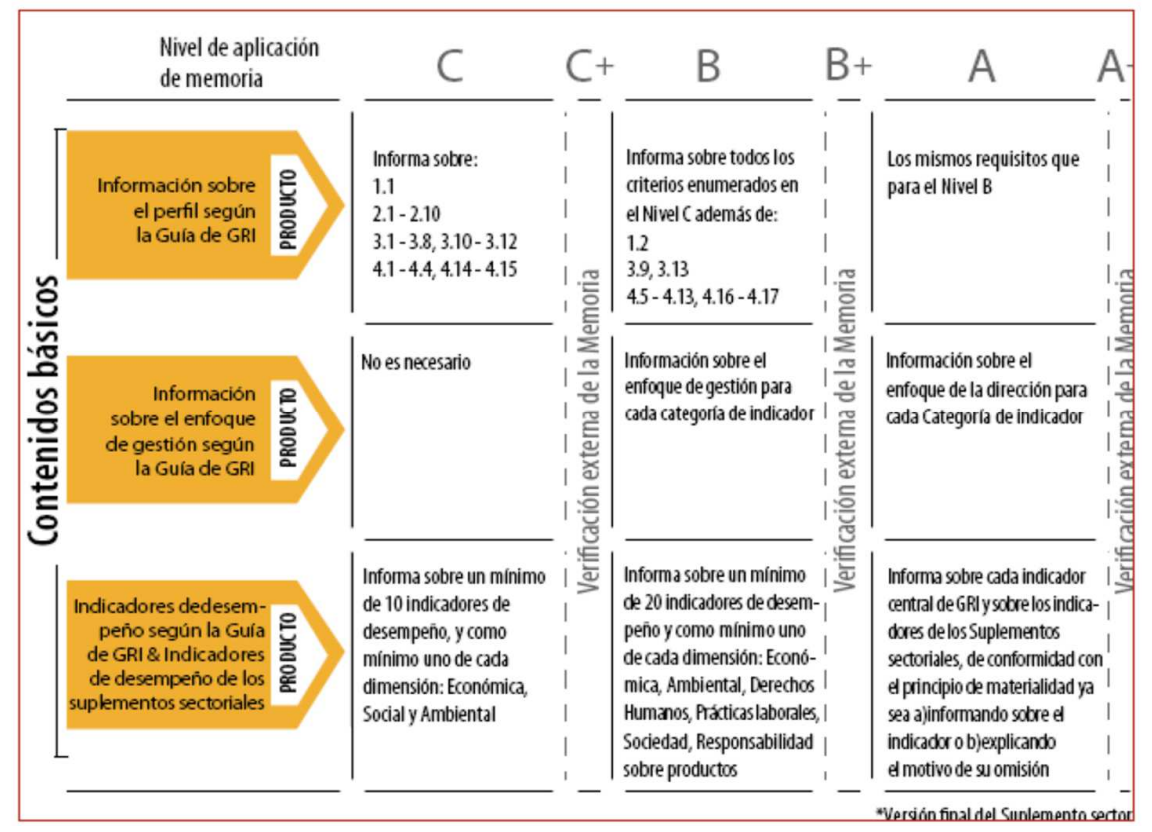

Fuente: GRI (2012).

Por ejemplo, una empresa que elabora la memoria por primera vez, podría decidir utilizar el Nivel C y realizar una memoria más sencilla (que contiene 10 indicadores materiales), limitada a unos pocos aspectos; por otro lado, una gran organización que lleva muchos años elaborando memorias, puede que tenga los recursos y la experiencia necesarios para hacer una memoria completamente exhaustiva de Nivel A. Todas las organizaciones pueden empezar como principiantes (Nivel C) e ir avanzando a niveles superiores con posterioridad.

Todas las memorias que se publicaron después del 31 de diciembre de 2015 debieron elaborarse "de conformidad" con la Guía G4.

Cabe aclarar que cuando una organización divulga una serie de contenidos básicos descritos en la Guía G4 pero no cumple todos los requisitos de las opciones "de 
conformidad", en la memoria ha de incluirse la siguiente aclaración: "En la presente memoria figuran Contenidos básicos de la Guía para la elaboración de memorias de la GRI”. Junto a esta declaración debería facilitarse una lista de dichos Contenidos básicos y su ubicación en la memoria de la organización.

La guía de elaboración de memorias G4 establece que aquellas organizaciones que deseen elaborar sus memorias de sostenibilidad "de conformidad" con la Guía tienen dos opciones: la opción Esencial y la opción Exhaustiva. Todas las organizaciones, independientemente de su tamaño, sector o ubicación, pueden aplicar cualquiera de las opciones. Ambas opciones se centran en el proceso de identificación de los aspectos materiales. Los aspectos materiales son aquellos que reflejan los efectos económicos, ambientales y sociales significativos de la organización, o bien aquellos que tienen un peso notable en las evaluaciones y decisiones de los grupos de interés. La opción Esencial consta de los elementos fundamentales de una memoria de sostenibilidad, constituye un marco mediante el cual las organizaciones transmiten las consecuencias de su desempeño económico, ambiental, social y de gobierno. Por otra parte, la opción Exhaustiva desarrolla la Esencial, a la que incorpora nuevos contenidos básicos relativos a la estrategia, el análisis, el gobierno, la ética y la integridad de las organizaciones. Además, éstas deben describir su desempeño de un modo más pormenorizado, para lo cual tienen que cubrir todos los indicadores relacionados con los aspectos materiales.

Según la GRI, la elaboración de memorias de sostenibilidad ayuda a las organizaciones a marcarse objetivos, medir el desempeño y gestionar el cambio con el propósito de que sus operaciones sean más sostenibles. Las memorias de sostenibilidad contienen información sobre la incidencia de las organizaciones, ya sea ésta positiva o negativa, en el medio ambiente, la sociedad y la economía. Son estas memorias de sostenibilidad las que contienen los indicadores para el seguimiento de las prácticas de RSE. Otro aporte sustancial de las memorias de sostenibilidad se origina al acordar a nivel internacional los contenidos y los sistemas de medida, puesto que esto favorece la accesibilidad y la comparabilidad de la información y, por consiguiente, mejora la calidad de la información para que los grupos de interés tomen las decisiones pertinentes (GRI, 2013). 
Cabe destacar que el marco para la elaboración de Memorias de Sostenibilidad de la GRI se creó para facilitar un "lenguaje común" que pudiera ser aplicado por todo tipo de organizaciones y se ha redactado con referencia a un gran número de acuerdos y normas internacionales. Cientos de personas y de organizaciones que integran la red de la GRI han descubierto que el proceso de elaboración de memorias de la GRI es la mejor manera de comprender y cuantificar el alcance de esas repercusiones (GRI, 2012).

Respecto a la elaboración de las memorias de sostenibilidad, en primer lugar la GRI propuso la Guía G3, en donde se le permitía a las empresas elegir el nivel en el que querían elaborar la memoria (desde C, para los principiantes, hasta A+ para los más experimentados), reflejando los diferentes grados de utilización del Marco de la GRI. Luego la GRI elaboró la Guía G4 y todas las memorias que se publicaron después del 31 de diciembre de 2015 debieron confeccionarse "de conformidad" con ella.

La Guía de elaboración de memorias G4, establece que aquellas organizaciones que deseen elaborar sus memorias de sostenibilidad "de conformidad" con la Guía tienen dos opciones: la opción Esencial y la opción Exhaustiva. Todas las organizaciones, independientemente de su tamaño, sector o ubicación, pueden aplicar cualquiera de las opciones, que se centran en el proceso de identificación de los aspectos materiales. Los aspectos materiales son aquellos que reflejan los efectos económicos, ambientales y sociales significativos de la organización, o bien aquellos que tienen un peso notable en las evaluaciones y decisiones de los grupos de interés. De esta manera la opción Esencial consta de los elementos fundamentales de una memoria de sostenibilidad. Constituye un marco mediante el cual las organizaciones transmiten las consecuencias de su desempeño económico, ambiental, social y de gobierno. La opción Exhaustiva desarrolla la Esencial, a la que incorpora nuevos contenidos básicos relativos a la estrategia, el análisis, el gobierno, la ética y la integridad de las organizaciones. Además, estas deben describir su desempeño de un modo más pormenorizado, para lo cual tienen que cubrir todos los indicadores relacionados con los aspectos materiales.

Respecto a la Guía G4, en la mayoría de los casos se profundizó lo estipulado en la Guía G3, desarrollándose más indicadores para cada dimensión. 
De esta manera, las memorias de sostenibilidad contienen información sobre:

1. Perfil de la organización

2. Enfoque de dirección

3. Indicadores de desempeño

Cabe aclarar que los indicadores ofrecen información sobre el desempeño o los efectos económicos, ambientales y sociales de la organización en referencia a sus aspectos materiales. Los aspectos materiales son aquellos que reflejan los impactos económicos, ambientales y sociales significativos de la organización, o bien aquellos que tienen un peso notable en las evaluaciones y decisiones de los grupos de interés.

Los indicadores propuestos en la Guía G4 se agrupan en 3 dimensiones: Económica (compuesta por 9 indicadores), Ambiental (compuesta por 34 indicadores) y, por último, Social, compuesta a su vez por 4 subdimensiones: Prácticas Laborables y Ética en el Trabajo (16 indicadores), Derechos Humanos (12 indicadores), Sociedad (11 indicadores) y Responsabilidad sobre Productos (9 indicadores).

\subsubsection{Participación de las empresas argentinas en el GRI}

Teniendo en cuenta la participación de las organizaciones argentinas en la GRI (1.3\%), vemos que ésta no ha significado todavía una palanca de cambio relevante en la cultura empresarial y la aplicación real de políticas de RSE es todavía escasa, si nos comparamos con otros países como Brasil que tiene una participación de más del doble (3.6\%). A su vez, los países con mayor participación son: China con un 9,7\%, Estados Unidos 8\%, Taiwán 6.7\%, Japón 5\% y Reino Unido 4,4\% (Tabla 2.6). 
Tabla 2.6. Participación de las organizaciones según país en la GRI

\begin{tabular}{|lrr|}
\hline País & Cantidad empresas & Porcentaje \\
\hline Países con Participación Menor del 1\% (88) & 981 & 14.2 \\
Bélgica & 69 & 1.0 \\
Indonesia & 74 & 1.1 \\
Chile & 75 & 1.1 \\
Austria & 76 & 1.1 \\
Turquía & 76 & 1.1 \\
República de Corea & 83 & 1.2 \\
Rusia & 87 & 1.3 \\
Argentina & 92 & 1.3 \\
Noruega & 97 & 1.4 \\
Hong Kong & 98 & 1.4 \\
Tailandia & 106 & 1.5 \\
Méjico & 110 & 1.6 \\
Italia & 125 & 1.8 \\
Finlandia & 137 & 2.0 \\
Canadá & 138 & 2.0 \\
Holanda & 139 & 2.0 \\
Suiza & 159 & 2.3 \\
India & 160 & 2.3 \\
España & 170 & 2.5 \\
Suecia & 186 & 2.7 \\
Colombia & 192 & 2.8 \\
Australia & 199 & 2.9 \\
Alemania & 685 \\
Francia & & 100.0 \\
Brasil & 205 & 3.0 \\
Sudáfrica & 215 & 3.1 \\
Reino Unido de Gran Bretaña & 251 & 3.6 \\
Japón & 266 & 3.9 \\
Taiwán & 304 & 4.4 \\
Estados Unidos de América & 342 & 5.0 \\
China & 459 & 6.7 \\
\hline Total & 550 & 8.0 \\
\hline & 965 \\
\hline
\end{tabular}

Fuente: elaboración propia en base a lista de reportes de sustentabilidad, base GRI al $2 / 3 / 2018$ 


\subsubsection{Indicadores GRI y los vínculos entre los 10 principios del Pacto Global de Naciones Unidas (2000)}

Como se puede observar en la Tabla 2.7, elaborada por la GRI, los 10 principios propuesto por el Pacto Global, todos ellos están incluidos en las categorías e indicadores propuestos por el GRI. Por lo tanto, una empresa que elabora las memorias de sostenibilidad según los estándares propuestos por el GRI está contribuyendo indirectamente al logro de los 10 objetivos de desarrollo del milenio propuestos en el año 2000 por el Pacto Global.

Tabla 2.7. Vínculo entre los 10 principios del Pacto Global de Naciones Unidas (2000) y el GRI

\begin{tabular}{|c|c|}
\hline Principios del Pacto Mundial de las Naciones Unidas (2000) & Guía de GRI \\
\hline $\begin{array}{l}\text { Principio no 1. Las empresas deben apoyar y respetar la } \\
\text { protección de los derechos humanos proclamados en el } \\
\text { ámbito internacional }\end{array}$ & $\begin{array}{l}\text { Subcategoría: Derechos humanos (todos los } \\
\text { Aspectos) } \\
\text { Subcategoría: Sociedad } \\
\text { Comunidades locales } \\
\end{array}$ \\
\hline $\begin{array}{l}\text { Principio no 2. Las empresas deben asegurarse de no ser } \\
\text { cómplices en abusos a los derechos humanos }\end{array}$ & $\begin{array}{l}\text { Subcategoría: Derechos humanos (todos los } \\
\text { Aspectos) }\end{array}$ \\
\hline $\begin{array}{l}\text { Principio no } 3 \text {. Las empresas deben respetar la libertad de } \\
\text { asociación y el reconocimiento efectivo del derecho a la } \\
\text { negociación colectiva }\end{array}$ & $\begin{array}{l}\text { G4-11 } \\
\text { Subcategoría: Prácticas laborales y trabajo digno } \\
\text { Relaciones entre los trabajadores y la dirección } \\
\text { Subcategoría: Derechos humanos } \\
\text { Libertad de asociación y negociación colectiva }\end{array}$ \\
\hline $\begin{array}{l}\text { Principio } n=4 \text {. Las empresas deben eliminar todas las } \\
\text { formas de trabajo forzoso u obligatorio }\end{array}$ & $\begin{array}{l}\text { Subcategoría: Derechos humanos } \\
\text { Trabajo forzoso }\end{array}$ \\
\hline $\begin{array}{l}\text { Principio no } 5 \text {. Las empresas deben abolir de forma efectiva } \\
\text { el trabajo infantil }\end{array}$ & $\begin{array}{l}\text { Subcategoría: Derechos humanos } \\
\text { Trabajo infantil }\end{array}$ \\
\hline $\begin{array}{l}\text { Principio no 6. Las empresas deben eliminar la } \\
\text { discriminación con respecto al empleo y la ocupación }\end{array}$ & $\begin{array}{l}\text { G4-10 } \\
\text { Subcategoría: Prácticas laborales y trabajo digno } \\
\text { (todos los Aspectos) } \\
\text { Subcategoría: Derechos humanos } \\
\text { No discriminación } \\
\end{array}$ \\
\hline $\begin{array}{l}\text { Principio } \mathrm{n} \text { - 7. Las empresas deben apoyar los métodos } \\
\text { preventivos con respecto a problemas ambientales }\end{array}$ & Categoría: Medio ambiente (todos los Aspectos) \\
\hline $\begin{array}{l}\text { Principio } \mathrm{n} \text { o 8. Las empresas deben adoptar iniciativas para } \\
\text { promover una mayor responsabilidad ambiental }\end{array}$ & Categoría: Medio ambiente (todos los Aspectos) \\
\hline $\begin{array}{l}\text { Principio no 9. Las empresas deben fomentar el desarrollo y } \\
\text { la difusión de tecnologías inofensivas para el medio } \\
\text { ambiente }\end{array}$ & Categoría: Medio ambiente (todos los Aspectos) \\
\hline $\begin{array}{l}\text { Principio no } 10 \text {. Las empresas deben trabajar contra la } \\
\text { corrupción en todas sus formas, incluyendo la extorsión y el } \\
\text { soborno }\end{array}$ & $\begin{array}{l}\text { Subcategoría: Sociedad } \\
\text { Lucha contra la corrupción } \\
\text { Política pública }\end{array}$ \\
\hline
\end{tabular}

Fuente: GRI (2013) 


\subsubsection{De los Objetivos de Desarrollo del Milenio (ODM) a los Objetivos de Desarrollo Sustentable (ODS)}

Entre el año 2000 y el 2015, los Objetivos de Desarrollo del Milenio (ODM) proporcionaron un marco de desarrollo importante y lograron el éxito en una serie de áreas, tales como la reducción de la pobreza y una mejora en la salud y la educación en los países en desarrollo (SDG, 2016).

Los ODS sustituyen los ODM, ampliando los desafíos que deben ser abordados para eliminar la pobreza y abarcando una amplia gama de temas interconectados a través de las dimensiones económicas, sociales y ambientales del desarrollo sostenible.

El 25 de septiembre de 2015, los líderes mundiales adoptaron un conjunto de objetivos globales para erradicar la pobreza, proteger el planeta y asegurar la prosperidad para todos como parte de una nueva agenda de desarrollo sostenible. Cada objetivo tiene metas específicas que deben alcanzarse en los próximos 15 años.

Para alcanzar estas metas, todo el mundo tiene que hacer su parte: los gobiernos, el sector privado y la sociedad civil. De allí la importancia de la incorporación de prácticas por parte de las empresas que contribuyan a la consecución de los ODS.

De esta manera es que la SDG establece que los objetivos son universalmente aplicables a países en desarrollo y desarrollados, por igual. Si bien los ODS tienen como destinatario principal a los gobiernos, reconocen el rol fundamental que las empresas pueden y deben desempeñar en el logro de dichos objetivos.

A continuación se listan los 17 ODS:

- Objetivo 1: Poner fin a la pobreza en todas sus formas en todo el mundo.

- Objetivo 2: Poner fin al hambre, lograr la seguridad alimentaria y la mejora de la nutrición y promover la agricultura sostenible.

- Objetivo 3: Garantizar una vida sana y promover el bienestar para todos en todas las edades. 
- Objetivo 4: Garantizar una educación inclusiva, equitativa y de calidad y promover oportunidades de aprendizaje durante toda la vida para todos.

- Objetivo 5: Lograr la igualdad entre los géneros y empoderar a todas las mujeres y las niñas.

- Objetivo 6: Garantizar la disponibilidad de agua y su gestión sostenible y el saneamiento para todos.

- Objetivo 7: Garantizar el acceso a una energía asequible, segura, sostenible y moderna para todos.

- Objetivo 8: Promover el crecimiento económico sostenido, inclusivo y sostenible, el empleo pleno y productivo y el trabajo decente para todos.

- Objetivo 9: Construir infraestructuras resilientes, promover la industrialización inclusiva y sostenible y fomentar la innovación.

- Objetivo 10: Reducir la desigualdad en y entre los países.

- Objetivo 11: Lograr que las ciudades y los asentamientos humanos sean inclusivos, seguros, resilientes y sostenibles.

- Objetivo 12: Garantizar modalidades de consumo y producción sostenibles.

- Objetivo 13: Adoptar medidas urgentes para combatir el cambio climático y sus efectos.

- Objetivo 14: Conservar y utilizar en forma sostenible los océanos, los mares y los recursos marinos para el desarrollo sostenible.

- Objetivo 15: Proteger, restablecer y promover el uso sostenible de los ecosistemas terrestres, gestionar los bosques de forma sostenible, luchar contra la desertificación, detener e invertir la degradación de las tierras y poner freno a la pérdida de la diversidad biológica. 
- Objetivo 16: Promover sociedades pacíficas e inclusivas para el desarrollo sostenible, facilitar el acceso a la justicia para todos y crear instituciones eficaces, responsables e inclusivas a todos los niveles.

- Objetivo 17: Fortalecer los medios de ejecución y revitalizar la Alianza Mundial para el Desarrollo Sostenible.

Analizándolos 17 objetivos, se observa cómo claramente las organizaciones a través de sus distintas actividades pueden y deben contribuir a los mismos, de allí la importancia también de la generación de indicadores de medición de práctica de RSE alineadas a los ODS.

\subsubsection{Relación entre el GRI y los ODS}

En la última década, la práctica de divulgar la sostenibilidad corporativa ha aumentado, así como la demanda de información de los distintos grupos de interés con los que interactúan las empresas. Ante esta situación, se destaca cada vez más la importancia de reportar y comunicar periódicamente sobre el progreso de las empresas ante prácticas de RSE, buscando en la actualidad que estén alineadas a los nuevos ODS.

Los propios ODS en la meta 12.6 solicitan a los gobiernos de todo el mundo "Alentar a las empresas, en especial a las grandes empresas y a las empresas transnacionales, a que adopten prácticas sostenibles e incorporen información sobre la sostenibilidad en su ciclo de presentación de informes".

A su vez, en el reporte elaborado por la SDG (2016) se establece que es de fundamental interés que las empresas utilicen los estándares internacionalmente reconocidos para sus procesos de elaboración de reportes de sostenibilidad, tales como los estándares exhaustivos ofrecidos por GRI y/o mecanismos de información a nivel de aspecto como los del Carbon Disclosure Project (CDP) y otros.

De esta manera, se puede observar que varios de los principios establecidos por la GRI se convierten en algo aún más importante y realizable con la llegada de los ODS. Un ejemplo es el principio de "contexto de sostenibilidad", que direcciona a las empresas 
a presentar información sobre el desempeño en el contexto más amplio de sostenibilidad, y con referencia a condiciones y objetivos de desarrollo sostenible más amplios.

\subsubsection{Conclusiones parciales del análisis bibliográfico de los indicadores para la medición de prácticas de RSE}

En primer lugar se enumerarán ciertas limitaciones:

- La falta de claridad en la definición del concepto de RSE ha generado la abundancia de términos, no existiendo un consenso claro sobre las dimensiones de la RSE. Por lo tanto, según sea la definición y dimensiones abordadas por la misma es que han surgido diversas formas de medir el desempeño en estas prácticas.

- Muchos de los indicadores propuestos desde la academia implican presencia o ausencia de determinada práctica de RSE, pero no el nivel de avance, que permita analizar a lo largo del tiempo la evolución favorable o desfavorable respecto a determinada práctica.

- La diversidad de modelos para medir el desempeño de las empresas respecto a las prácticas de RSE, también hace difícil la comparación entre empresas o sectores, por lo que se debe ser cauteloso al momento de querer hacer análisis comparativos de las investigaciones.

Ante las limitaciones enumeradas anteriormente para el desarrollo de la metodología para la medición integral de prácticas de RSE, se propone la utilización de la información publicada en las memorias de sostenibilidad propuestas por el GRI. Las mismas facilitan la medición de prácticas de RSE puesto que favorecen la accesibilidad y la comparabilidad de la información, y por consiguiente, mejoran la calidad de la 
información, a la vez que son aplicables a cualquier tipo de organización, lo cual es otra ventaja a destacar.

De acuerdo con lo expuesto en el punto 2.3.1, para el desarrollo de la metodología se deberán operacionalizar las dimensiones de la RSE; y esas dimensiones se dividirán en variables, las cuales, luego serán medidas con indicadores.

Como se anticipó en el punto 2.2.6, se deberán generar indicadores cuantitativos tanto de manera integral como por dimensión, dada la multidimensionalidad de la RSE; en este sentido las dimensiones propuestas por el GRI tienen amplia aceptación por lo que serán utilizadas las mismas. Por otra parte, se destaca que la creación de indicadores cuantitativos de RSE posibilitará el análisis de la variación de los mismos a lo largo del tiempo.

Por último, es importante resaltar que analizar las empresas adheridas a la GRI, posibilita la obtención de indicadores económicos/financieros de las empresas, puesto que gran parte de las mismas cotizan en la Comisión Nacional de Valores (CNV), por lo que se encuentran obligadas a publicar sus Estados Contables. Esto permite llevar a cabo un análisis entre los indicadores de RSE que se desarrollarán mediante el modelo propuesto y los indicadores económico-financieros que se puedan calcular, es por tal motivo que en el punto a continuación se llevará a cabo un análisis teórico de este tipo de indicadores.

\subsection{Indicadores de performance financiera y de desempeño económico}

En este apartado en primer lugar se exponen distintos tipos de indicadores, profundizándose en los indicadores de tipo financiero, y poniendo el foco en aquellos tendientes a medir la rentabilidad: ya sea de las ventas, del activo, del patrimonio neto o de un proyecto o producto. Se enfatiza en la importancia de la medición para poder gestionar adecuadamente, y cómo el sistema de información contable es un factor clave para poder llevar adelante una medición eficiente y oportuna. 


\subsubsection{Tipos de indicadores financieros/económicos}

Según Herrero (2000), los indicadores pueden clasificarse en dos tipos: los económicos o duros y los cualitativos o blandos. Sus características, que son notablemente diferentes, por no decir opuestas, se presentan a continuación:

- Indicadores duros, entre sus características se destacan: fáciles de medir y cuantificar, fáciles de traducir a valores monetarios, objetivos, habituales en los datos de las empresas y altamente creíbles para la dirección. Ejemplos de estos podrían ser: ventas realizadas, volumen de facturación, número de clientes, rentabilidad y margen de ventas.

- Indicadores blandos, los mismos resultan difíciles de medir y más aún de cuantificar, difíciles de traducir a valores monetarios, subjetivos, poco habituales en los datos de las empresas. Algunos ejemplos podrían ser: motivación de los colaboradores, sugerencias realizadas, clima de trabajo y satisfacción de los clientes.

Es importante destacar la importancia de la medición, la misma debe producir información precisa, cierta y útil para la toma de decisiones. Medir es un hecho teleológico, directo o indirecto, mediato o inmediato. La subjetividad en la asignación de las técnicas de medición se determina por el fin pre-establecido (Soto, Galvis \& Salazar, 2010). La finalidad que busca la preparación y presentación de indicadores conlleva a la utilización de uno o varios métodos de medición, de selección de indicadores, dependiendo de la función, propósitos y usuarios de la información.

Las mediciones son importantes: "Si no puedes medirlo, no puedes gestionarlo". A su vez, el sistema de medición de una organización afecta muchísimo el comportamiento de la gente, tanto del interior como del exterior de la organización (Kaplan \& Norton 2002, p. 34).

Cabe agregar lo que expone Barbei (2012) citando la International Accounting Standards Board (IASB): 
"La medición es un aspecto clave de la emisión de información financiera. En realidad, es el corazón de lo que los contadores hacen. Un no-contable se sorprendería al descubrir que la medición es una de las áreas menos desarrolladas de los marcos conceptuales actuales de los distintos emisores de normas en todo el mundo".

De allí que la IASB destaca la importancia de la medición, la cual es clave para la administración y control. Como se resaltará más adelante, la medición deberá no sólo incluir aspectos exclusivamente financieros sino también aspectos no financieros tradicionales.

\subsubsection{Indicadores financieros}

Un indicador financiero puede ser definido como:

"La vinculación y/o relación de variables, medidas en términos monetarios, que permite tener algún conocimiento que surge de la comparación de esas variables vinculadas" (Ostengo, 2014).

La comparación entre variables monetarias y/o entre indicadores financieros, sirve para informar sobre el comportamiento de algún aspecto económico financiero o patrimonial, que sea de interés conocer por parte de la organización, para lograr un adecuado proceso decisorio y un adecuado control de esa gestión (Demo, 2016).

Por lo mencionado anteriormente, los indicadores financieros son el producto de establecer resultados numéricos basados en relacionar dos cifras o cuentas, bien sea del Estado de Situación Patrimonial y/o del Estado de Resultados. Los resultados así obtenidos, por sí solos no tienen mayor significado; sólo cuando los relacionamos unos con otros y son comparados con años anteriores o con empresas del mismo sector, y a su vez el analista se preocupa por conocer a fondo la operación de la compañía, se pueden obtener resultados significativos y sacar conclusiones sobre la real situación financiera de la empresa (Herrera, Gómez \& Granadillo, 2012).

Un tipo de indicador son las razones, y es importante interpretar cada razón comparándola con: 1) razones anteriores de la misma empresa, 2) razones estándar 
establecidas por el contexto competitivo y 3) razones de las mejores y las peores compañías del mismo sector.

\subsubsection{Clasificaciones de las Medidas de Performance Financiera (PF) y las de Desempeño económico (DE)}

Las medidas de Performance Financiera (PF) y las de Desempeño Económico (DE), pueden categorizarse de distintas maneras.

En primer lugar, expondremos las siguientes categorías: medidas de mercado, medidas contables y medidas de percepción (Tabla 2.8). Las medidas de mercado enfatizan al accionista como el principal stakeholder que determina la actividad de la empresa, pero la evolución de estos indicadores puede responder a estímulos externos a la empresa. Por otra parte, las medidas contables están relacionadas con la eficiencia de la empresa y dependen de la asignación de recursos y de las decisiones y capacidades de gestión de la empresa. Por último, en las medidas de percepción las respuestas están basadas en apreciaciones subjetivas de los empresarios (Olcese, 2011).

Cabe aclarar que si bien las utilidades, en sentido estricto, representan un resultado económico positivo de la empresa -ganancias- aunque esta definición está sujeta a distintas interpretaciones, en la perspectiva gerencial, las utilidades económicas son iguales al cash flow neto financiero (Sallenave J., 1993).

Tabla 2.8. Medidas de Performance Financiera/Desempeño Económico

\begin{tabular}{|l|l|}
\hline Categorías & Ejemplos de medidas utilizadas \\
\hline \multirow{2}{*}{ Medidas de mercado } & $\begin{array}{l}\text { Valor de la acción, Apreciación de la acción, Alpha, } \\
\text { Retorno total, retorno ajustado al riesgo, Beta, } \\
\text { Desviación estándar del retorno total }\end{array}$ \\
\hline Medidas contables & $\begin{array}{l}\text { ROE, ROA, ROI, ROS, Beneficios, Beneficios por } \\
\text { acción, } \\
\text { Crecimiento ventas, Deuda/Capital, Deuda/Activos, } \\
\text { Total Activos, Crecimiento ingresos operativos }\end{array}$ \\
\hline Medidas de percepción & $\begin{array}{l}\text { Encuestas sobre estimaciones de solidez financiera, } \\
\text { objetivos financieros respecto a la competencia, etc. }\end{array}$ \\
\hline
\end{tabular}

Fuente: Orlitzky et al. (2003) citado por (Olcese, 2011). 
Según Salas (2010), estas razones de performance financiera pueden clasificarse en tres grupos: Índices de estabilidad, Índices de gestión, así como Índices de rentabilidad.

Mientras que la utilidad de la empresa se manifiesta en unidades monetarias, la rentabilidad es una relación (tasa) que compara la utilidad con un aporte de fondos. Por lo tanto, se expresa en términos de porcentajes (Sallenave, 1993).

Los indicadores de rentabilidad surgen porque "las utilidades son importante, pero observadas aisladamente tienen poco significado a menos que se relacionen con la magnitud de los ingresos y con las inversiones realizadas para generar esas ganancias" (Salas, 2010, p.86). Lo mencionado, es clave para organizaciones de diversos tamaños ya que en empresas que generan miles de millones en ventas, puede que una ganancia de millones no sea suficiente por su alto volumen de ventas.

El desempeño financiero/desempeño económico de una empresa es uno de los aspectos más importantes pero difíciles de determinar. En la búsqueda de su determinación se han creado medidas cuantitativas y también otros indicadores de tipo cualitativos, tales como: innovación, perspectivas de mercado, talento y moral de los empleados, lealtad de los clientes, entre otros. Los indicadores cualitativos son menos estáticos y absolutos que los indicadores cuantitativos, por cuanto el desempeño no puede ser evaluado aisladamente, por ejemplo, a través de utilidades en un medio económico cambiante y de competencia inclemente (Sallenave, 1990).

Los indicadores cuantitativos pueden ser opacados por algunos factores, como la no consideración del tiempo para la obtención de utilidades, el peso desmesurado otorgado a los beneficios y otros de corto plazo, la ignorancia de los costos de oportunidades pérdidas y las ventajas financieras de largo plazo, producto de un desempeño efectivo de las actividades de manufactura, y la no capitalización del valor de uso eficiente de una red de retribución (Gayle, 1999, citado por Morillo (2004).

Cabe agregar que las medidas contables de la rentabilidad toman su fuente de información en los datos procedentes de los estados contables y financieros de la empresa elaborados de acuerdo con los criterios habitualmente establecidos en cada 
país. Su principal ventaja radica en la facilidad de obtención de los datos al estar disponibles tanto si se recurre a información primaria como secundaria (Tenorio Ronda \& Perez Rodríguez, 1999).

\subsubsection{Las medidas de rentabilidad}

Sallenave (1993), considera que existen cuatro nociones fundamentales de rentabilidad:

- La rentabilidad sobre ventas

- La rentabilidad sobre activos o rentabilidad económica

- La rentabilidad financiera o rentabilidad sobre el Patrimonio Neto (PN)

- La rentabilidad de un proyecto (o de un producto)

A continuación serán explicadas brevemente cada una de las nociones de rentabilidad

\subsubsection{Rentabilidad sobre ventas}

Este tipo de rentabilidad se mide por el margen sobre ventas, o sea, por la relación entre las utilidades netas y las ventas totales. El margen sobre ventas es la primera fuente de rentabilidad de la empresa. Cabe agregar que si la rentabilidad sobre ventas es nula, la rentabilidad económica y la rentabilidad financiera también lo son, por lo tanto se lo podría definir como uno de los principales generadores de valor para la empresa. En palabras de Sallenave (1993) se diría que "si las ventas son el motor de la empresa, el margen sobre ventas expresa el rendimiento de ese motor". Como índice global de rentabilidad, permite comparar el rendimiento de varias empresas en el mismo sector, sin que sea relevante su tamaño o estructura financiera. No obstante, el margen de utilidad sobre ventas tampoco puede servir como único criterio de comparación entre empresas que pertenecen a sectores diferentes, debido a que en ciertos sectores los márgenes de utilidad sobre ventas son generalmente pequeños y en otros sectores mayores. Por otra parte, aún si se comparan dos empresas del 
mismo sector, el margen sobre ventas no toma en consideración el capital utilizado, de esta forma una empresa podría tener un margen de utilidad ligeramente inferior al de otra pero emplear mucho menos capital, por lo que esta última será más rentable en términos de capital (Sallenave, 1993).

\subsubsection{Rentabilidad sobre activos}

El rendimiento sobre los activos (ROA) mide la rentabilidad obtenida de los activos totales de la empresa. La ROA también puede expresarse como el producto de la rentabilidad sobre ventas por la tasa de rotación del activo. Indica el rendimiento obtenido por la empresa derivado de toda su actividad, sean funciones típicas o no. Es un indicador que ayuda en la medición de la eficiencia y eficacia con que la administración ha utilizado sus recursos totales. Este índice se puede interpretar en términos porcentuales o unitarios (Zometa Saborío, 2017).

Al comparar esta razón a través del tiempo, permite evaluar qué tan eficiente ha sido la empresa en transformar la inversión en utilidades. A su vez, al analizarlo históricamente permite observar en el caso de que la empresa haya realizado inversiones en activos, si las utilidades han aumentado en la misma proporción de los activos o si, por el contrario, dicha estrategia ha generado un detrimento de estas.

Respecto a la tasa de rotación del activo de varias empresas que pertenecen a industrias diferentes, en principio no permite juzgar sobre la eficacia económica de las mismas, efectivamente, en las empresas intensivas en capital, las tasas de rotación del activo son por lo general débiles, pero los márgenes de utilidad sobre ventas son elevados, mientras que en industrias livianas y en las empresas de servicios, se encuentra la situación inversa. Por otra parte, la disminución de los activos no es la panacea para mejorar la rentabilidad económica de la empresa, puesto que es importante, que esta disminución de los activos no cause una disminución proporcional de las ventas y de las utilidades, pues, en este caso, no mejorarían ni la rotación ni el margen (Sallenave, 1993).

Por último, cabe destacar el aporte de Alfred P. Sloan antiguo presidente de General Motors (citado por Sallenave, 1993), expresa que la ROA sigue siendo el índice más fiable del desempeño económico intrínseco de la empresa: "El fin estratégico de una 
empresa es rentabilizar el capital invertido. Si no se logra un resultado satisfactorio a largo plazo, se debe corregir esta deficiencia o reconvertirse en una actividad más favorable".

\subsubsection{Rentabilidad sobre el patrimonio neto}

La rentabilidad sobre el patrimonio neto (ROE) expresa el rendimiento que obtienen los socios de su inversión en una empresa. La rentabilidad es la meta principal del inversionista al invertir su capital en un determinado negocio o proyecto. Cuanto mayor la ROE, mayor será la ganancia que recibirá el inversionista a cambio de la inversión realizada. Es importante destacar que la ROE debe ser mayor al costo de oportunidad que tiene el inversionista de invertir su dinero en alternativas de riesgo similar que ofrece el mercado. Por tanto, si al evaluar la ROE de la compañía, refleja valores que están por debajo de los rendimientos del mercado, genera una señal para el inversionista ya que está dejando de percibir ganancias, si hubiese invertido su capital en otro negocio. Ante tal situación, la compañía debe buscar los motivos que están afectando negativamente el rendimiento sobre el patrimonio, si es que están marginando por debajo de lo que hace su competencia en la venta de productos, si es que tiene poco poder de negociación para obtener precios más bajos en las materias primas o productos, o también, si es un problema de elevados gastos administrativos o financieros. Los anteriores son solo algunos de los casos que pueden afectar el rendimiento sobre el patrimonio y que deben ser determinados bajo un análisis en conjunto de todas las razones expuestas anteriormente, con históricos de la misma empresa y comparando la compañía con la industria (Zometa Saborío, A., 2017).

También la ROE puede ser expresada como el producto entre la ROA por su palanca financiera:

$R O E=R O A+[(R O A-C P P C) \times(1-t)] \times P / P N$

Dónde:

CPPC: Costo Promedio Ponderado del Capital

P/PN: Nivel de endeudamiento (intensidad de la palanca financiera) 
(ROA-CPPC): sentido de la palanca positiva o negativa

$\mathrm{t}=$ componente impositivo

Como se observa a través de la fórmula de la ROE, si la ROA>CPPP entonces el efecto palanca es positivo, mientras que si la ROA $\angle$ CPPC el efecto palanca será negativo. A su vez la intensidad de la palanca estará definida por el nivel de endeudamiento (P/PN).

Cabe agregar que recurrir a la palanca financiera es una medida sana dentro de una coyuntura de expansión, siempre y cuando se observen las siguientes reglas esenciales: 1) que la deuda a largo plazo financie los activos fijos y la deuda a corto plazo financie los activos circulantes; 2 ) que la tasa de interés del préstamo sea inferior a la tasa de rentabilidad esperada del activo (Sallenave, 1993).

\subsubsection{Rentabilidad de un proyecto (o de un producto)}

La rentabilidad de un proyecto o de un producto se mide por la relación entre la utilidad del proyecto, ya sea proyectada o real y la inversión necesaria para llevar a cabo el mismo. Para la evaluación de proyectos, se evita la trampa de las medidas estáticas, buscando índices dinámicos de desempeño, es decir, índices que tienen en cuenta los flujos de caja futuros del proyecto. Utilizando para su cálculo la fórmula del Valor Presente Neto como la sumatoria de los flujos de caja actualizados al costo de capital.

Cada medida de rentabilidad es apropiada a una situación determinada: el director de mercadeo deseoso de medir la eficacia del servicio comercial, efectuará la evaluación según la rentabilidad de las ventas y no del ROE; el gerente general que quiere medir la evolución desempeño del negocio, examinará la ROA; el jefe de proyectos basará sus requerimientos presupuestarios según la rentabilidad de cada proyecto, mientras que el accionista analizará la ROE (Sallenave, 1993).

Los indicadores de rentabilidad definidos anteriormente se tratan de cálculos puramente económicos, por lo que deja de lado el impacto cualitativo. Por ello, sus resultados se deberían sumar a los resultados no económicos obtenidos en el cálculo de los beneficios. No obstante, el cálculo de la rentabilidad por sí sólo es enormemente útil para tomar decisiones sobre los niveles de inversión en formación y 
aporta datos altamente valorados y deseados por los órganos directivos (Herrero,2000).

\subsubsection{Indicadores no financieros}

La dimensión financiera de la actuación de la unidad de negocio ha sido altamente desarrollada. Sin embargo, muchos han criticado el amplio, e incluso exclusivo uso de las mediciones financieras en los negocios. En el fondo, un énfasis excesivo en la consecución y mantenimiento de resultados financieros a corto plazo, puede hacer que las empresas inviertan excesivamente a corto plazo y demasiado poco en la creación de valor a largo plazo especialmente por lo que respecta a los activos intangibles e intelectuales que generan un crecimiento futuro (Kaplan \& Norton, 2002).

Dadas las limitaciones involucradas en el uso único de indicadores financieros, se hace necesario el uso de indicadores no financieros. Actualmente, muchas organizaciones complementan la información interna con información externa y con información no financieros, afianzándose en el sistema Balanceado de Indicadores, incluyendo medidas tanto de resultados como de satisfacción al cliente, innovación, calidad, tiempo de respuesta, etc. (Morillo, 2001).

En relación con los indicadores no financieros, investigaciones y desarrollos investigativos realizados a partir de la década del '70 muestran que estos intangibles ocupan hoy un lugar cada vez más preponderante en las decisiones empresarias. Estos cambios implicaron y aún hoy implican, que se debe incorporar otra información sobre la que debería basarse la estrategia del negocio. Así aparece la figura del capital intangible, el que está conformado con variables no financieras, que tiene tanto valor como el activo contable y que, además, es necesario medirlas para realizar su evaluación y analizar su evolución. La información no financiera puede adquirir distintas formas, desde valores de un parámetro bien definido hasta material descriptivo en diarios y revistas técnicas. Esto permite determinar que las fuentes de 
información no financiera son más amplias y flexibles que las de la información financiera (Demo, 2016).

Como se observa en el capítulo anterior, los indicadores de sustentabilidad se clasifican dentro de los indicadores no financieros de allí que dada su importancia, es que para esta investigación los mismos fueron desarrollados exhaustivamente en el capítulo anterior.

\subsubsection{La importancia del Sistema de Información Contable para la generación de indicadores}

Si las empresas han de sobrevivir y prosperar en la competencia de la era de la información, han de utilizar sistemas de medición y de gestión, derivados de sus estrategias y capacidades. Desagraciadamente, muchas organizaciones adoptan estrategias con respecto a las relaciones con los clientes, las competencias centrales y las capacidades organizativas, mientras que motivan y miden la actuación sólo con indicadores financieros (Kaplan \& Norton, 2002).

Partiendo de la definición de contabilidad como: "como cuerpo de conocimientos, es una ciencia empírica, de naturaleza económica, cuyo objeto es la descripción y predicción, cualitativa y cuantitativa del Estado y la evolución económica de una entidad específica, realizada a través de métodos propios de captación, medida, valoración, representación e interpretación, con el fin de poder comunicar a sus usuarios información objetiva, relevante y válida para la toma de decisiones (Pereyra, 2009), de allí la relevancia del sistema de información contable y la medición.

De esta manera, la contabilidad concebida como sistema de información y comunicación posee elementos de entrada, procesamiento, elementos de salida, medios, emisores y receptores, que permiten ver la contabilidad desde un enfoque dinámico y más significativo que si se reduce a un conjunto de cifras e informes obtenidos mediante procesos técnicos. Cabe agregar que la gestión del sistema de información contable busca además de hacer eficientes los procesos operativos, lograr una fluida comunicación y entendimiento entre emisores y receptores. Es en este 
diálogo donde se requiere potenciar las habilidades analíticas, comunicativas, interpretativas y expresivas de los contadores para lograr que la realidad contable sea de fácil acceso y comprensión por los distintos agentes de interés organizacional (Correa García, 2016).

El sistema de información contable, es un componente esencial e integral de las organizaciones y como principal proveedor del insumo informacional de la gerencia, debe considerar conceptos, ideas y principios de la complejidad, la no linealidad, lo dinámico, lo cambiante y la incertidumbre (De Nobrega, 2011).

El sistema de contabilidad constituye el conjunto de elementos o componentes que interactuando de forma coordinada proporciona información y facilita el control útil para la toma de decisiones gerenciales en una empresa. El sistema de información contable opera con la información y datos provenientes de todas las unidades que efectúan, directa o indirectamente, transacciones financieras, y hacia las mismas debe proporcionar información y control a la medida de sus necesidades y procesos de cambio (De Nobrega, 2011).

\subsubsection{Conclusiones parciales del análisis teórico de los indicadores financieros y de desempeño económico}

En primer lugar, cabe resaltar la importancia de generación de indicadores para la medición, puesto que lo que no se mide no de administra, enfatizando en la importancia del rol que ocupa en este aspecto el sistema de información contable de la empresa.

Por otra parte, es importante destacar que dada la complejidad, el entorno cambiante y la incertidumbre es que el sistema de información contable, no puede limitarse al esquema de pensamiento cuantitativo en su gestión y apoyo a la gerencia y debe incorporar elementos cualitativos a la misma: es la gestión de información y control bajo nuevos esquemas de pensamientos en organizaciones sociales complejas, de allí la importancia de la medición de la RSE, así como los indicadores de percepción tales como la reputación corporativa y la imagen. 
Habiendo en este capítulo detallado distintas medidas de rentabilidad, se concluye que la ROA se considera el índice más fiable del desempeño económico intrínseco de la empresa. Puesto que la unidad de análisis de esta tesis son empresas que cotizan en la CNV, se propone relacionar los indicadores para la medición de prácticas de RSE que se calcularán según el modelo propuesto, con los indicadores económicos que se podrán calcular para cada empresa en su respectivo año, así como también el indicador de percepción Reputación Corporativa utilizando información de fuentes secundaria, como el MERCO (el mismo se explica en el Capítulo 3 de metodología).

Se considera oportuno en un principio considerar para el análisis la ROA y también la ROE, de manera de analizar el apalancamiento financiero de las empresas, también será analizado el crecimiento de la empresa mediante una variable proxy: logaritmo neperiano de las ventas.

\subsection{Síntesis de las conclusiones del marco teórico}

Como principales conclusiones que permitirán el desarrollo de la metodología para la medición integral de prácticas de RSE se pueden mencionar:

- Deberán generarse indicadores de RSE tanto por dimensiones como de tipo integral, es decir que considere en conjunto todas las dimensiones (social, medioambiental y económica).

- Se enfatiza la importancia de la aplicación de una metodología apoyada en herramientas estadísticas siempre que sea posible para lograr mayor objetividad y dar mayor robustez a las conclusiones a las que se arribe.

- Se propone la utilización de la información publicada en las memorias de sostenibilidad propuestas por el GRI, las mismas facilitan la medición de prácticas de RSE puesto que favorecen la accesibilidad y la comparabilidad de la información, y, por consiguiente, mejora la calidad de la información, a su vez son aplicables a cualquier tipo de organización, lo cual es otra ventaja a destacar. 
- Por último, este primer análisis dejó en evidencia no sólo la importancia del desarrollo de una metodología para la medición de prácticas de RSE, sino también su posterior vinculación con medidas de creación de valor, tanto contables (ROA, ROE, utilidad neta, margen bruto) como de percepción (reputación corporativa, Imagen, éxito competitivo). Por tal razón, esta tesis no se limitará al desarrollo y aplicación de una metodología para la medición integral de prácticas de RSE, sino que se analizará también la vinculación entre RSE con el desempeño económico y la reputación corporativa. 


\section{CAPÍTULO 3: METODOLOGÍA PARA LA MEDICIÓN DE PRÁCTICAS DE RESPONSABILIDAD SOCIAL EMPRESARIA}

Este capítulo se divide en tres secciones. En primer lugar, se realiza la operacionalización de las variables de manera de explicar en detalle la definición que adoptarán las variables propuestas para el desarrollo de la metodología para la medición integral de prácticas de RSE. Luego se detallan los pasos de la metodología desarrollada, de manera de arribar a la conceptualización de la misma.

Del desarrollo de la metodología se concluye que mediante ésta se logra medir los aspectos intangibles de la RSE, tanto por dimensión como de manera integral, posibilitando la comparación de de las dimensiones y determinando en qué medida aporta cada una a la valoración integral de la RSE.A su vez la metodología, posibilita el análisis de la evolución en el tiempo de las prácticas de RSE, pudiendo considerar distintas unidades de análisis como ser: la misma empresa, empresas de distintos sectores o empresas de distintas regiones.

Finalmente en virtud del extenso desarrollo del marco teórico, se pueden enunciar distintos usos que se le podrían dar a la metodología de medición de prácticas de RSE desarrollada; la misma posibilita el análisis de diversas hipótesis, entre ellas: si la aplicación de RSE genera una ventaja competitiva para la empresa, si a mayor aplicación de prácticas de RSE, mayor la utilidad por acción.

\subsection{Operacionalización de las variables}

Medir significa atribuir a los objetos valores que representan conceptualmente propiedades de los objetos. Una variable es un rasgo o aspecto de un objeto de estudio capaz de asumir distintos valores. Los distintos estados de las variables se denominan categorías (Sautu, et. al, 2005).

Una variable es operacionalizada con la finalidad de convertir un concepto abstracto en uno empírico, susceptible de ser medido a través de la aplicación de un instrumento.

La operacionalización de las variables es el proceso a través del cual el investigador explica en detalle la definición que adoptará de las categorías y/o variables de estudio, 
tipos de valores (cuanti o cualitativos) que podrían asumir las mismas y los cálculos que se tendrían que realizar para obtener los valores de las variables cuantitativas. Por tal razón, las variables deben estar claramente definidas y convenientemente operacionalizadas.

Es importante remarcar que esta tabla se elaboró en base a las conclusiones arribadas en el marco teórico. Como fue mencionado en el punto 2.2.6 cualquier intento de medir un concepto multidimensional como la RSE, debe contemplar esta característica, de allí que se generan indicadores de RSE tanto por dimensiones como de manera integral y el punto 2.3.1 donde se resalta según el BID (2016) que en el paradigma neopositivista se deben hacer "observables" los conceptos, para lo cual es necesario operacionalizar los mismos en categorías y esas categorías dividirlas en variables, las cuales serán medidas con indicadores.

En la Tabla 3.1 se presenta la operacionalización de la variable RSE que será utilizada para el diseño de la metodología para la medición integral de prácticas de RSE.

Por otra parte, en el punto 2.3 .10 se propuso la utilización de la información publicada en las memorias de sostenibilidad propuestas por el GRI, es por eso que se las utiliza para la elaboración de los indicadores. Como ya se mencionó, las mismas favorecen la accesibilidad y la comparabilidad de la información, y, por consiguiente, mejora la calidad de la información y son aplicables a cualquier tipo de organización. 
Tabla 3.1 Operacionalización de la variable Responsabilidad Social Empresaria RSE

\begin{tabular}{|c|c|c|c|c|c|c|}
\hline Definición de la variable & Categoría & $\begin{array}{c}\text { Definición operacional de } \\
\text { dimensión }\end{array}$ & Subcategoría (definidas según GRI) & Indicadores $(*)$ & Unidad de medida para cada indicador & Fuente de información \\
\hline \multirow{6}{*}{$\begin{array}{l}\text { RSE: "libre voluntad de la } \\
\text { empresa de aportar el } \\
\text { mayor valor posible a sus } \\
\text { diferentes grupos de } \\
\text { interés" Izquierdo (2004) }\end{array}$} & Económica & $\begin{array}{c}\text { Impacto de la empresa } \\
\text { sobre las condiciones } \\
\text { económicas de sus grupos } \\
\text { de interés y de los sistemas } \\
\text { económicos a nivel local, } \\
\text { nacional y mundial }\end{array}$ & Económica & \begin{tabular}{|l|} 
Clientes \\
Proveedores \\
Empleados \\
Proveedores de capital \\
Sector público
\end{tabular} & $\begin{array}{l}\text { Dicotómica: } 1=\text { si se disponía de } \\
\text { información en la memoria GRI } \\
0=\text { si no se disponía de información en } \\
\text { la memoria GRI }\end{array}$ & $\begin{array}{l}\text { Información obtenida } \\
\text { del análisis de las } \\
\text { memorias de } \\
\text { sostenibilidad } \\
\text { publicadas por las } \\
\text { empresas }\end{array}$ \\
\hline & \multirow{4}{*}{ Social } & \multirow{4}{*}{\begin{tabular}{|c|} 
Impacto de la actividad de la \\
empresa sobre los sistemas \\
sociales en los que opera
\end{tabular}} & Prácticas laborales y trabajo decente & $\begin{array}{l}\text { Empleo } \\
\text { Relaciones empresa/trabajadores } \\
\text { Salud y seguridad } \\
\text { Formación y educación } \\
\text { Diversidad y oportunidad }\end{array}$ & $\begin{array}{l}\text { Dicotómica: } 1 \text { = si se disponía de } \\
\text { información en la memoria GRI } \\
0=\text { si no se disponía de información en } \\
\text { la memoria GRI }\end{array}$ & \begin{tabular}{|l|} 
Información obtenida \\
del análisis de las \\
memorias de \\
sostenibilidad \\
publicadas por las \\
empresas \\
\end{tabular} \\
\hline & & & Derechos humanos & $\begin{array}{l}\text { Estrategia y gestión } \\
\text { No discriminación } \\
\text { Libertad de asociación y } \\
\text { negociación colectiva } \\
\text { Trabajo infantil }\end{array}$ & $\begin{array}{l}\text { Dicotómica: } 1 \text { = si se disponía de } \\
\text { información en la memoria GRI } \\
0=\text { si no se disponía de información en } \\
\text { la memoria GRI }\end{array}$ & \begin{tabular}{|l|} 
Información obtenida \\
del análisis de las \\
memorias de \\
sostenibilidad \\
publicadas por las \\
empresas \\
\end{tabular} \\
\hline & & & Prácticas sociales & \begin{tabular}{|l|} 
Comunidad \\
Corrupción \\
Contribuciones políticas \\
Competencia y precios \\
\end{tabular} & $\begin{array}{l}\text { Dicotómica: } 1 \text { = si se disponía de } \\
\text { información en la memoria GRI } \\
0=\text { si no se disponía de información en } \\
\text { la memoria GRI }\end{array}$ & $\begin{array}{l}\text { Información obtenida } \\
\text { del análisis de las } \\
\text { memorias de } \\
\text { sostenibilidad } \\
\text { publicadas por las } \\
\text { empresas } \\
\end{array}$ \\
\hline & & & Responsabilidad de producto & $\begin{array}{l}\text { Salud y seguridad del cliente } \\
\text { Productos y servicios } \\
\text { Publicidad }\end{array}$ & $\begin{array}{l}\text { Dicotómica: } 1 \text { = si se disponía de } \\
\text { información en la memoria GRI } \\
0=\text { si no se disponía de información en } \\
\text { la memoria GRI }\end{array}$ & \begin{tabular}{|l} 
Información obtenida \\
del análisis de las \\
memorias de \\
sostenibilidad \\
publicadas por las \\
empresas \\
\end{tabular} \\
\hline & Ambiental & $\begin{array}{c}\text { Impacto de la empresa en } \\
\text { los sistemas naturales vivos } \\
\text { e inertes, incluidos los } \\
\text { ecosistemas, el suelo, el aire } \\
\text { y el agua }\end{array}$ & Ambiental & \begin{tabular}{|l|} 
Materias primas \\
Energía \\
Agua \\
Biodiversidad \\
Emisiones, vertidos y residuos
\end{tabular} & $\begin{array}{l}\text { Dicotómica: } 1 \text { = si se disponía de } \\
\text { información en la memoria GRI } \\
0=\text { si no se disponía de información en } \\
\text { la memoria GRI }\end{array}$ & \begin{tabular}{|l} 
Información obtenida \\
del análisis de las \\
memorias de \\
sostenibilidad \\
publicadas por las \\
empresas \\
\end{tabular} \\
\hline
\end{tabular}

(*) El detalle de la totalidad de los indicadores propuestos por el GRI y considerados para el desarrollo de esta metodología se detallan en el Anexo 1 


\subsection{Metodología propuesta para la medición integral de prácticas de RSE}

A continuación, se detallan los pasos de la metodología desarrollada para la medición integral de prácticas de RSE:

1- Recolección y sistematización de la información publicada en las Memorias de Sostenibilidad.

Se procedió a asignar un número secuencial para cada una de las observaciones (par ordenado: empresa y año) y a consignar las siguientes variables según lo informado en las memorias de sostenibilidad: nombre de la empresa, año de la memoria, tamaño de la empresa, tipo de la guía GRI utilizada para la elaboración de la memoria y sector de actividad.

2- Generación de variables binarias para cada uno de los indicadores a informar, conforme la GRI en cada memoria de sostenibilidad relevada.

Respecto a los indicadores informados, se generó para cada uno de los mismos una variable del tipo binaria de forma que un determinado indicador se valoró con un " 1 " si se disponía de la información sobre el mismo en la memoria publicada y con " 0 " en caso contrario.

3- Cálculo de indicadores para la medición por dimensión de la RSE.

Puesto que en esta investigación se considera importante analizar las distintas "dimensiones" de la RSE de manera de identificar aquellas que requieren atención, con el fin de proporcionar información para en un futuro hacer comparaciones y desarrollar planes de mejora, es que se procedió a realizar para cada una de las dimensiones que propone la GRI un subíndice, definido mediante el cociente entre la sumatoria del número del total de indicadores identificados y el número total de indicadores que constituyen el mismo.

Por lo tanto, cada subíndice se definió de la siguiente manera:

$$
E C=\sum \frac{E C 1+E C 2+E C 3+\cdots+E C 9}{9} \times 100
$$




$$
\begin{aligned}
L A & =\sum \frac{L A 1+L A 2+L A 3+\cdots+L A 16}{16} \times 100 \\
H R & =\sum \frac{H R 1+H R 2+H R 3+\cdots+H R 12}{12} \times 100 \\
S O & =\sum \frac{S O 1+S O 2+S O 3+\cdots+S O 11}{11} \times 100 \\
P R & =\sum \frac{P R 1+P R 2+P R 3+\cdots+P R 9}{9} \times 100 \\
E N & =\sum \frac{E N 1+E N 2+E N 3+\cdots+E N 34}{34} \times 100
\end{aligned}
$$

Donde:

EC=Indicadores de Desempeño económico; $L A=$ Indicadores de Prácticas Laborales y Trabajo Decente; $\mathrm{HR}=$ Indicadores de Derechos Humanos; $\mathrm{SO}=$ Indicadores sobre Prácticas Sociales; $\mathrm{PR}=$ Indicadores sobre Responsabilidad de Producto y EN= Indicadores de Desempeño Medioambiental.

4- Generación de indicador para la medición integral de la RSE.

Puesto que la RSE no es una "variable" y debe considerarse la misma como una medida multidimensional del comportamiento social de las empresas en función de múltiples cuestiones relacionadas con la RSE (Charlo Molina \& Moya Clemente, 2010). Por tal motivo, como medida proxy para expresar de manera integral la variable de RSE, se consideró el valor de la sumatoria de los subíndices calculados para cada dimensión dividido la cantidad de subíndices.

De esta manera se crea el indicador integral de "RSE", como:

$$
R S E=\sum \frac{E C+L A+H R+S O+P R+E N}{6} \times 100
$$

Cabe destacar que se considera que todas las dimensiones tienen la misma relevancia, de allí que se le asigna el mismo peso relativo a cada una, por lo tanto el indicador integral surge de la división de los subíndices por la suma de la cantidad de estos.

También es preciso agregar que, debido a que la cantidad de indicadores varía según se presente memorias G3 o G4; es pertinente aclarar que esto fue contemplado al 
momento de los cálculos y que los indicadores propuestos tuvieron ajustes en el número de indicadores en el caso de tratarse de indicadores extraídos de una memoria elaborada según la Guía GRI G3 o G4.

Por lo mencionado, los pasos de la metodología desarrollada para la medición integral de prácticas de RSE se pueden sintetizar mediante el siguiente esquema (Imagen3.1).

Imagen 3.1. Pasos propuestos para el desarrollo de la metodología para la medición integral de RSE

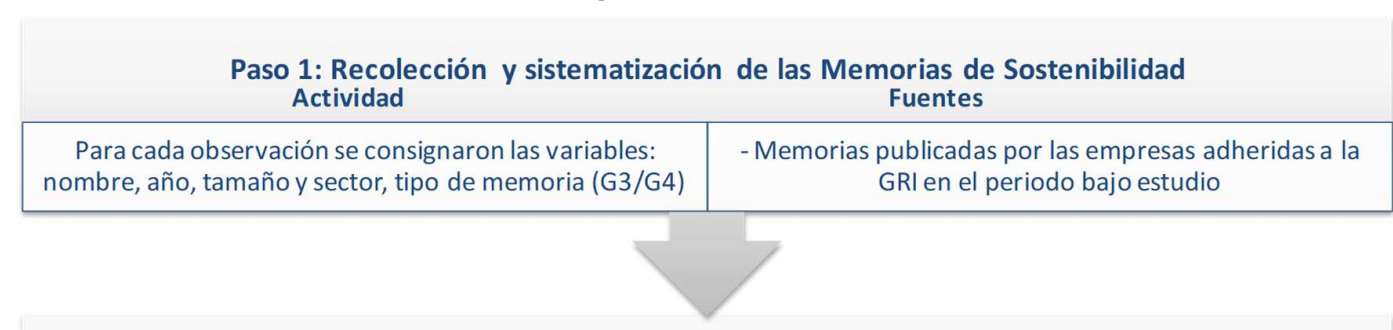

Paso 2: Generación de variables binarias para cada uno de los indicadores propuestos por el GRI Actividad Fuentes

\begin{tabular}{|c|c|}
\hline $\begin{array}{c}\text { Se valoró cada indicador con un " } 1 \text { " si se disponía de la } \\
\text { información y con " } 0 \text { " en caso contrario }\end{array}$ & $\begin{array}{c}\text { - Anexo de indicadores que conforman las memorias de } \\
\text { sostenibilidad de la GRI }\end{array}$ \\
\hline
\end{tabular}

Paso 3: Cálculo de Indicadores para la medición por dimensión de la RSE

Realizar para cada una de las dimensiones analizadas un subíndice: cociente entre la sumatoria del número del total de indicadores identificados y el número total de indicadores que constituyen el subíndice

Paso 4: Generación de Indicador para la medición integral de la RSE

Realizar el cálculo del indicador integral de RSE como el cociente entre la sumatoria de los subíndices calculados para cada dimensión y el número total de dimensiones

Fuente: elaboración propia.

Luego del cálculo de los subíndices y el indicador integral de RSE, se propone realizar un análisis descriptivo a nivel "dimensión" e "integral" de los indicadores que se calculen, así como también elaborar tablas de frecuencia que posibiliten analizar si se presenta relación entre el nivel de indicadores de RSE informados y el tamaño de las empresas. Del mismo modo, se desarrollar pruebas de Chi-cuadrado de Pearson para 
determinar si existe relación entre el nivel de indicadores de RSE informados y el tipo de memoria presentada (G3 o G4).

\subsection{Conceptualización de la metodología desarrollada para la medición integral de la RSE}

En primer lugar, la metodología desarrollada tiene un enfoque cuantitativo ya que usa la recolección de datos para posibilitar la posterior medición numérica y el análisis estadístico, posibilitando establecer patrones de comportamiento y probar hipótesis.

Puesto que la RSE estima valores tangibles como intangibles, debe contemplarse en la valoración la característica cualitativa de la RSE, entre otros aspectos, la evaluación de las relaciones entre todos los stakeholders relevantes y dar indicaciones específicas para sus mejoras. Mediante la metodología desarrollada, al medir la RSE mediante los indicadores propuestos por el GRI y generando indicadores por dimensión e integral, se logra cuantificar los aspectos intangibles de la RSE, haciendo medibles los mismos; es decir, se logra hacer "observable" medible la RSE.

\subsection{Uso de la metodología para el análisis de la RSE con el Desempeño Económico (DE) y la Reputación Corporativa (RC)}

Lo que se buscará mediante esta propuesta es analizar si "cuanto mayor desempeño económico y mejor la reputación corporativa, mayor desempeño de RSE" (Figura 3.1). 
Imagen3.1: Modelo explicativo: Desempeño económico y reputación corporativa y su relación con la RSE

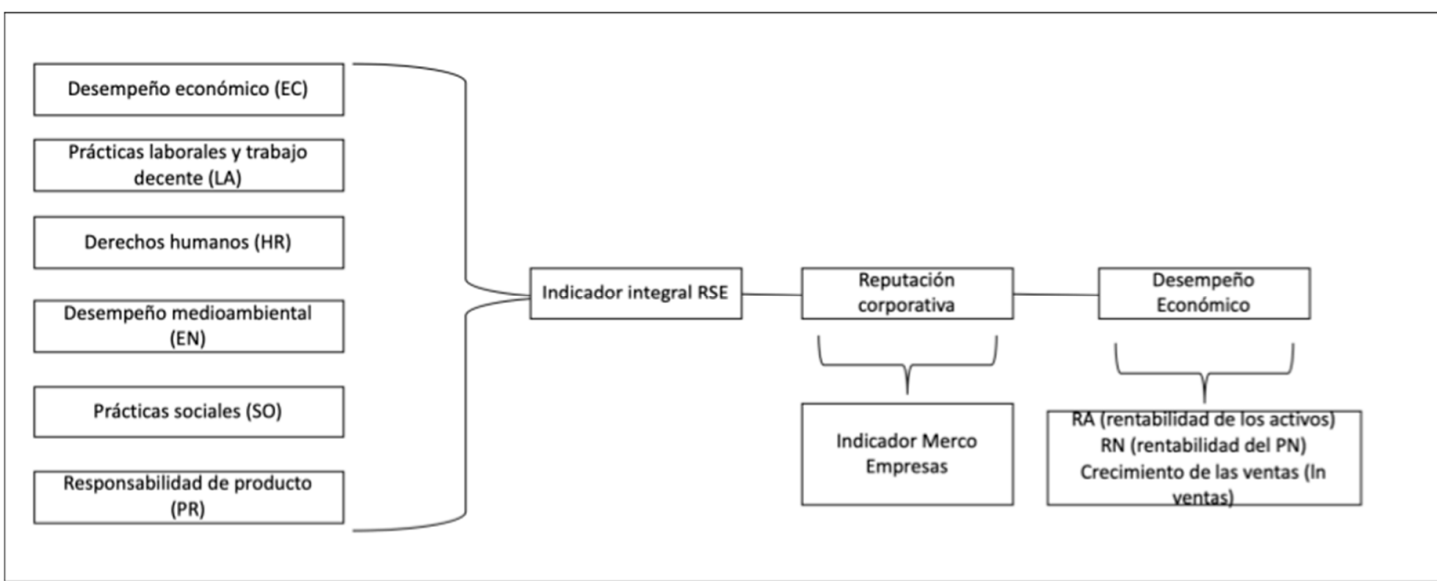

Fuente: elaboración propia

Para este análisis, se aplicarán modelos de regresión lineal múltiple cuyas variables dependientes surgen de la aplicación de la "metodología para la medición integral de la RSE" desarrollada en el punto 3.1.

En la Tabla 3.2 se presenta la operacionalización de las variables desempeño económico y reputación corporativa que serán utilizadas para relacionarlas con la medición de la RSE.

Es importante remarcar que esta Tabla 3.2 se elaboró en base a las conclusiones arribadas en el marco teórico, específicamente en el punto 2.4 .8 en el que se concluye que la ROA se considera el índice más fiable del desempeño económico intrínseco de la empresa. Además, puesto que la unidad de análisis de esta tesis son empresas que cotizan en la CNV, se propone relacionar los indicadores para la medición de prácticas de RSE que se calcularán según el modelo propuesto, con los indicadores económicos que se podrán calcular para cada empresa en su respectivo año, la ROA y también la ROE, de manera de analizar el apalancamiento financiero de las empresas. También será analizado el crecimiento de la empresa mediante una variable proxy: logaritmo neperiano de las ventas, así como también el indicador de percepción Reputación Corporativa utilizando información de fuentes secundaria (MERCO). 
Tabla 3.20peracionalización de las variables: Desempeño Económico y Reputación Corporativa

\begin{tabular}{|c|c|c|c|c|c|}
\hline Definición & Categoría & Definición operacional de dimensión & Indicadores & $\begin{array}{l}\text { Característica } \\
\text { de la variable }\end{array}$ & Fuente de información \\
\hline \multirow{4}{*}{ Desempeño Económico } & $\begin{array}{l}\text { Rentabilidad del Patrimonio } \\
\text { Neto (RN) }\end{array}$ & $\begin{array}{l}\text { Mide el cociente entre la Utilidad Neta } \\
\text { (UN) y el volumen del Patrimonio Neto } \\
\text { (PN) de la empresa }\end{array}$ & $(\mathrm{UN} / \mathrm{PN}) \times 100$ & $\begin{array}{l}\text { Cuantitativa } \\
\text { (Porcentaje) }\end{array}$ & $\begin{array}{l}\text { Cifras tomadas para el cálculo de los } \\
\text { EECC publicados en la CNV }\end{array}$ \\
\hline & Rentabilidad del Activo (ROA) & $\begin{array}{l}\text { Mide el cociente entre la Utilidad } \\
\text { Operativa (UO) y el volumen del Activo } \\
\text { (A) de la empresa }\end{array}$ & $(\mathrm{UO} / \mathrm{A}) \times 100$ & $\begin{array}{l}\text { Cuantitativa } \\
\text { (Porcentaje) }\end{array}$ & $\begin{array}{l}\text { Cifras tomadas para el cálculo de los } \\
\text { EECC publicados en la CNV }\end{array}$ \\
\hline & $\begin{array}{l}\text { Crecimiento de las ventas } \\
\text { (Inventas) }\end{array}$ & $\begin{array}{l}\text { Mide la variación de las ventas de un } \\
\text { período a otro }\end{array}$ & $\begin{array}{l}\text { Logaritmo neperiano del volumen de } \\
\text { las ventas de la empresa i para el año } \\
\text { t. }\end{array}$ & $\begin{array}{l}\text { Cuantitativa } \\
\text { (tasa } \\
\text { crecimiento) }\end{array}$ & $\begin{array}{l}\text { Cifras tomadas para el cálculo de los } \\
\text { EECC publicados en la CNV }\end{array}$ \\
\hline & Tamaño & $\begin{array}{l}\text { Empresas medianas o grandes según } \\
\text { definición de la Unión Europea }\end{array}$ & $\begin{array}{l}\text { Toma el valor } 1 \text { si la es empresa } \\
\text { mediana y } 0 \text { en el caso de que sea } \\
\text { una empresa grande. }\end{array}$ & $\begin{array}{l}\text { Categórica } \\
\text { (binaria) }\end{array}$ & $\begin{array}{l}\text { Información obtenida del análisis de } \\
\text { las memorias de sostenibilidad } \\
\text { publicadas por as empresas }\end{array}$ \\
\hline Reputación Corporativa & Reputación Corporativa & $\begin{array}{l}\text { Valuación realizada por el Monitor } \\
\text { Empresarial de Reputación Corporativa } \\
\text { (MERCO). }\end{array}$ & $\begin{array}{l}\text { Toma el valor } 1 \text { en función que la } \\
\text { empresa i en el año t forma parte de } \\
\text { las empresas con mejor reputación } \\
\text { en la Argentina según el indicador } \\
\text { elaborado por el MERCO, } 0 \text { en caso } \\
\text { contrario }\end{array}$ & $\begin{array}{l}\text { Categórica } \\
\text { (binaria) }\end{array}$ & $\begin{array}{l}\text { Según información publicada por el } \\
\text { MERCO }\end{array}$ \\
\hline
\end{tabular}

Fuente: elaboración propia. 
A continuación se detallan las variables independientes o explicativas del modelo:

Reputación corporativa $(\mathrm{RC})$ : variable que toma el valor 1 en función de que la empresa $\mathrm{i}$ en el año $\mathrm{t}$ forma parte de las empresas con mejor reputación en la Argentina según el indicador elaborado por el Monitor Empresarial de Reputación Corporativa (MERCO).

El MERCO es un instrumento de evaluación de la reputación lanzado en el año 2000, basado en una metodología multistakeholder compuesta por cinco evaluaciones y doce fuentes de información. A su vez, MERCO es el único monitor de reputación en el mundo que asume el reto de ser verificado por una auditoría de reconocido prestigio internacional. El seguimiento de la metodología para la elaboración del ranking de empresas con mejor reputación es objeto de revisión independiente por parte de KPMG según la norma ISAE 3000 (MERCO, 2017).

Puesto que se utilizará la variable Reputación Corporativa considerando la valoración asignada por el MERCO, a continuación se resumirá la metodología que utilizan para el cálculo de la misma.

EI MERCO utiliza un proceso basado en diversas etapas, destinadas a recopilar los datos procedentes de diferentes fuentes de información. El resultado final es un índice que constituye, a su vez, la base de un ranking que se publica anualmente. Los distintos procesos de los que se obtiene la información necesaria para la elaboración de Merco Empresas, incluye:

1. Encuesta a directivos

2. Evaluación de expertos

3. Evaluación de mérito

4. MERCO Consumo

5. MERCO Talento 
1) Encuesta a directivos: tiene como objetivo conocer la opinión sobre la reputación corporativa de las empresas que desarrollan actividades en nuestro país desde el punto de vista de los directivos de las compañías más importantes de Argentina.

2) Evaluación de expertos: pretende aportar a la valoración de la reputación corporativa realizada por Merco el punto de vista de diversos agentes externos con capacidad para:

a - Analizar y valorar el posicionamiento reputacional de las empresas evaluadas, dado su conocimiento experto acerca de uno o varios factores clave para la determinación de la reputación de una empresa.

b- Influir en la opinión pública desde su conocimiento experto, con el consiguiente impacto sobre la reputación de las organizaciones, más allá de su propio ámbito de actuación.

En esta fase, las empresas seleccionadas en el proceso anterior son valoradas por 8 grupos de expertos: Analistas Financieros, Asociaciones de Consumidores, ONG, Sindicatos, Periodistas de Información Económica, Catedráticos de Economía y directores de departamento del área de empresa, Influencers y Gobierno.

3) Evaluación directa: el objetivo es la valoración por parte de técnicos cualificados de Análisis e Investigación, de los méritos relativos a su reputación corporativa presentados por las 95 empresas seleccionadas a partir del ranking provisional. Esta valoración requerirá a las empresas la acreditación de sus valores reputacionales, a través de la cumplimentación de un cuestionario y la presentación de la documentación que apoye los datos incluidos en dicho cuestionario.

4) MERCO Consumo: esta fase tiene como objetivo la valoración de la reputación de las empresas seleccionadas por parte de la población general. Con este fin, MERCO Empresas incluye entre sus fuentes de información una valoración específica acerca de la reputación corporativa de la empresa tomada de Merco Consumo, un monitor que incluye preguntas orientadas a conocer las diferentes facetas de la reputación corporativa y su evolución desde el punto de vista del consumidor final. 
5) MERCO Talento: al igual que ocurre con MERCO Consumo, MERCO Talento es un monitor independiente. En particular, trata de valorar el atractivo de las diferentes empresas como lugares para trabajar, partiendo en este caso de los puntos de vista de diferentes agentes: los trabajadores de las empresas, estudiantes universitarios, antiguos alumnos de escuelas de negocio, la población general, directores de recursos humano, y expertos en recursos humanos y headhunters. Asimismo, Merco Talento realiza una comparación de los principales indicadores de gestión de personas, a través de un proceso de benchmarking. El ranking final se calcula tras el cierre de cada una de las fases detalladas con anterioridad como la suma ponderada de las puntuaciones obtenidas en dichas etapas. Las ponderaciones utilizadas en dicha suma son las incluidas en la siguiente Tabla 3.3.

Tabla 3.3. Tabla de ponderaciones para la elaboración del indicador de reputación corporativa MERCO

\begin{tabular}{|l|c|}
\hline Ponderación de RANKING DE DIRECTIVOS & $25 \%$ \\
\hline Ponderación de ANALISTAS FINANCIEROS & $7 \%$ \\
\hline Ponderación de SINDICATOS & $4 \%$ \\
\hline Ponderación de ASOCIACIONES DE CONSUMIDORES & $4 \%$ \\
\hline Ponderación de ONG & $4 \%$ \\
\hline Ponderación de PERIODISTAS DE INFORMACIÓN ECONÓMICA & $7 \%$ \\
\hline $\begin{array}{l}\text { Ponderación de CATEDRÁTICOS Y DIRECTORES DE DEPARTAMENTO DEL ÁREA } \\
\text { DE EMPRESA }\end{array}$ & $4 \%$ \\
\hline Ponderación de INFLUENCERS & $4 \%$ \\
\hline Ponderación de GOBIERNO & $6 \%$ \\
\hline Ponderación de MERCO CONSUMO & $10 \%$ \\
\hline Ponderación de MERCO TALENTO & $10 \%$ \\
\hline Ponderación de EVALUACIÓN DIRECTA & $15 \%$ \\
\hline
\end{tabular}

Fuente: MERCO (2017) 


\section{Desempeño económico}

En función de las conclusiones arribadas en el Capítulo 2, a continuación se detallan las variables que fueron utilizadas para la medición del desempeño económico:

- Rentabilidad del Patrimonio Neto (RN): esta variable mide el cociente entre la Utilidad Neta (UN) y el volumen del Patrimonio Neto (PN) de la empresa (UN/PN).

- Rentabilidad del Activo (ROA): esta variable mide el cociente entre la Utilidad Operativa (UO) y el volumen del Activo (A) de la empresa (UO/A).

- Crecimiento de las ventas (Inventas): logaritmo neperiano del volumen de las ventas de la empresa i para el año t.

Variable de control: por las conclusiones a las que se arribó a partir del análisis bibliográfico, se consideró la generación de la variable tamaño como "variable de control". Puesto que las empresas de la muestra estaban clasificadas como medianas o grandes, se generó la variable "Tamaño" que tomó el valor 1, en caso de tratarse de una empresa mediana y 0 en el caso de que fuera una empresa grande.

La variable tamaño fue considerada según la definición que utiliza la GRI para esta clasificación, definiendo el tamaño según la Unión Europea: empresa mediana aquella con entre 50-249 empleados, volumen de facturación <= 50 millones de euros o activo $<=43$ millones; y empresas grandes aquellas con más de 250 empleados, volumen de facturación > 50 millones de euros o activo $>43$ millones.

Para llevar adelante el análisis, se propone aplicar las siguientes regresiones lineales múltiples:

$$
\begin{aligned}
R S E & =\beta_{0+} \beta_{1} \mathrm{RC}+\beta_{2} \mathrm{RN}_{+} \beta_{3} \mathrm{ROA}_{+} \beta_{4} \text { Inventas }_{+} \beta_{5} \text { Tamaño }+\varepsilon \\
E C & =\beta_{0}+\beta_{1} \mathrm{RC}+\beta_{2} \mathrm{RN}_{+} \beta_{3} \mathrm{ROA}_{+} \beta_{4} \text { Inventas }_{+} \beta_{5} \text { Tamaño }_{+} \varepsilon \\
L A & =\beta_{0} \beta_{1} \mathrm{RC}_{+} \beta_{2} \mathrm{RN}_{+} \beta_{3} \mathrm{ROA}_{+} \beta_{4} \text { Inventas }_{+} \beta_{5} \mathrm{Tamaño}_{+} \varepsilon \\
H R & =\beta_{0+} \beta_{1} \mathrm{RC}_{+} \beta_{2} \mathrm{RN}_{+} \beta_{3} \mathrm{ROA}_{+} \beta_{4} \text { Inventas }_{+} \beta_{5} \mathrm{Tamaño}_{+} \varepsilon
\end{aligned}
$$




$$
\begin{aligned}
& S O=\beta_{0}+\beta_{1} \mathrm{RC}+\beta_{2} \mathrm{RN}+\beta_{3} \mathrm{ROA}_{+} \beta_{4} \text { Inventas }_{+} \beta_{5} \text { Tamaño }+\varepsilon \\
& P R=\beta_{0}+\beta_{1} \mathrm{RC}+\beta_{2} \mathrm{RN}+\beta_{3} \mathrm{ROA}_{+} \beta_{4} \text { Inventas }_{+} \beta_{5} \text { Tamaño }_{+} \varepsilon \\
& E N=\beta_{0} \beta_{1} \mathrm{RC}+\beta_{2} \mathrm{RN}_{+} \beta_{3} \mathrm{ROA}_{+} \beta_{4} \text { Inventas }_{+} \beta_{5} \text { Tamaño }+\varepsilon
\end{aligned}
$$

Además, previo al análisis de regresión, se propone en primer lugar desarrollar un análisis descriptivo de las variables dependientes e independientes (o explicativas), luego un análisis de correlación de estas y, por último, sí desarrollar los modelos de regresión lineal para analizar la relación entre las prácticas de RSE (por dimensión y a nivel integral), con la reputación corporativa y el desempeño económico.

Para poder ser más concluyente respecto a la relación entre la RSE con el desempeño económico y la reputación corporativa, también se propone el análisis de las siguientes hipótesis:

Ha: La implementación de RSE redunda en un mayor desempeño económico.

Hb: La implementación de RSE redunda en una mejor reputación corporativa.

La RSE fue abordada según la metodología propuesta, mediante el indicador integral.

Para la medición del desempeño económico se consideró nuevamente la Rentabilidad del Activo (ROA), definida, como el cociente entre la Utilidad Operativa (UO) y el volumen del Activo (A) de la empresa (UO/A).

Respecto a la Reputación Corporativa (RC), nuevamente se utilizó la metodología y el indicador propuesto por el Monitor Empresarial de Reputación Corporativa (MERCO), desarrollado con profundidad en el punto 2.4 .

De esta manera para analizar la relación entre el Desempeño Económico (DE) y el indicador de RSE integral, se propone realizar un análisis de "Diferencia de medias para muestras independientes" (Prueba Chi-cuadrado de Pearson), puesto que los datos se clasifican en función de una variable dicotómica "ROA" que toma los siguientes valores: 
Empresas muy rentables $(R O A)=1$, si la ROA era $>=a$ la media muestral más un desvío estándar $(\mu+\sigma)$.

Empresas poco rentables $(\mathrm{ROA})=0$, si la ROA era $<$ a la media muestral más un desvío estándar $(\mu+\sigma)$.

De esta manera se busca contrastar la siguiente hipótesis nula de igualdad de medias:

$$
\text { Ho: } \mu_{\text {roa_empresas muy rentables }}=\mu_{\text {roa_empresas pocos rentables }}
$$

Por otra parte, para analizar la relación entre la Reputación Corporativa (RC) y el indicador de RSE integral, se propone nuevamente, realizar un análisis de "Diferencia de medias para muestras independientes" (Prueba Chi-cuadrado de Pearson), puesto que los datos se clasifican en función de una variable dicotómica "RC" que toma los siguientes valores:

Empresas con alta Reputación Corporativa $(\mathrm{RC})=1$, si la $\mathrm{RC}$ era $>=$ a la media muestral más un desvío estándar $(\mu+\sigma)$.

Empresas con baja reputación Corporativa $(\mathrm{RC})=0$, si la $\mathrm{RC}$ era $<$ a la media muestral más un desvío estándar $(\mu+\sigma)$.

De esta manera se busca contrastar la siguiente hipótesis nula de igualdad de medias:

$$
\text { Ho: } \mu_{R C_{\text {empresas con alta reputación }}}=\mu_{R C_{\text {empresas con baja reputación }}}
$$

\subsection{Conclusiones de la metodología propuesta}

Mediante la metodología desarrollada se logra, en primer lugar, medir los aspectos intangibles de la RSE, tanto por dimensión como de manera integral, esto posibilita la 
comparación de las dimensiones por separado, así como también determinar si existe relación entre ellas y en qué medida aporta cada una a la valoración integral de la RSE.

A su vez, puesto que los indicadores incorporan magnitud y son expresados en la misma unidad de medida, esto permite como se mencionó en el párrafo anterior no solo la comparación entre dimensiones, sino entre distintas empresas y distintos sectores. También se podría analizar la evolución de las prácticas de RSE en un determinado período, pudiendo considerar distintas unidades de análisis como ser: la misma empresa, empresas de distintos sectores o empresas de distintas regiones.

En virtud del extenso desarrollo del marco teórico y el desarrollo de la metodología para la medición de RSE, se puede enunciar distintos usos que se le podrían dar a la misma; ésta posibilita el análisis de diversas hipótesis en futuras investigaciones, entre ellas:

- El nivel de endeudamiento influye positivamente en el nivel de aplicación de prácticas de RSE.

- La aplicación de RSE genera una ventaja competitiva para la empresa.

- A mayor aplicación de prácticas de RSE, mayor la utilidad por acción.

- A mayor aplicación de prácticas de RSE, mejor la imagen de la organización.

- La aplicación de prácticas de RSE, disminuye la rotación del personal y mejora la eficiencia laboral.

- La aplicación de prácticas de RSE, impacta de manera positiva en la capacidad innovadora.

- A mayor aplicación de prácticas de RSE, mayor el crecimiento de las ventas.

Tal como se observa, el desarrollo de la metodología de medición de RSE permite el análisis de la relación de ésta con muchas otras variables generadoras de valor para las organizaciones, por lo que abre puertas a nuevas futuras investigaciones. 


\section{CAPÍTULO 4: VALIDACIÓN DE LA METODOLOGÍA PROPUESTA}

En este capítulo se aplicará la metodología propuesta para la medición integral de prácticas de RSE, desarrollada en el Capítulo 3. En primer lugar, se realizó una caracterización de las empresas en cuanto a tamaño y sector y se procedió al cálculo de los distintos indicadores por dimensiones e integral. Luego, se realizó un análisis descriptivo que contempló el cálculo de media, desvío estándar, mínimo y máximo) para cada indicador. También se analizó la relación entre los valores que arrojaron cada uno de los indicadores por dimensión e integral de RSE, en relación con el tamaño.

Más adelante, se aplicó la metodología propuesta para analizar la relación entre RSE con el desempeño económico y reputación corporativa, de manera de darle un uso adicional. En primer lugar, se expone el análisis descriptivo de las variables independientes, luego se presenta la matriz de correlaciones y por último los resultados de los modelos de regresión lineales múltiples planteados en la investigación. A su vez, se desarrolla un análisis mediante "árboles de decisión" y pruebas Chi-cuadrado de Pearson para aportar mayor robustez a los resultados.

Finalmente de manera de ordenar las conclusiones a las que se arribó, primero se exponen aquellas vinculadas a la validación de la metodología desarrollada para la medición integral de RSE y luego las relacionadas al uso de la misma para relacionar la RSE con desempeño económico y la reputación corporativa.

\subsection{Población objeto de la validación}

Como se mencionó en el Capítulo 1 la población objeto de la validación son las 37 empresas argentinas adheridas a la Global Reporting Initiative (GRI) que cotizan en la Comisión Nacional de Valores (CNV), durante el período 2012-2016. Las razones que llevaron a elegir esta población son la búsqueda de disponibilidad de la información y la homogeneidad de los datos a tratar. Por lo tanto, las fuentes utilizadas para la recolección de datos son secundarias, ya que el estudio se centró en la recopilación de 
las memorias de sostenibilidad y los estados contables presentados por las empresas. De las 37 empresas, se recopilaron y analizaron 95 memorias de sostenibilidad y 61 estados contables.

\subsection{Caracterización de las empresas analizadas}

En primer lugar, se realizó una caracterización de las empresas en cuanto a tamaño y sector. De esta manera se puede observar que del total de empresas, un $73 \%$ son grandes empresas y el $27 \%$ medianas (Tabla 4.1).

Tabla 4.1. Tamaño de las empresas analizadas

\begin{tabular}{lrr}
\hline Tamaño & Cantidad & \multicolumn{2}{r}{ Porcentaje } \\
\hline Grandes & 27 & 73 \\
Medianas & 10 & 27 \\
\hline Total & 37 & 100 \\
\hline
\end{tabular}

Fuente: elaboración propia

Respecto al sector de actividad de las empresas, el 24,3\% corresponde a empresas que brindan servicios financieros, el 13,5 \% son empresas del sector energía, el 13,5 \% son empresas fabricantes de productos alimenticios y bebidas y el resto de las empresas corresponden a sectores que tienen un peso relativo inferior a $6 \%$ (Tabla 4.2). 
Tabla 4.2. Sector de actividad de las empresas

\begin{tabular}{lcr}
\hline Sector & Frecuencia & Porcentaje \\
\hline Servicios financieros & 9 & 24,3 \\
Energía & 5 & 13,5 \\
Productos alimenticios y bebidas & 5 & 13,5 \\
Automotriz & 2 & 5,4 \\
Servicios de energía & 2 & 5,4 \\
Minería & 2 & 5,4 \\
Telecomunicaciones & 2 & 5,4 \\
Agricultura & 1 & 2,7 \\
Químicas & 1 & 2,7 \\
Comercial & 1 & 2,7 \\
Conglomerados & 1 & 2,7 \\
Materiales para construcción & 1 & 2,7 \\
Consumo Durable & 1 & 2,7 \\
Papeleras & 1 & 2,7 \\
Medios de comunicación & 1 & 2,7 \\
Producción de metales & 1 & 2,7 \\
Tecnología & 1 & 2,7 \\
\hline Total & 37 & 100,0 \\
\hline
\end{tabular}

Fuente: elaboración propia

Como se puede observar en la Tabla 4.3, hay una distribución relativamente uniforme respecto a los años de publicación de las memorias analizadas, aunque el valor ha ido disminuido en los últimos 3 años. Por otra parte, respecto al tipo de memoria (es decir, si fue elaborada de acuerdo con la Guía G3 o a la G4), el valor es similar: 47,4 \% de acuerdo con la Guía G3 y 52,6 \% de acuerdo con la Guía G4 (Tabla 4.4). 
Tabla 4.3. Año de publicación de las memorias de sostenibilidad

\begin{tabular}{lrr}
\hline Año & Frecuencia & Porcentaje \\
\hline 2012 & 21 & 22,1 \\
2013 & 23 & 24,2 \\
2014 & 19 & 20,0 \\
2015 & 18 & 18,9 \\
2016 & 14 & 14,7 \\
\hline Total & 95 & 100,0 \\
\hline
\end{tabular}

Fuente: elaboración propia

Tabla 4.4. Tipo de memoria de sostenibilidad (Guía G3 ó G4)

\begin{tabular}{lrr}
\hline Tipo de memoria & Frecuencia & Porcentaje \\
\hline Guía G3 & 45 & 47,4 \\
Guía G4 & 50 & 52,6 \\
\hline Total & 95 & 100,0
\end{tabular}

Fuente: elaboración propia

\subsection{Aplicación de la metodología para la medición integral de RSE}

Se procedió al cálculo de los distintos subíndices por dimensiones planteados en el Capítulo 3. De esta manera, como se puede observar en la Tabla 4.5, aquellos indicadores que son más reportados son los relacionados con Prácticas laborales arrojando un valor de media de 72,74 \%, seguidos de Prácticas sociales61,48 \%, Desempeño medioambiental 54,8 \%, Desempeño económico 58,25 \%, Responsabilidad de producto $53,68 \%$ y Derechos Humanos $49,07 \%$. Por otra parte, el índice integral de RSE que se diseñó y calculó para el total de las observaciones arrojó el valor de 58,34 $\%$. 
Tabla 4.5. Indicadores de RSE reportados en las memorias de sustentabilidad, por dimensión y a nivel integral

\begin{tabular}{lccccc}
\hline Dimensión & N & Media & Desvío estándar & Mínimo & Máximo \\
\hline Desempeño económico (EC) & 95 & 58.25 & 28.89 & 0 & 100 \\
Prácticas laborales y trabajo decente (LA) & 95 & 72.74 & 24.08 & 22.2 & 100 \\
Derechos humanos (HR) & 95 & 49.07 & 33.69 & 0 & 100 \\
Prácticas sociales (SO) & 95 & 61.48 & 27.33 & 8.3 & 100 \\
Responsabilidad de producto (PR) & 95 & 53.68 & 33.99 & 0 & 100 \\
Desempeño medioambiental (EN) & 95 & 54.82 & 28.55 & 8.3 & 100 \\
\hline Indicador integral de RSE & $\mathbf{9 5}$ & $\mathbf{5 8 . 3 4}$ & $\mathbf{2 5 . 2 4}$ & $\mathbf{1 2}$ & $\mathbf{1 0 0}$ \\
\hline Fuente: & & & & &
\end{tabular}

Fuente: elaboración propia

Si se analizan los indicadores reportados por dimensión y de manera integral, como se observa en la Tabla 4.6, si bien no necesariamente se trata de las mismas empresas, al comparar las memorias de sustentabilidad por año no se evidencia que al pasar los años los indicadores tengan tendencia a aumentar. Esto será profundizado mediante los análisis que se plantearan en los apartados "4.7 Relación entre el grado de divulgación de indicadores de RSE y la versión de la memoria presentada (G3 o G4)" y “4.8 Divulgación de indicadores de RSE por la misma empresa a lo largo del tiempo".

Tabla 4.6. Indicadores de RSE reportados en las memorias de sustentabilidad, por dimensión y a nivel integral (por año reportado)

\begin{tabular}{lccccc}
\hline Dimensión & $\begin{array}{c}\mathbf{2 0 1 2} \\
\mathbf{( N = 2 1 )}\end{array}$ & $\begin{array}{c}\mathbf{2 0 1 3} \\
\mathbf{( N = 2 3 )}\end{array}$ & $\begin{array}{c}\mathbf{2 0 1 4} \\
\mathbf{( N = 1 9 )}\end{array}$ & $\begin{array}{c}\mathbf{2 0 1 5} \\
\mathbf{( N = 1 8 )}\end{array}$ & $\begin{array}{c}\mathbf{2 0 1 6} \\
(\mathbf{N}=\mathbf{1 4})\end{array}$ \\
\hline $\begin{array}{l}\text { Desempeño económico (EC) } \\
\text { Prácticas laborales y trabajo }\end{array}$ & 62.45 & 64.27 & 50.88 & 55.57 & 55.56 \\
decente (LA) & & & & & \\
Derechos humanos (HR) & 79.10 & 83.09 & 71.04 & 61.12 & 63.51 \\
Prácticas sociales (SO) & 61.92 & 61.49 & 39.77 & 37.03 & 37.50 \\
Responsabilidad de producto (PR) & 59.26 & 61.83 & 48.54 & 47.53 & 46.83 \\
Desempeño medioambiental (EN) & $\mathbf{7 8 . 5 7}$ & $\mathbf{7 2 . 1 0}$ & 55.70 & 45.82 & 46.43 \\
\hline Indicador integral de RSE & $\mathbf{6 8 . 1 5}$ & $\mathbf{6 7 . 8 5}$ & $\mathbf{5 2 . 6 9}$ & $\mathbf{4 8 . 1 3}$ & $\mathbf{4 8 . 8 1}$ \\
\hline
\end{tabular}

Fuente: elaboración propia

El análisis descriptivo contempló el cálculo de media, desvío estándar, mínimo y máximo) para cada indicador por dimensión y a nivel integral. En cuanto a los sectores con más relevancia en la muestra (aquellos que tenían 10 o más observaciones), como 
se observa en la Tabla 4.7 y Gráfico 4.1, se destaca la información sobre RSE publicada por las empresas de los sectores "Productos alimenticios y bebidas" con un valor medio del indicador integral de RSE de 74.25\%, "Automotriz" un 57.25\%, seguido por el sector "Servicio financiero" con un 55.71\%, "Energía" 45.14\% y "Comercial" con un $40.46 \%$. 
Tabla 4.7. Estadísticos descriptivos de los indicadores de RSE por dimensión y a nivel integral (para los sectores con mayor relevancia para la muestra)

\begin{tabular}{|c|c|c|c|c|c|c|}
\hline Sector & Dimensión & $\mathbf{N}$ & Media & Desvío estándar & Mínimo & Máximo \\
\hline \multirow[t]{7}{*}{ Automotriz } & EC & 20 & 57.79 & 16.78 & 33.3 & 77.8 \\
\hline & LA & 20 & 78.90 & 17.43 & 55.6 & 100 \\
\hline & $\mathrm{HR}$ & 20 & 50.57 & 29.33 & 16.7 & 88.9 \\
\hline & PR & 20 & 34.43 & 11.93 & 22.2 & 55.6 \\
\hline & EN & 20 & 68.53 & 12.70 & 52.8 & 83.3 \\
\hline & so & 20 & 53.32 & 22.37 & 8.3 & 75 \\
\hline & RSE & 20 & 57.25 & 15.35 & 35.6 & 76.4 \\
\hline \multirow[t]{7}{*}{ Comercial } & EC & 10 & 31.14 & 21.48 & 11.1 & 55.6 \\
\hline & LA & 10 & 68.90 & 15.09 & 50 & 88.9 \\
\hline & $\mathrm{HR}$ & 10 & 42.22 & 19.56 & 25 & 77.8 \\
\hline & PR & 10 & 35.54 & 30.91 & 0 & 88.9 \\
\hline & EN & 10 & 15.00 & 30.17 & 0 & 72.2 \\
\hline & so & 10 & 50.00 & 26.65 & 33.3 & 100 \\
\hline & RSE & 10 & 40.46 & 22.06 & 23.1 & 80.6 \\
\hline \multirow[t]{7}{*}{ Energía } & EC & 13 & 39.32 & 41.24 & 0 & 100 \\
\hline & $\mathrm{LA}$ & 13 & 54.26 & 33.97 & 22.2 & 100 \\
\hline & $\mathrm{HR}$ & 13 & 36.33 & 42.72 & 0 & 100 \\
\hline & PR & 13 & 31.62 & 38.45 & 0 & 100 \\
\hline & EN & 13 & 47.88 & 35.04 & 16.7 & 100 \\
\hline & so & 13 & 61.53 & 30.55 & 33.3 & 100 \\
\hline & RSE & 13 & 45.14 & 35.77 & 12 & 100 \\
\hline \multirow[t]{7}{*}{ Servicios financieros } & EC & 29 & 58.64 & 26.22 & 0 & 100 \\
\hline & LA & 29 & 71.84 & 21.25 & 22.2 & 100 \\
\hline & $\mathrm{HR}$ & 29 & 40.62 & 33.47 & 0 & 100 \\
\hline & $\mathrm{PR}$ & 29 & 60.17 & 33.80 & 0 & 100 \\
\hline & EN & 29 & 45.60 & 25.49 & 8.3 & 100 \\
\hline & SO & 29 & 57.47 & 21.63 & 33.3 & 100 \\
\hline & RSE & 29 & 55.71 & 22.82 & 12 & 100 \\
\hline \multirow{7}{*}{$\begin{array}{l}\text { Productos alimenticios } \\
\text { y bebidas }\end{array}$} & EC & 11 & 66.67 & 19.90 & 33.3 & 100 \\
\hline & LA & 11 & 84.85 & 23.98 & 44.4 & 100 \\
\hline & $\mathrm{HR}$ & 11 & 71.97 & 19.51 & 25 & 88.9 \\
\hline & PR & 11 & 81.81 & 26.90 & 33.3 & 100 \\
\hline & EN & 11 & 67.69 & 11.87 & 50 & 86.1 \\
\hline & so & 11 & 72.74 & 32.93 & 16.7 & 100 \\
\hline & RSE & 11 & 74.25 & 21.11 & 35.6 & 90.7 \\
\hline
\end{tabular}

Fuente: elaboración propia 
Gráfico 4.1. Valor medio del indicador integral de RSE para los sectores con mayor relevancia

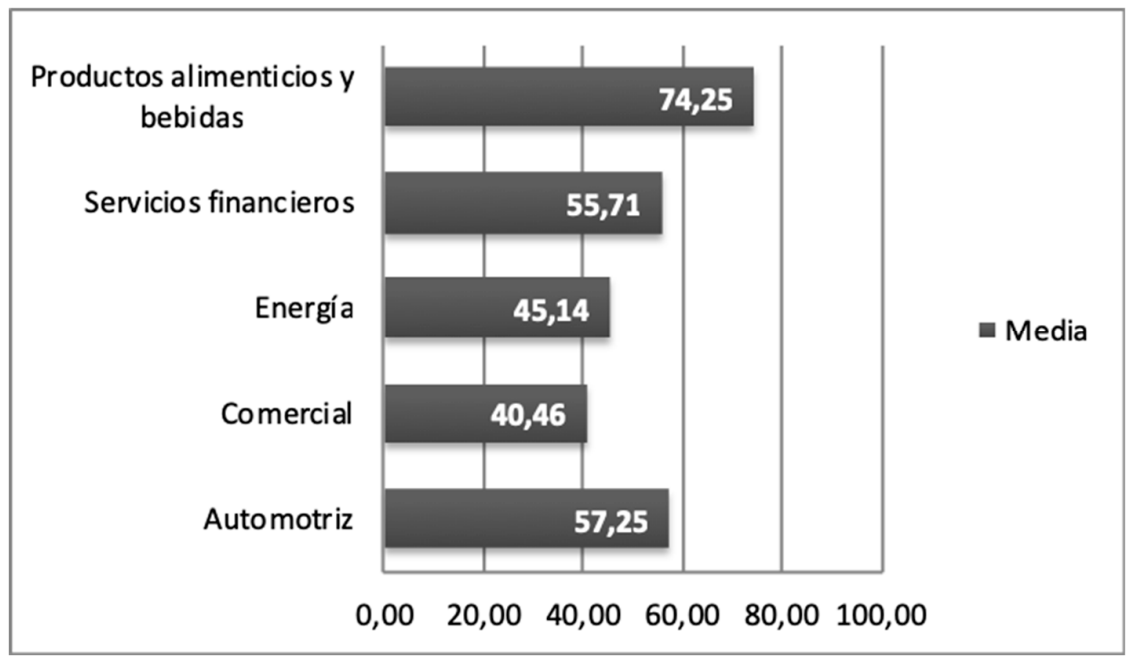

Fuente: elaboración propia

Para continuar con el análisis de los distintos indicadores elaborados, también se aplicó un análisis de correlación simple entre todos los posibles pares de indicadores.

Cabe recordar que el coeficiente de correlación simple $(\mathrm{P})$ mide el grado de asociación lineal entre dos variables medidas en escala de intervalo o de razón, tomando valores entre -1 y 1 . Valores de $\mathrm{P}$ próximos a 1 indicarán fuerte asociación lineal positiva (a medida que aumentan los valores de una de las dos variables, aumentan los de la otra); valores $\mathrm{P}$ próximos a -1 indicarán fuerte asociación lineal negativa (a medida que aumentan los valores de una de las dos variables, disminuyen los de la otra) y valores de $\mathrm{P}$ próximos a 0 indicarán no asociación lineal, lo que no significa que no pueda existir otro tipo de asociación (Ferrán Aranaz M., et al., 2001).

Como resultado del análisis, en todos los casos los coeficientes de correlación resultaron ser superiores a 0.50 con un p-valor $<0.01$, evidenciándose la fuerte relación positiva entre los indicadores de RSE entre si y a nivel integral (Tabla 4.7), es así como se observa que quienes aplican prácticas de RSE, aunque en mayor o menor medida lo hacen en todas sus dimensiones, dejando presente que contemplan la RSE en su "sentido" amplio. 
Tabla 4.7. Análisis de correlación de los indicadores de RSE reportados, por dimensión y a nivel integral

\begin{tabular}{|c|c|c|c|c|c|c|c|c|c|c|c|c|c|c|}
\hline & \multicolumn{2}{|l|}{ EC } & \multicolumn{2}{|l|}{ LA } & \multicolumn{2}{|l|}{$\mathrm{HR}$} & \multicolumn{2}{|l|}{ PR } & \multicolumn{2}{|l|}{ EN } & \multicolumn{2}{|l|}{ SO } & \multicolumn{2}{|l|}{ RSE } \\
\hline EC & 1 & & 0.7730 & $* * *$ & 0.6397 & $* * *$ & 0.6326 & $* * *$ & 0.6248 & $* * *$ & 0.6635 & $* * *$ & 0.8373 & $* * *$ \\
\hline LA & 0.7730 & $* * *$ & 1.0000 & & 0.7170 & $* * *$ & 0.6855 & $* * *$ & 0.7060 & $* * *$ & 0.7992 & $* * *$ & 0.8995 & $* * *$ \\
\hline$H R$ & 0.6397 & $* * *$ & 0.7170 & $* * *$ & 1.0000 & & 0.5811 & $* * *$ & 0.7452 & $* * *$ & 0.7918 & $* * *$ & 0.8747 & $* * *$ \\
\hline PR & 0.6326 & $* * *$ & 0.6855 & $* * *$ & 0.5811 & $* * *$ & 1.0000 & & 0.5063 & $* * *$ & 0.7229 & $* * *$ & 0.8117 & $* * *$ \\
\hline EN & 0.6248 & $* * *$ & 0.7060 & $* * *$ & 0.7452 & $* * *$ & 0.5063 & $* * *$ & 1.0000 & & 0.6697 & $* * *$ & 0.8222 & $* * *$ \\
\hline SO & 0.6635 & $* * *$ & 0.7992 & $* * *$ & 0.7918 & $* * *$ & 0.7229 & $* * *$ & 0.6697 & $* * *$ & 1.0000 & $* * *$ & 0.9018 & $* * *$ \\
\hline RSE & 0.8373 & $* * *$ & 0.8995 & $* * *$ & 0.8747 & $* * *$ & 0.8117 & $* * *$ & 0.8222 & $* * *$ & 0.9018 & $* * *$ & 1.0000 & \\
\hline
\end{tabular}

La correlación es significativa al nivel 0,01 (bilateral).

Fuente: elaboración propia

Por lo tanto, del análisis de la Tabla 4.7 se pueden enunciar las siguientes proposiciones:

- Si una empresa aplica prácticas de RSE, lo hará en todas sus dimensiones.

- Si mejoran las prácticas de RSE en alguna de las dimensiones, mejoran también las prácticas en cualquiera de las otras.

- Si se expanden las prácticas de RSE en la dimensión laboral, en la de recursos humanos o en las de prácticas de producto, se expanden en mayor medida las prácticas en la dimensión social.

\subsection{Relación entre el grado de divulgación de indicadores de RSE y el tamaño de las empresas}

Por otra parte, para analizar la relación entre los valores que arrojaron cada uno de los subíndices y el indicador de RSE integral, en relación a la variable tamaño de la empresa, se procedió a realizar un análisis de "Diferencia de medias para muestras independientes" (Prueba Chi-cuadrado de Pearson), puesto que los datos se clasificaron en función de una variable dicotómica "tamaño" que tomó los siguientes valores: 


$$
\begin{aligned}
& \text { Empresas grandes (Tamaño) }=1, y \\
& \text { Empresas medianas (Tamaño) }=0
\end{aligned}
$$

De esta manera se buscó contrastar la siguiente hipótesis nula de igualdad de medias:

$$
H_{0}: \mu_{\text {grandes }}=\mu_{\text {medianas }}
$$

Este test se llevó a cabo para cada uno de los subíndices y para el indicador integral de RSE. Es así como se observa en la Tabla 4.8 que las diferencias de medias no resultaron significativas ( $p$-valor>0.1) en los casos de Desempeño económico, Prácticas sociales y Responsabilidad de producto; por lo tanto, en estos casos no se rechaza la $\mathrm{H}_{0}$ por lo que las medias muestrales no son significativamente distintas.

Por otra parte, las diferencias sí resultaron significativas según fueran empresas grandes o medianas para los siguientes indicadores: Prácticas laborales y el indicador integral de RSE ( $p$-valor<0.10); Derechos humanos ( $p$-valor<0.5) y Desempeño medioambiental ( $p$-valor<0.01). Por lo tanto, se pueden definir las siguientes proposiciones:

- Cuanto menor sea el tamaño de la empresa, tanto mayor será la aplicación de prácticas de RSE en las dimensiones Prácticas Laborales, Derechos Humanos y Medioambiental.

- Cuanto menor sea el tamaño de la empresa, tanto mayor será la aplicación de prácticas de RSE de manera integral. 
Tabla 4.8. Test de Diferencia de Medias:

Subíndices de RSE según tamaño de las empresas

\begin{tabular}{lrrr} 
& \multicolumn{3}{c}{ Media $(\mu)$} \\
\cline { 2 - 4 } & Empresas & Empresas & \multirow{2}{*}{ Diferencia } \\
Subíndice de RSE & Medianas & Grandes \\
\hline Desempeño Económico (EC) & 65,35 & 55,72 & $9,63^{*}$ \\
Prácticas Laborales y Trabajo Decente (LA) & 79,99 & 70,15 & $9,83^{*}$ \\
Derechos Humanos (HR) & 60,68 & $44,92^{*}$ & $15,75^{* *}$ \\
Prácticas Sociales (SO) & 66,99 & 59,52 & $7,46^{*}$ \\
Responsabilidad de Producto (PR) & 54,22 & 53,49 & $0,72^{*}$ \\
Desempeño Medioambiental (EN) & 70,99 & 49,05 & $21,94^{* * *}$ \\
Indicador integral RSE & 66,34 & 55,48 & $10,85^{*}$ \\
\hline
\end{tabular}

*** p-valor $<0,01 ;{ }^{* *} p$-valor $<0.05 ;{ }^{*} p$-valor $<0,10 ;{ }^{*} p$ valor $>0,10$

Fuente: elaboración propia

\subsection{Relación entre el grado de divulgación de indicadores de RSE y la versión de la memoria presentada (G3 o G4)}

Para analizar si existen diferencias significativas entre el valor de los indicadores de RSE y el tipo de memoria de sostenibilidad presentado (G3 o G4), nuevamente se procedió a aplicar el test de diferencia de medias, para lo cual la variable se clasificó de la siguiente manera:

$$
\begin{aligned}
& \text { Empresas que presentaron memoria G4 }\left(E_{-} G 4\right)=1, y \\
& \text { Empresas que presentaron memoria G3 }\left(E_{-} G 4\right)=0
\end{aligned}
$$

De esta manera se buscó contrastar la siguiente hipótesis nula de igualdad de medias:

$$
H_{0}: \mu_{E_{-} G 3}=\mu_{E_{-} G 4}
$$

Se aplicó la prueba de Chi-cuadrado de Pearson a nivel de subíndice y del indicador integral de RSE. Como se observa en la Tabla 7.9, las diferencias de medias según sean empresas que presentaron memorias con metodología G3 o G4 no resultaron 
significativas ( $p$-valor $>0.1$ ) en los casos de Desempeño económico y Responsabilidad de producto; por lo tanto, para estos casos no se rechaza la HO por lo que las medias muestrales no son significativamente distintas.

Por otra parte, las diferencias sí resultaron significativas según fuera empresas que presentaron reportes con metodología G3 o G4 para los siguientes indicadores: Desempeño medioambiental, Prácticas sociales, Derechos humanos y el Indicador integral de RSE ( $p$-valor $<0.01$ ), y Prácticas laborales y trabajo decente ( $p$-valor $<0.5)$. De esta manera:

- Las empresas que elaboraron las memorias de sustentabilidad de acuerdo a la Guía G3 presentaron mayor divulgación de prácticas de RSE respecto a las dimensiones Medioambiental, Prácticas sociales, Derechos humanos y Prácticas laborales y trabajo decente.

- Las empresas que elaboraron las memorias de sustentabilidad de acuerdo a la Guía G3 presentaron mayor divulgación de prácticas de RSE de manera integral.

Tabla 4.9. Test de Diferencia de Medias:

Subíndices de RSE según Tipo de Memoria Presentada (G3 o G4)

\begin{tabular}{|c|c|c|c|c|}
\hline \multirow[b]{2}{*}{ Subíndice de RSE } & \multicolumn{4}{|c|}{ Media $(\mu)$} \\
\hline & $\begin{array}{l}\text { Reportes } \\
\text { G3 }\end{array}$ & $\begin{array}{l}\text { Reportes } \\
\text { G4 }\end{array}$ & Diferencia & \\
\hline Desempeño económico (EC) & 59,76 & 56,89 & 2,87 & 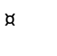 \\
\hline Prácticas laborales y trabajo decente (LA) & 79,12 & 67 & 12,12 & ** \\
\hline Derechos humanos (HR) & 59,52 & 39,66 & 19,85 & *** \\
\hline Prácticas sociales (SO) & 74,81 & 49,49 & 25,31 & *** \\
\hline Responsabilidad de producto (PR) & 59 & 48,89 & 10,11 & $\not$ \\
\hline Desempeño medioambiental (EN) & 64,51 & 46,1 & 18,41 & *** \\
\hline Indicador integral RSE & 66,12 & 51,33 & 14,78 & *** \\
\hline
\end{tabular}

*** $\mathrm{p}$-valor<0,01; ** $\mathrm{p}$-valor $<0.05$; * $\mathrm{p}$ - valor<0,10; ${ }^{\not} \mathrm{p}$ valor $>0,10$

Fuente: elaboración propia 


\subsection{Divulgación de indicadores de RSE por la misma empresa a lo largo del tiempo}

En este apartado se analizó si las empresas reportaban más exhaustivamente sus indicadores de RSE a medida que pasaban los años, para lo cual se comparó el primer valor que arroja el indicador integral de RSE y el último.

Es de suma importancia aclarar que, ante las diferencias significativas del nivel de información según se trata de una memoria publicada de conformidad con la Guía G3 o a la G4, y puesto que a partir del año 2015 es exigible esta última para la elaboración de las memorias de sustentabilidad, se decidió analizar únicamente aquellas memorias publicadas de conformidad con la Guía G4.

De las 50 memorias publicadas de conformidad con la Guía G4, en algunos casos algunas empresas solo habían publicado una memoria, por lo cual no era posible realizar una comparación; en otros casos, su indicador integral de RSE arrojaba el mismo valor debido a que sus memorias abarcaban un período bianual. Depurando la base de estos casos, se contó solamente con 14 empresas para el análisis.

Como se puede observar en la Tabla 4.10, las empresas que mejoran su nivel de información integral de RSE a lo largo del tiempo asciende a 57,1\% y el $42,9 \%$ empeoran su nivel de información integral de RSE. Si bien, como se aclaró previamente, el análisis está hecho para un grupo de empresas muy reducido, hay que ser cauteloso y no concluyente con esta evidencia. 
Tabla 4.10. Memorias Publicadas de Conformidad con la Guía G4.

Evolución en el Tiempo del Indicador integral de RSE

\begin{tabular}{lrr}
\hline Diferencia del indicador integral de RSE (último - primero) & Frecuencia & Porcentaje \\
\hline Positivo & 8 & 57,1 \\
Negativo & 6 & 42,9 \\
\hline Total de empresas analizadas & 14 & 100
\end{tabular}

Fuente: elaboración propia

\subsection{Validación de la metodología para el análisis de la RSE con el Desempeño Económico (DE) y la Reputación Corporativa (RC)}

Como se estableció en el Capítulo 3 respecto a la metodología desarrollada para la medición integral de prácticas de RSE, se le dará una utilización adicional, de manera de analizar la siguiente hipótesis:

“Cuanto mayor desempeño económico y mejor la reputación corporativa, mayor puntuación de RSE".

Para analizar la hipótesis se aplicaron regresiones lineales múltiples, cuya variable independiente surge de la metodología desarrollada para la medición integral de RSE.

Las regresiones lineales múltiples que se definieron son:

$$
\begin{aligned}
& R S E=\beta_{0+} \beta_{1} \mathrm{RC}+\beta_{2} \mathrm{RN}_{+} \beta_{3} \mathrm{ROA}_{+} \beta_{4} \text { Inventas }_{+} \beta_{5} \text { Tamaño }+\varepsilon \\
& E C=\beta_{0}+\beta_{1} \mathrm{RC}+\beta_{2} \mathrm{RN}+\beta_{3} \mathrm{ROA}_{+} \beta_{4} \text { Inventas }_{+} \beta_{5} \text { Tamaño }+\varepsilon \\
& L A=\beta_{0}+\beta_{1} \mathrm{RC}+\beta_{2} \mathrm{RN}+\beta_{3} \mathrm{ROA}_{+} \beta_{4} \text { Inventas }_{+} \beta_{5} \mathrm{Tamaño}_{+} \varepsilon \\
& H R=\beta_{0}+\beta_{1} \mathrm{RC}+\beta_{2} \mathrm{RN}_{+} \beta_{3} \mathrm{ROA}_{+} \beta_{4} \text { Inventas }_{+} \beta_{5} \text { Tamaño }+\varepsilon \\
& S O=\beta_{0}+\beta_{1} \mathrm{RC}+\beta_{2} \mathrm{RN}+\beta_{3} \mathrm{ROA}_{+} \beta_{4} \text { Inventas }_{+} \beta_{5} \text { Tamaño }+\varepsilon \\
& P R=\beta_{0}+\beta_{1} \mathrm{RC}+\beta_{2} \mathrm{RN}+\beta_{3} \mathrm{ROA}_{+} \beta_{4} \text { Inventas }_{+} \beta_{5} \text { Tamaño }+\varepsilon \\
& E N=\beta_{0}+\beta_{1} \mathrm{RC}+\beta_{2} \mathrm{RN}+\beta_{3} \mathrm{ROA}_{+} \beta_{4} \text { Inventas }_{+} \beta_{5} \text { Tamaño }+\varepsilon
\end{aligned}
$$

Donde: 
$E C=$ Indicadores de Desempeño económico; $L A=$ Indicadores de Prácticas Laborales y Trabajo Decente; HR= Indicadores de Derechos Humanos; SO= Indicadores sobre Prácticas Sociales; $\mathrm{PR}=$ Indicadores sobre Responsabilidad de Producto y $E N=$ Indicadores de Desempeño Medioambiental; RC: Reputación Corporativa; RN: Rentabilidad del Patrimonio Neto; ROA: Rentabilidad del Activo y Lnventas: logaritmo neperiano de las Ventas.

Cabe aclarar que la relación inversa "El desempeño económico de la empresa y la reputación corporativa está relacionado con mayor puntuación de RSE" también se analizó y se presentan los resultados en los puntos 4.9 .2 y 4.9.3.

\subsubsection{Resultados}

A continuación se presentan los resultados del análisis de la hipótesis: "Cuanto mayor desempeño económico y mejor la reputación corporativa, mayor puntuación de RSE". En primer lugar, se expone el análisis descriptivo de las variables independientes, luego se presenta la matriz de correlaciones y por último los resultados de los modelos de regresión lineales múltiples planteados en la investigación. A su vez, se desarrolla un análisis mediante "árboles de decisión" para aportar mayor robustez a los resultados.

\subsubsection{Estadísticas descriptivas de las variables independientes}

En la Tabla 4.11 se presenta la media, desvío estándar, mínimo y máximo para cada una de las variables independientes. Cabe aclarar que se omite el valor de media y el desvío estándar de las variables Reputación Corporativa (RC) y Tamaño, puesto que ambas son variables binarias; por tal motivo es presentada la Tabla 4.12 de frecuencias para ambas variables, de la que se destaca que un $63.93 \%$ de la muestra forma parte de las empresas con mejor reputación según el índice MERCO, y el $80.33 \%$ de la muestra corresponde a grandes empresas. 
Tabla 4.11. Estadísticas descriptivas de las variables independientes (explicativas)

\begin{tabular}{lccccc}
\hline Variables independientes & N & Media & Desvío estándar & Mínimo & Máximo \\
\hline Reputación Corporativa (RC)* & 61 & - & - & 0 & 1 \\
Rentabilidad del Patrimonio Neto (RN) & 61 & 0.046 & 0.083 & -0.281 & 0.384 \\
Rentabilidad del Activo (ROA) & 61 & 0.091 & 0.081 & -0.061 & 0.293 \\
Crecimiento de las ventas (Inventas) & 61 & 8.733 & 1.463 & 4.948 & 13.215 \\
Tamaño* & 61 & - & - & 0 & 1 \\
\hline
\end{tabular}

* Variables dummies con valores posibles 1 ó 0.

Fuente: elaboración propia

Tabla 4.12 Frecuencia de las variables independientes binarias

\begin{tabular}{lcc}
\hline Variables independientes binarias & Frecuencia & Porcentaje \\
\hline Reputación Corporativa (RC) & 61 & - \\
$1=$ presente en MERCO & 39 & 63.93 \\
$0=$ ausente en MERCO & 22 & 36.07 \\
\hline Tamaño & 61 & - \\
$1=$ empresa mediana & 12 & 19.67 \\
$0=$ empresa grande & 49 & 80.33 \\
\hline
\end{tabular}

Fuente: elaboración propia

\subsubsection{Análisis de Correlación de las variables independientes cuantitativas}

En primer lugar, cabe recordar que el coeficiente de correlación simple $(P)$ mide el grado de asociación lineal entre dos variables medidas en escala de intervalo o de razón, tomando valores entre -1 y 1 . Valores de $P$ próximos a 1 indicarán fuerte asociación lineal positiva (a medida que aumentan los valores de una de las dos variables, aumentan los de la otra); valores $P$ próximos a -1 indicarán fuerte asociación lineal negativa (a medida que aumentan los valores de una de las dos variables, disminuyen los de la otra) y valores de $P$ próximos a 0 indicarán no asociación lineal, lo que no significa que no pueda existir otro tipo de asociación (Ferrán Aranaz, 2001).

Se aplicó el análisis de correlación entre los pares de variables independientes cuantitativas. Como se observa en la Tabla 4.13, podemos destacar del análisis que los coeficientes de correlación entre los pares de variables "Inventas y ROA" y "Inventas y $\mathrm{RN}$ " no son interpretables puesto que el p-valor arroja un valor superior a 0.10 . Por 
otra parte, el resultado del coeficiente de correlación entre las variables "ROA y RN" cuyo valor (0.472) evidencia una fuerte relación positiva entre ambas variables con un p-valor es menor a 0.01, evidenciándose que las empresas que conforman la población en promedio se encuentran apalancadas positivamente, puesto que mayor ROA, mayor RN.

Además, del análisis de correlaciones se evidencia que podría haber problema de multicolinealidad entre las variables independientes ROA y ROE puesto que su coeficiente de correlación es muy cercano a 0.5 (0.472). Por lo tanto, se puede concluir que a mayor ROA, mayor ROE, evidenciando efecto palanca positivo.

Tabla 4.13. Correlación de las variables independientes cuantitativas del modelo

\begin{tabular}{|c|c|ccc|}
\cline { 3 - 5 } \multicolumn{1}{c}{} & \multicolumn{2}{c|}{ Inventas } & ROA & RN \\
\hline \multirow{3}{*}{ Inventas } & Correlación de Pearson & 1 & -0.142 & 0.094 \\
& Sig. (bilateral) & & 0.275 & 0.471 \\
& $\mathrm{~N}$ & 61 & 61 & 61 \\
\hline \multirow{2}{*}{ ROA } & Correlación de Pearson & -0.142 & 1 & $0.472^{* * *}$ \\
& Sig. (bilateral) & 0.275 & & 0.000 \\
& N & 61 & 61 & 61 \\
\hline \multirow{2}{*}{ RN } & Correlación de Pearson & 0.094 & $0.472^{* * *}$ & 1 \\
& Sig. (bilateral) & 0.471 & 0.000 & \\
& $\mathrm{~N}$ & 61 & 61 & 61 \\
\hline
\end{tabular}

La correlación es significativa al nivel 0,01 (bilateral).

Fuente: elaboración propia

\subsubsection{Modelos de regresión explicativos de la RSE por dimensión y a nivel integral}

En primer lugar, dada las pruebas hechas sobre la totalidad de las variables independientes, dónde quedo en evidenciada "multicolinealidad" en el modelo planteado, dada la existencia de alta relación entre dos de las variables explicativas (Gujarati, D., 1997, p 316), la ROA y RN. Se optó por eliminar del análisis la RN, puesto que estaba fuertemente correlacionada con la ROA, y miden los dos indicadores aspectos similares.

Ante lo mencionado, los modelos de regresión lineal múltiple que se plantearon finalmente fueron: 


$$
\begin{aligned}
& R S E=\beta_{0}+\beta_{1} \mathrm{RC}+\beta_{2} \mathrm{ROA}_{+} \beta_{3} \text { Inventas }_{+} \beta_{4} \text { Tamaño }_{+} \varepsilon \\
& E C=\beta_{0}+\beta_{1} \mathrm{RC}+\beta_{2} \mathrm{ROA}_{+} \beta_{3} \operatorname{lnventas}_{+} \beta_{4} \text { Tamaño }_{+} \varepsilon \\
& L A=\beta_{0}+\beta_{1} \mathrm{RC}+\beta_{2} \mathrm{ROA}_{+} \beta_{3} \text { lnventas } \beta_{4} \text { Tamaño }_{+} \varepsilon \\
& H R=\beta_{0+} \beta_{1} \mathrm{RC}+\beta_{2} \mathrm{ROA}_{+} \beta_{3} \text { Inventas }_{+} \beta_{4} \text { Tamaño }_{+} \varepsilon \\
& S O=\beta_{0}+\beta_{1} \mathrm{RC}+\beta_{2} \mathrm{ROA}+\beta_{3} \text { Inventas }+\beta_{4} \text { Tamaño }+\varepsilon \\
& P R=\beta_{0+} \beta_{1} \mathrm{RC}+\beta_{2} \mathrm{ROA}_{+} \beta_{3} \text { lnventas }_{+} \beta_{4} \text { Tamaño }_{+} \varepsilon \\
& E N=\beta_{0}+\beta_{1} \mathrm{RC}+\beta_{2} \mathrm{ROA}_{+} \beta_{3} \text { Inventas }_{+} \beta_{4} \mathrm{Tamaño}_{+} \varepsilon
\end{aligned}
$$

Donde:

$E C=$ Indicadores de Desempeño económico; $L A=$ Indicadores de Prácticas Laborales y Trabajo Decente; HR= Indicadores de Derechos Humanos; $\mathrm{SO}=$ Indicadores sobre Prácticas Sociales; $\mathrm{PR}=$ Indicadores sobre Responsabilidad de Producto y EN= Indicadores de Desempeño Medioambiental; RC: Reputación Corporativa; ROA: Rentabilidad del Activo y Lnventas: logaritmo neperiano de las Ventas.

\subsubsection{Resultados de los modelos de regresión explicativos de la RSE por dimensión y a nivel integral}

De los resultados de los análisis de regresión que se efectuaron (Tabla 4.13), tanto para la variable dependiente RSE a nivel integral como por dimensión, los coeficientes de las variables independientes no son interpretables para determinar la relación entre las variables. El motivo se debe a que en todos los casos los p-valor resultaron muy por encima del $>0.05$, a su vez el $\mathrm{R} 2$ de los modelos arrojan valores muy bajo; por lo tanto, para la muestra analizada, no se evidencia relación lineal entre la RSE y las variables explicativas seleccionadas. 
Tabla4.13. Coeficientes de los modelos de regresión. Variables dependientes RSE

(integral y por dimensión)

\begin{tabular}{|c|c|c|c|c|c|c|c|c|c|c|c|c|}
\hline \multirow{2}{*}{$\begin{array}{c}\text { Variables } \\
\text { Independientes }\end{array}$} & \multicolumn{3}{|c|}{ RSE } & \multicolumn{3}{|c|}{ EC } & \multicolumn{3}{|c|}{ LA } & \multicolumn{3}{|c|}{ HR } \\
\hline & Coef. & $\mathbf{T}$ & P-valor & Coef. & $\mathbf{T}$ & P-valor & Coef. & $\mathbf{T}$ & P-valor & Coef. & $T$ & P-valor \\
\hline (Constante) & 57.16 & 2.61 & 0.012 & 9.99 & 0.39 & 0.696 & 67.91 & 2.97 & 0.004 & 56.48 & 2 & 0.05 \\
\hline ROA & -8.52 & -0.19 & 0.846 & 21.83 & 0.43 & 0.668 & -9.1 & -0.2 & 0.842 & -2.55 & -0.05 & 0.964 \\
\hline Inventas & 0.295 & 0.12 & 0.904 & 6.07 & 2.14 & 0.036 & 0.67 & 0.26 & 0.793 & -1.5 & -0.48 & 0.634 \\
\hline RC & -0.7 & -0.09 & 0.925 & -9.72 & -1.14 & 0.26 & -3.11 & -0.4 & 0.687 & 6.08 & 0.64 & 0.525 \\
\hline Tamaño & 6.274 & 0.71 & 0.478 & 1.9 & 0.19 & 0.853 & 3.04 & 0.33 & 0.741 & 11.61 & 1.03 & 0.309 \\
\hline $\mathbf{N}$ & \multicolumn{3}{|c|}{61} & \multicolumn{3}{|c|}{61} & \multicolumn{3}{|c|}{61} & \multicolumn{3}{|c|}{61} \\
\hline R-sq (R2) & \multicolumn{3}{|c|}{0.01} & \multicolumn{3}{|c|}{0.08} & \multicolumn{3}{|c|}{0.06} & \multicolumn{3}{|c|}{0.03} \\
\hline Variables & \multicolumn{3}{|c|}{ PR } & \multicolumn{3}{|c|}{ EN } & \multicolumn{3}{|c|}{ so } & & & \\
\hline Independientes & Coef. & $T$ & P-valor & Coef. & $T$ & P-valor & Coef. & $T$ & P-valor & & & \\
\hline (Constante) & 0.67 & 2.32 & 0.024 & 57.74 & 2.65 & 0.011 & 0.82 & 3.64 & 0.001 & & & \\
\hline ROA & -0.29 & -0.51 & 0.609 & -42.5 & -0.98 & 0.332 & 0.1 & -0.9 & 0.822 & & & \\
\hline Inventas & -0.01 & -0.26 & 0.799 & -0.29 & -0.12 & 0.905 & -0.02 & -0.52 & 0.371 & & & \\
\hline RC & 0.064 & 0.66 & 0.512 & 0.18 & 0.02 & 0.98 & -0.04 & 1.34 & 0.604 & & & \\
\hline Tamaño & -0.02 & -0.17 & 0.865 & 10.98 & 1.26 & 0.214 & 0.12 & 3.64 & 0.185 & & & \\
\hline $\mathbf{N}$ & \multicolumn{3}{|c|}{61} & \multicolumn{3}{|c|}{61} & \multicolumn{3}{|c|}{61} & & & \\
\hline R-sq (R2) & \multicolumn{3}{|c|}{0.01} & \multicolumn{3}{|c|}{0.05} & \multicolumn{3}{|c|}{0.05} & & & \\
\hline
\end{tabular}

Fuente: elaboración propia

\subsubsection{Limitaciones planteadas como resultado del análisis de regresión lineal}

La metodología propuesta no muestra evidencia contundente respecto a qué mejor desempeño económico y reputación corporativa repercute en mejor puntuación en los indicadores de RSE, la relación no puede interpretarse de manera concluyente puesto que los resultados no arrojan valores significativos.

En primer lugar, es menester mencionar limitaciones con las que se enfrentó la presente investigación, para que los resultados de la misma sean interpretados cuidadosamente:

- Número limitado de las observaciones con las que efectuar el análisis.

- Dado que se contaba con observaciones sólo para los años 2012-2016, no se pudo hacer un desfasaje temporal entre las variables RSE y el desempeño económico y la reputación corporativa. 
- A través del análisis de regresión planteado en el modelo, se busca evidenciar relación lineal entre las variables dependientes e independientes, no algún otro tipo de relación que no sea del tipo lineal.

\subsubsection{Metodología alternativa de análisis: árboles de decisión}

Debido a las limitaciones que se presentaron en el punto 4.1.9.5 al implementar el análisis de regresión lineal múltiple, se plantea como metodología alternativa: "árboles de decisión". Los mismos constituyen un método de segmentación, que trata de resolver los problemas de discriminación de una población segmentando de forma progresiva la muestra para obtener finalmente una clasificación fehaciente en grupos homogéneos, según la variable de interés denominada variable de segmentación. La asignación de un elemento poblacional a un segmento se realiza de acuerdo a los valores de determinadas variables medidas sobre él que constituyen las variables independientes del modelo (Pérez, C. 2013).

Para el modelo se consideró variable de segmentación la variable "RSE integral", que tomó el valor de " 1 " en el caso de tener valor superior a la media y valor " 0 " en caso contrario. Por otra parte las variables independientes han sido definidas como:

- ROA: valor de "1" en el caso de tener valor superior a la media y valor "0" en caso contrario.

- Reputación Corporativa (RC): valor de "1" en el caso de tener valor superior a la media y valor " 0 " en caso contrario.

Dada las características de la variable de segmentación (binaria), se procedió a aplicar "árboles de Chi-square Automatic Interaction Detector (CHAID)" (Imagen 4.2), la variable dependiente puede ser cuantitativa o cualitativa. Para las variables cualitativas, el análisis lleva a cabo una serie de análisis Chi-cuadrado entre las variables independientes y la variable de segmentación, las que dan lugar a un "árbol de clasificación" (Pérez, 2013). 
Imagen4.2. Árbol de clasificación. RSE: desempeño económico y reputación corporativa

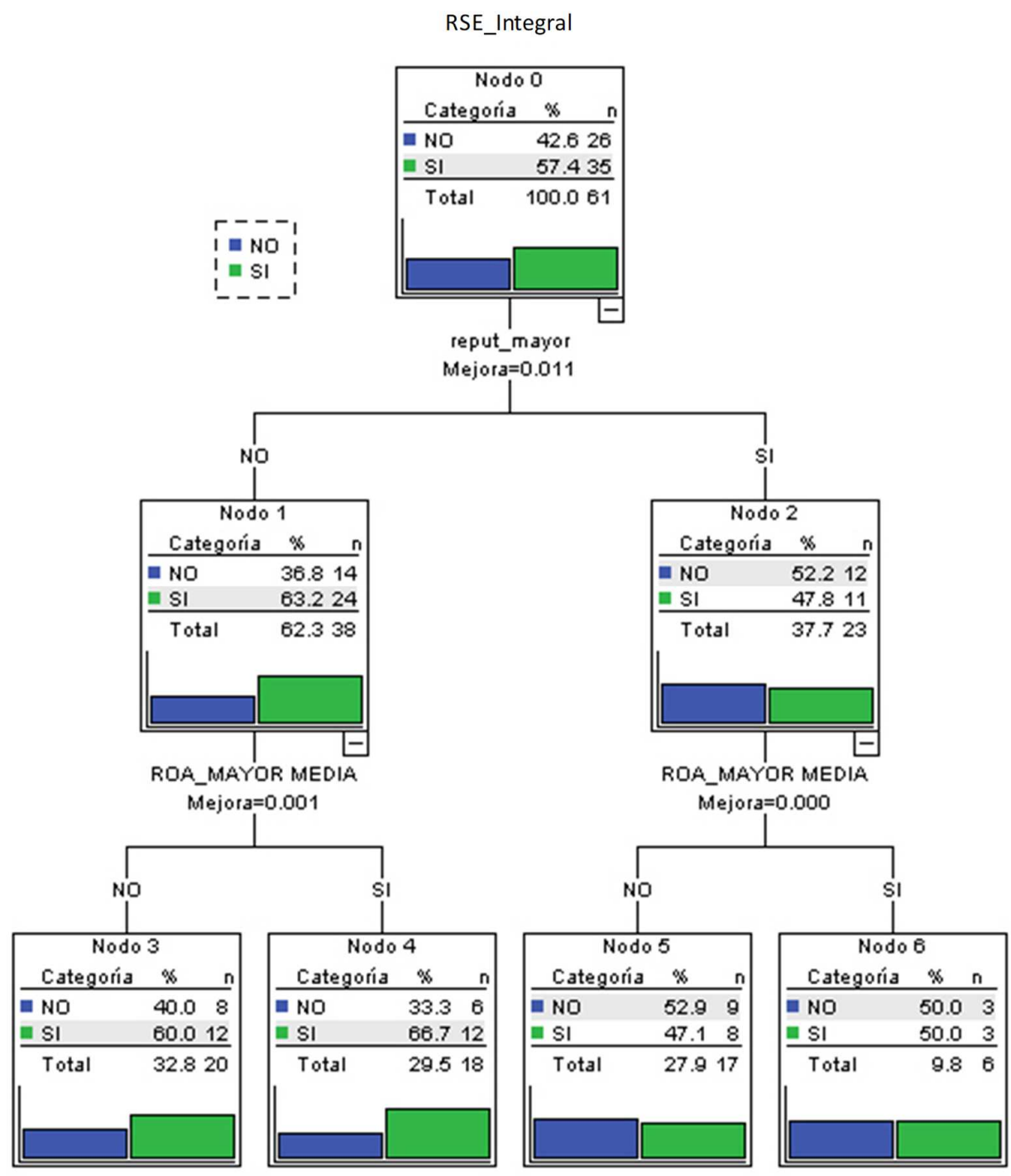

Fuente: elaboración propia

Del análisis del árbol de clasificación (Imagen 8.2), lo primero que observamos es que el $57,4 \%$ de las empresas tiene una puntuación del indicador integral de RSE. A continuación, se observa que la reputación corporativa $(\mathrm{RC})$ es el mejor predictor de la 
puntuación de la RSE integral, ya que representa la primera ramificación en el árbol. Para el nodo 2 (RC), el 47,8\% tienen reputación más alta que la media.

El siguiente predictor es la ROA, podemos destacar los nodos 5 y 6 , donde se observa en el nodo 6 que aquellas empresas con mayor RC, cuentan con una ROA mayor que la media un $50 \%$ (nodo 6 ) contra un $47,1 \%$ (nodo 5 ).

Como conclusión general, el árbol de clasificación no aporta mejor clasificación, por un lado solo aporta información cuando la reputación está por debajo de la media porque cuando está por encima la mejora es 0 y los porcentajes de ambos grupos son prácticamente idénticos. Y cuando la reputación es mejor que la media la mejora no es 0 pero casi y no hay diferencias significativas a simple vista.

Por tanto, nuevamente se concluye que no hay evidencia de que a mayor reputación corporativa mayor sea la puntuación RSE ni tampoco que a mayor RSE mayor desempeño medido por ROA.

\subsubsection{Resultados para la hipótesis: "La implementación de RSE redunda en un mayor desempeño económico"}

Como se puede observar en la Tabla 4.15, el 25\% de las empresas de la muestra fueron clasificadas como muy rentables y el $75 \%$ como poco rentables. La media del índice integral arrojó el valor de 0.6239 para las empresas muy rentables, mientras que para las poco rentables el valor fue 0.036 inferior (es decir de 0.5879), dado que el resultado del test de diferencia de medias arrojo un $p$-valor $>0.10$, la mencionada diferencia resulta no ser significativa, por lo tanto, no se rechaza la $\mathrm{H}_{0}$ por lo que las medias muestrales no son significativamente distintas. 
Tabla 4.15. Test de diferencia de medias: Índice integral de RSE y rentabilidad de las empresas

\begin{tabular}{lcccc}
\cline { 2 - 4 } & $\begin{array}{c}\text { Empresas } \\
\text { muy } \\
\text { rentables }\end{array}$ & $\begin{array}{c}\text { Empresas } \\
\text { poco } \\
\text { rentables }\end{array}$ & Diferencia \\
\hline Cantidad de empresas $(\%)(\mathrm{N}=61)$ & 0.25 & 0.75 & \\
\hline Índice integral de RSE Media $(\mu)$ & 0.6239 & 0.5879 & 0.036 & \\
\hline
\end{tabular}

" $p$ valor $>0,10$

Fuente: elaboración propia

\subsubsection{Resultados para la hipótesis: "La implementación de RSE redunda en una mejor reputación corporativa".}

Como se puede observar en la Tabla 4.16, el 38\% de las empresas de la muestra fueron clasificadas como con alta reputación corporativa y el $62 \%$ con baja reputación corporativa. La media del índice integral arrojo el valor de 0.5346 para las empresas con alta reputación, mientras que para las poco rentables el valor fue 0.099 superior (es decir de 0.6344), no obstante dado que el resultado del test de diferencia de medias arrojo un $p$-valor $>0.10$, la mencionada diferencia resulta no ser significativa, por lo tanto, no se rechaza la $\mathrm{H}_{0}$ por lo que las medias muestrales no son significativamente distintas. 
Tabla 4.16 Test de diferencia de medias: Índice integral de RSE y reputación corporativa

\begin{tabular}{|c|c|c|c|}
\hline & \\
\hline & $\begin{array}{l}\text { Empresas con } \\
\text { alta } \\
\text { reputación } \\
\text { corporativa }\end{array}$ & $\begin{array}{l}\text { Empresas con } \\
\text { baja } \\
\text { reputación } \\
\text { corporativa }\end{array}$ & Diferencia \\
\hline Cantidad de empresas (\%) (N=61) & 0.38 & 0.62 & \\
\hline Media $(\mu)$ & 0.5346 & 0.6344 & -0.0998 \\
\hline
\end{tabular}

\subsection{Conclusiones de la validación de la metodología}

De manera de ordenar las conclusiones a las que se arribó, primero se exponen aquellas vinculadas a la validación de la metodología desarrollada para la medición integral de RSE y luego las relacionadas al uso de la misma para relacionar la RSE con desempeño económico y la reputación corporativa.

\subsubsection{Conclusiones de la aplicación de la metodología para la medición integral de prácticas de RSE}

En primer lugar, respecto a los indicadores presentados por las empresas que han comunicado sus memorias de sostenibilidad, es de destacar que el grado de divulgación integral de RSE asciende a un 58,34\%, lo que evidencia que las empresas no estarían informando en promedio un $41,66 \%$ de los indicadores propuestos por la GRI. Cuando esto es analizado a nivel de subíndice (dimensión), como se mencionó, varía de un 49,07 \% (Dimensión Social - Derechos humanos) a un 72,74 \% (Dimensión Social - Prácticas laborales), es decir que es en la Dimensión Social, según sea el aspecto, donde menos y más se informa. 
Puesto que el indicador Prácticas laborales arrojó un valor de $72,74 \%$, se observa lo importante que resulta para las empresas informar las prácticas de RSE relacionadas con sus recursos humanos, dejando en evidencia que sería en esta dimensión sobre la que más prácticas estarían llevando a cabo las empresas. Esta idea se alinea con lo que plantea Welsch, G. et al. (1990, p. 2) es la "gente" quien constituye la parte más crítica de la administración - no la tierra, los edificios, el equipo o los materiales. Desarrollar un personal eficaz, crear un ambiente auténtico de trabajo y motivar positivamente a la gente determinan, en gran medida, el éxito de la mayor parte de la empresa.

Este análisis permite concluir que resulta de suma importancia para futuras investigaciones ahondar en cada una de las dimensiones, fundamentalmente en la Dimensión Social de Derechos humanos para analizar qué indicadores están omitiendo informar las empresas y cuáles podrían ser las causas, y la Dimensión Social Prácticas laborales, al ser la que más se informa, para poder profundizar y cuantificar más exhaustivamente los indicadores que la componen, como ser evaluaciones, prestaciones otorgadas por sexo y categoría profesional, la reincorporación luego de baja por maternidad/paternidad, entre otros.

Respecto al nivel de indicadores de RSE informados por las empresas y su relación con el tamaño, quedó demostrado que hay cierta relación en algunos casos, debiéndose destacar que en aquellos en que las diferencias resultaron significativas fueron las medianas empresas las que más informaron sobre sus prácticas de RSE.

En relación al nivel de indicadores de RSE informados por las empresas y el tipo de memoria elaborada (G3 o G4), las diferencias de medias en casi todos los casos resultaron significativas a favor de las memorias elaboradas según la Guía GRI G3. Es muy probable que esto se deba a que los indicadores propuestos en la Guía GRI G3 son menos en cuanto a cantidad y, en algunos casos, menos exhaustivos, de allí que las empresas en caso de elaboración de sus memorias según la Guía G3 hayan podido tener un mejor cumplimiento en la comunicación de los indicadores por ella propuestos.

Por último, al analizar la divulgación de información de RSE por parte de las empresas, se observó que solo un 57,1 \%, mejoró su grado de divulgación, es decir, se infiere, 
que a medida que pasa el tiempo, no todas las empresas divulgan con mayor grado de detalle sus prácticas de RSE, esta conclusión no debe considerarse concluyente y debe tomarse con cautela puesto que fue muy escaso el número de empresas con las que se pudo efectuar dicho análisis.

Es importante resaltar que, de la aplicación de la metodología para la medición integral de prácticas de RSE, se pudieron desprender las siguientes proposiciones:

- Si mejoran las prácticas de RSE en alguna de las dimensiones mejoran también las prácticas en cualquiera de las otras.

- Si se expanden las prácticas de RSE en la dimensión laboral, en la de recursos humanos o en las de prácticas de producto, se expanden en mayor medida las prácticas en la dimensión social.

- Las empresas que elaboraron las memorias de sustentabilidad de acuerdo a la Guía G3 presentaron mayor divulgación de prácticas de RSE respecto a las dimensiones Medioambiental, Prácticas sociales, Derechos humanos y Prácticas laborales y trabajo decente.

- Las empresas que elaboraron las memorias de sustentabilidad de acuerdo a la Guía G3 presentaron mayor divulgación de prácticas de RSE de manera integral.

- Cuanto menor sea el tamaño de la empresa, tanto mayor será la aplicación de prácticas de RSE en las dimensiones Prácticas Laborales, Derechos Humanos y Medioambiental.

- Cuanto menor sea el tamaño de la empresa, tanto mayor será la aplicación de prácticas de RSE de manera integral. 


\subsubsection{Conclusiones respecto a la relación de la RSE con el desempeño económico y la reputación corporativa}

En primer lugar, respecto a las conclusiones enfocadas al modelo del análisis de regresión, para futuras investigaciones sería interesante aplicar un desfase temporal de tres años al medir la relación entre la RSE y los resultados económicos de las empresas y discriminar el análisis entre empresas de sectores cuyo comportamiento (desde un punto de vista RSE) es homogéneo o heterogéneo. Por lo tanto, sería recomendable ampliar el período de análisis para que sea factible llevar a cabo el desfase temporal y contar a su vez con un mayor número de observaciones.

Como se mencionó anteriormente, a partir del análisis efectuado no se evidencia relación lineal entre las variables dependientes y las variables independientes, al respeto cabe destacar que aunque la mayoría de los estudios existentes parten de alguna de estas hipótesis lineales sobre la relación RSE y resultados económicos, también existen trabajos que han considerado la posibilidad de la existencia de una relación no lineal o en forma de $U$ invertida, esta relación supone que existe un nivel óptimo de RSC a partir del cual los gastos adicionales realizados afectan negativamente al resultado económico (Valenzuela Fernández, Jara-Bertin, \& Pineaur, 2015).

En este sentido cabe agregar que Olcese (2011), considera que variables como el tipo de industria, riesgo o gastos en I+D, podría explicar el hecho que en algunos estudios no se encuentren correlaciones concluyentes entre RSE y DE, debido al efecto "moderador" que generarían estas variables. A su vez, agrega otra limitación: que tanto la performance financiera como el desempeño económico son el resultado final de una larga cadena de variables intermedias e independientes y, por ello, aislar unas variables relacionadas con el desempeño en RSE para hallar una causalidad sobre el resultado económico de la empresa es una cuestión sumamente compleja.

Ante la falta de evidencia de una relación lineal entre la implementación de prácticas de RSE y el desempeño económico, implica falta de relación tanto positiva como negativa, esto demuestra que las empresas que invierten en RSE no verán disminuida su rentabilidad. 
Al haber complementado la metodología con el "árbol de clasificación" y llevado a cabo pruebas Chi-cuadrado de Pearson, los resultados se alinean con la "Hipótesis de las variables moderadoras" la misma concluye que entre la RSE y el DE no existe ninguna correlación, en cuanto la variable de RSE no puede alterar la variable DE, ni viceversa, la relación no es clara, ni significativa (Bonsón, \& Bednarová, 2015).

Por último, otro aspecto a reflexionar es que la mayor parte de las investigaciones que analizan la relación entre RSE y el desempeño económico o entre la RSE y la reputación se basan en empresas estadounidenses o europeas, por lo que se podría plantear la posibilidad de que el comportamiento fuese diferente en empresas de países latinoamericanos o también por tratarse de economías desarrolladas o en desarrollo. 


\section{CAPITULO 5: CONCLUSIONES Y PROPUESTAS}

La primera parte de este Capítulo se dedica a recoger las principales conclusiones a las que se arribó para dar respuesta a los objetivos específicos planteados en la investigación, estableciendo previamente una breve mención de las metodologías aplicadas en cada caso.

La segunda parte se destina a efectuar recomendaciones y futuras líneas de investigación.

\section{CONCLUSIONES}

\subsection{Sobre la identificación de indicadores relevantes para la medición de prácticas de RSE}

El primer objetivo específico de la investigación consistió en:

"Identificar indicadores relevantes para la medición integral de prácticas de RSE".

El Capítulo 2 correspondiente al marco teórico, permitió identificar posibles indicadores para la medición integral de prácticas de RSE. Del análisis se pudieron observar ciertas limitaciones a tener en cuenta:

- La falta de claridad en la definición del concepto de RSE ha generado la abundancia de términos, no existiendo un consenso claro sobre las dimensiones de la RSE, por lo tanto según sea la definición y dimensiones abordadas por la misma es que han surgido diversas formas de medir el desempeño en estas prácticas.

- Muchos de los indicadores propuestos desde la academia implican presencia o ausencia de determinada práctica de RSE, pero no el nivel de avance, que 
permita analizar a lo largo del tiempo la evolución favorable o desfavorable respecto a determinada práctica.

- La diversidad de modelos para medir el desempeño de las empresas respecto a las prácticas de RSE, también hace difícil la comparación entre empresas o sectores, por lo que se debe ser cauteloso al momento de querer hacer análisis comparativos de las investigaciones.

Ante las limitaciones enumeradas anteriormente para el desarrollo de la metodología para la medición integral de prácticas de RSE, se propuso la utilización de la información publicada en las memorias de sostenibilidad de la GRI, ya que las mismas facilitan la medición de prácticas de RSE puesto que favorecen la accesibilidad y la comparabilidad de la información, y por consiguiente, mejora la calidad de la información, a su vez son aplicables a cualquier tipo de organización, lo cual es otra ventaja a destacar.

A su vez, se aconsejó la generación de indicadores cuantitativos tanto de manera integral como por dimensión, dada la multidimensionalidad de la RSE. este sentido, fueron utilizadas las dimensiones propuestas por el GRI al tener amplia aceptación. Por otra parte, se destacó la creación de indicadores cuantitativos de RSE que posibilitó el análisis de la variación de los mismos a lo largo del tiempo.

Por último, analizar las empresas adheridas a la GRI posibilitó la obtención de indicadores económicos/financieros de las empresas, puesto que gran parte de estas empresas cotizan en la Comisión Nacional de Valores (CNV), por lo que se encuentran obligadas a publicar sus Estados Contables. Esto permitió llevar a cabo un análisis entre los indicadores de RSE desarrollados mediante el modelo propuesto y los indicadores económico-financieros que se pudieron calcular, según se analizó en el Capítulo 2, punto 2.4.7. 


\subsection{Diseño de una metodología para la medición integral de prácticas de RSE}

El segundo objetivo específico de la investigación fue planteado en los siguientes términos:

"Diseñar la metodología para la medición integral de prácticas de RSE"

En primer lugar, se realizó la operacionalización de las variables de manera de explicar en detalle la definición que adoptarían las variables propuestas para el desarrollo de la metodología para la medición integral de prácticas de RSE.

Luego, se detallaron los pasos de la metodología desarrollada, de manera de arribar a la conceptualización de la misma.

A continuación, se detallan los pasos de la metodología desarrollada para la medición integral de prácticas de RSE:

1- Recolección y sistematización de la información publicada en las Memorias de Sostenibilidad.

Se procedió a asignar un número secuencial para cada una de las observaciones (par ordenado: empresa y año) y a consignar las siguientes variables según lo informado en las memorias de sostenibilidad: nombre de la empresa, año de la memoria, tamaño de la empresa, tipo de la guía GRI utilizada para la elaboración de la memoria y sector de actividad.

2- Generación de variables binarias para cada uno de los indicadores a informar conforme la GRI en cada memoria de sostenibilidad relevada.

Respecto a los indicadores informados, se generó para cada uno de los mismos, una variable del tipo binaria de forma que un determinado indicador se valoró con un " 1 " si se disponía de la información sobre el mismo en la memoria publicada y con "0" en caso contrario.

3- Cálculo de indicadores para la medición por dimensión de la RSE. 
En esta investigación se considera importante analizar las distintas "dimensiones" de la RSE de manera de identificar aquellas que requieren atención, con el fin de proporcionar información para hacer futuras comparaciones y desarrollar planes de mejora. Es por ello que se procedió a realizar para cada una de las dimensiones que propone la GRI un subíndice, definido mediante el cociente entre la sumatoria del número del total de indicadores identificados y el número total de indicadores que constituyen el mismo.

Por lo tanto, cada subíndice se definió de la siguiente manera:

$$
\begin{aligned}
E C & =\sum \frac{E C 1+E C 2+E C 3+\cdots+E C 9}{9} \times 100 \\
L A & =\sum \frac{L A 1+L A 2+L A 3+\cdots+L A 16}{16} \times 100 \\
H R & =\sum \frac{H R 1+H R 2+H R 3+\cdots+H R 12}{12} \times 100 \\
S O & =\sum \frac{S O 1+S O 2+S O 3+\cdots+S O 11}{11} \times 100 \\
P R & =\sum \frac{P R 1+P R 2+P R 3+\cdots+P R 9}{9} \times 100 \\
E N & =\sum \frac{E N 1+E N 2+E N 3+\cdots+E N 34}{34} \times 100
\end{aligned}
$$

Donde:

$E C=$ Indicadores de Desempeño económico; $L A=$ Indicadores de Prácticas Laborales y Trabajo Decente; HR= Indicadores de Derechos Humanos; SO= Indicadores sobre Prácticas Sociales; $P R=$ Indicadores sobre Responsabilidad de Producto y $E N=$ Indicadores de Desempeño Medioambiental.

4-Generación de indicador para la medición integral de la RSE.

Puesto que la RSE no es una "variable", debe considerarse la misma como una medida multidimensional del comportamiento social de las empresas en función de múltiples cuestiones relacionadas con la RSE (Charlo Molina \& Moya Clemente, 2010), es por tal 
motivo que como medida proxy para expresar de manera integral la variable de RSE, se consideró el valor de la sumatoria de los subíndices calculados para cada dimensión dividido la cantidad de subíndices.

De esta manera se crea el indicador integral de "RSE", como:

$$
R S E=\sum \frac{E C+L A+H R+S O+P R+E N}{6} \times 100
$$

Respecto a esto último, debido a que la cantidad de indicadores varía según se presente memorias G3 $\circ$ G4; es pertinente aclarar que esto fue contemplado al momento de los cálculos y que los indicadores que se presentan a continuación tuvieron ajustes en el número de indicadores en el caso de tratarse de indicadores extraídos de una memoria elaborada según la Guía GRI G3 o G4.

Luego se propuso utilizar la metodología desarrollada para la medición integral de prácticas de RSE, de manera de analizar si: "cuanto mayor desempeño económico y mejor la reputación corporativa, mayor puntuación de RSE." (Figura 5.1).

Imagen 5.1: Modelo explicativo: Desempeño económico y reputación corporativa y su relación con la RSE

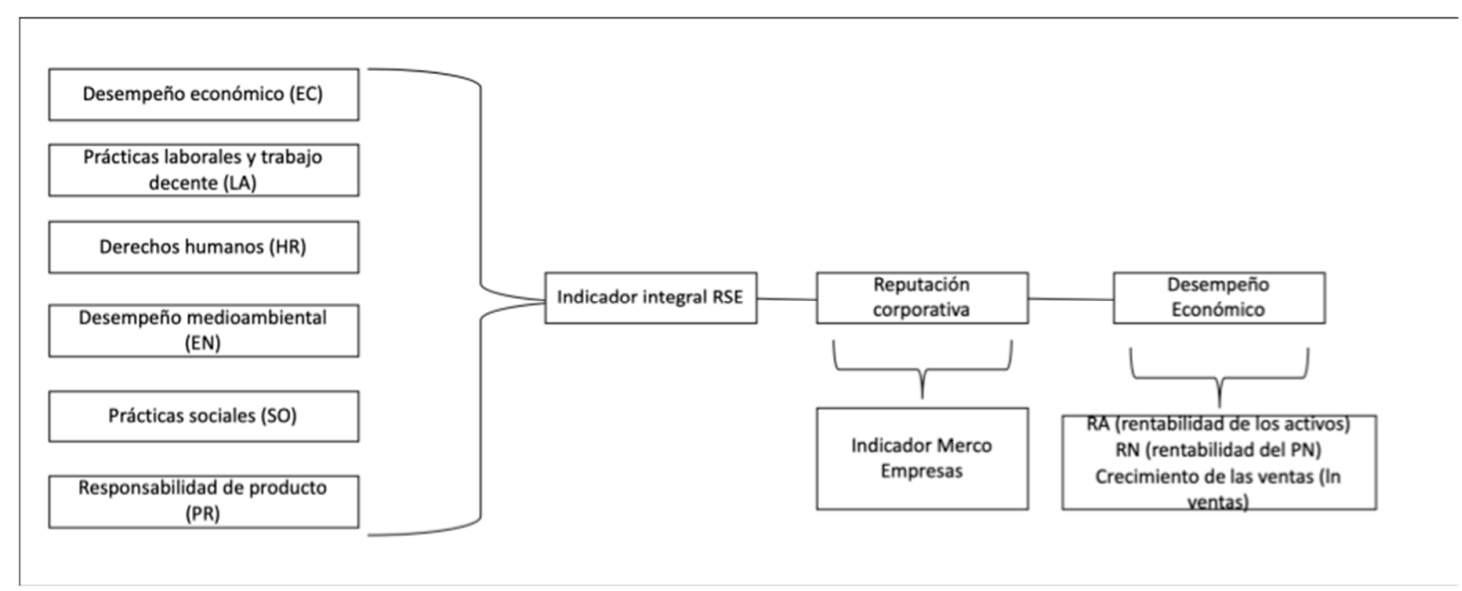

Fuente: elaboración propia 
Para llevar adelante el análisis, se desarrollaron las siguientes regresiones lineales múltiples:

$$
\begin{aligned}
& R S E=\beta_{0+} \beta_{1} \mathrm{RC}+\beta_{2} \mathrm{RN}_{+} \beta_{3} \mathrm{ROA}_{+} \beta_{4} \text { Inventas }_{+} \beta_{5} \text { Tamaño }+\varepsilon \\
& E C=\beta_{0}+\beta_{1} \mathrm{RC}+\beta_{2} \mathrm{RN}+\beta_{3} \mathrm{ROA}_{+} \beta_{4} \text { Inventas }_{+} \beta_{5} \text { Tamaño }+\varepsilon \\
& L A=\beta_{0}+\beta_{1} \mathrm{RC}+\beta_{2} \mathrm{RN}_{+} \beta_{3} \mathrm{ROA}_{+} \beta_{4} \text { Inventas }_{+} \beta_{5} \mathrm{Tamaño}_{+} \varepsilon \\
& H R=\beta_{0}+\beta_{1} \mathrm{RC}+\beta_{2} \mathrm{RN}_{+} \beta_{3} \mathrm{ROA}_{+} \beta_{4} \text { Inventas }_{+} \beta_{5} \mathrm{Tamaño}_{+} \varepsilon \\
& S O=\beta_{0}+\beta_{1} \mathrm{RC}+\beta_{2} \mathrm{RN}+\beta_{3} \mathrm{ROA}_{+} \beta_{4} \text { Inventas }_{+} \beta_{5} \text { Tamaño }+\varepsilon \\
& P R=\beta_{0}+\beta_{1} \mathrm{RC}+\beta_{2} \mathrm{RN}+\beta_{3} \mathrm{ROA}+\beta_{4} \text { Inventas }+\beta_{5} \text { Tamaño }+\varepsilon \\
& E N=\beta_{0} \beta_{1} \mathrm{RC}+\beta_{2} \mathrm{RN}+\beta_{3} \mathrm{ROA}_{+} \beta_{4} \text { Inventas }_{+} \beta_{5} \text { Tamaño }_{+} \varepsilon
\end{aligned}
$$

Previo al análisis de regresión, se debió desarrollar un análisis descriptivo de las variables dependientes e independientes (o explicativas), luego un análisis de correlación de las mismas y por último sí desarrollar los modelo de regresión lineal para analizar la relación entre las prácticas de RSE (por dimensión y a nivel integral), con la reputación corporativa y el desempeño económico.

Mediante la metodología desarrollada en primer lugar se logró medir los aspectos intangibles de la RSE, tanto por dimensión como de manera integral, esto posibilitó la comparación de las dimensiones por separado, así como también determinar si existe relación entre ellas y en qué medida aporta cada una a la valoración integral de la RSE.

A su vez, puesto que los indicadores incorporan magnitud y son expresados en la misma unidad de medida, como se mencionó en el párrafo anterior, posibilitó no solo la comparación entre dimensiones, sino entre distintas empresas y distintos sectores. Finalmente, permitió el análisis de la evolución de las prácticas de RSE en un determinado período, pudiendo considerar distintas unidades de análisis como ser: la misma empresa, empresas de distintos sectores o empresas de distintas regiones o países. 


\subsection{Validación de la metodología para medir el nivel de aplicación de prácticas de RSE en las empresas argentinas}

El tercer objetivo de la investigación consistió en:

"Validar la metodología para determinar el nivel de aplicación de prácticas de RSE en las empresas argentinas".

La población objeto del estudio fueron las empresas argentinas adheridas a la GRI que cotizan en la Comisión Nacional de Valores (CNV), durante el período 2012-2016, en total 37 empresas, de las que se obtuvieron 95 memorias de sostenibilidad y 61 Estados Contables.

La aplicación de la metodología desarrollada en el Capítulo 3, permitió determinar el nivel de implementación de prácticas de RSE en las empresas argentinas adheridas al GRI. Al respecto se concluyó que el indicador integral de RSE asciende a un 58,34\%, lo que evidencia que las empresas no estarían informando en promedio un $41,66 \%$ de los indicadores propuestos por la GRI. Cuando esto es analizado a nivel de subíndice (dimensión), como se mencionó, varía de un 49,07 \% (Dimensión Social - Derechos humanos) a un 72,74 \% (Dimensión Social - Prácticas laborales).

Puesto que el indicador Prácticas laborales arrojó un valor de $72,74 \%$, se observa lo importante que resulta para las empresas informar las prácticas de RSE relacionadas con sus recursos humanos, dejando en evidencia que sería en esta dimensión sobre la que más prácticas estarían llevando a cabo las empresas. Esto corrobora la idea de que es la "gente" quien constituye el valor más importante de la administración - no la tierra, los edificios, el equipo o los materiales, de allí la importancia de desarrollar un ambiente auténtico de trabajo y motivar positivamente al personal.

Respecto al nivel de indicadores de RSE informados por las empresas y su relación con el tamaño, se destaca que en los casos en que las diferencias resultaron significativas fueron las medianas empresas las que más informaron sobre sus prácticas de RSE. 
En relación al nivel de indicadores de RSE informados por las empresas y el tipo de memoria elaborada (G3 $\circ \mathrm{G} 4$ ), las diferencias de medias en casi todos los casos resultaron significativas a favor de las memorias elaboradas según la Guía GRI G3. Es muy probable que esto se deba a que los indicadores propuestos en la Guía GRI G3 son menos en cuanto a cantidad y, en algunos casos, menos exhaustivos, de allí que las empresas en caso de elaboración de sus memorias según la Guía G3 hayan podido tener un mejor cumplimiento en la comunicación de los indicadores por ella propuestos.

Por último, al analizar la divulgación de información de RSE por parte de las empresas, se observó que solo un 57,1 \%, mejoró su grado de divulgación, es decir, se infiere, que a medida que pasa el tiempo, no todas las empresas divulgan con mayor grado de detalle sus prácticas de RSE, esta conclusión no debe considerarse concluyente y debe tomarse con cautela puesto que fue muy escaso el número de empresas con las que se pudo efectuar dicho análisis.

Luego, se utilizó la metodología diseñada para la medición integral de prácticas de RSE para determinar su relación con el desempeño económico (DE) y la reputación corporativa (RC)

En el Capítulo 3 se planteó la siguiente hipótesis: “El desempeño económico de la empresa y la reputación corporativa está relacionado con mayor puntuación de RSE".

De acuerdo a la metodología planteada, se aplicaron las siguientes regresiones lineales múltiples:

$$
\begin{gathered}
R S E=\beta_{0}+\beta_{1} \mathrm{RC}+\beta_{2} \mathrm{ROA}_{+} \beta_{3} \text { Inventas }_{+} \beta_{4} \text { Tamaño }_{+} \varepsilon \\
E C=\beta_{0} \beta_{1} \mathrm{RC}+\beta_{2} \mathrm{ROA}_{+} \beta_{3} \text { Inventas }_{+} \beta_{4} \text { Tamaño }_{+} \varepsilon \\
L A=\beta_{0+} \beta_{1} \mathrm{RC}+\beta_{2} \mathrm{ROA}_{+} \beta_{3} \text { Inventas }_{+} \beta_{4} \text { Tamaño }_{+} \varepsilon \\
H R=\beta_{0+} \beta_{1} \mathrm{RC}_{+} \beta_{2} \mathrm{ROA}_{+} \beta_{3} \text { Inventas }_{+} \beta_{4} \text { Tamaño }_{+} \varepsilon \\
S O=\beta_{0} \beta_{1} \mathrm{RC}+\beta_{2} \mathrm{ROA}_{+} \beta_{3} \text { Inventas }_{+} \beta_{4} \text { Tamaño }_{+} \varepsilon
\end{gathered}
$$




$$
\begin{aligned}
& P R=\beta_{0+} \beta_{1} \mathrm{RC}+\beta_{2} \mathrm{ROA}_{+} \beta_{3} \text { Inventas }_{+} \beta_{4} \text { Tamaño }+\varepsilon \\
& E N=\beta_{0}+\beta_{1} \mathrm{RC}+\beta_{2} \mathrm{ROA}_{+} \beta_{3} \text { Inventas }_{+} \beta_{4} \text { Tamaño }_{+} \varepsilon
\end{aligned}
$$

De los resultados de los análisis de regresión que se efectuaron en el Capítulo 4, tanto para la variable dependiente RSE integral como por dimensión, los coeficientes de las variables independientes no son interpretables para determinar la relación lineal entre las variables, debido a que en todos los casos los p-valor resultaron muy por encima del 0.05 y a su vez el R2 de los modelos arrojaron valores muy bajos, por lo tanto, para la muestra analizada no se evidencia relación lineal entre la RSE y las variables explicativas seleccionadas.

Ante este resultado se planteó una metodología alternativa: "árboles de decisión" y otras pruebas Chi-cuadrado de Pearson. Para el modelo, se consideró variable de segmentación la variable "RSE integral", que tomó el valor de "1" en el caso de tener valor superior a la media y valor " 0 " en caso contrario. Por otra parte, las variables independientes han sido definidas como:

- ROA: valor de "1" en el caso de tener valor superior a la media y valor "0" en caso contrario

- Reputación Corporativa (RC): valor de "1" en el caso de tener valor superior a la media y valor "0" en caso contrario.

Mediante el "árbol de decisión" y las pruebas Chi-2 de Pearson nuevamente se concluyó que no hay evidencia de que a mayor reputación corporativa mayor sea la puntuación RSE ni tampoco que a mayor RSE mayor sea el desempeño económico medido por ROA.

Las conclusiones a las que se arribó son consistentes con la "Hipótesis de las variables moderadoras" que establece que entre la RSE y el DE no existe ninguna correlación, en cuanto la variable de RSE no puede alterar la variable DE, ni viceversa, la relación no es clara, ni significativa.

Se podría considerar que las variables tipo de industria, riesgo o gastos en investigación y desarrollo, podrían explicar el hecho que no se encontraron 
correlaciones concluyentes entre RSE y DE, debido al efecto "moderador" que generarían estas variables. A su vez, cabe agregar otra limitación que tanto la performance financiera como el desempeño económico, son el resultado final de una gran cantidad de variables intermedias e independientes $y$, por ello, aislar unas variables relacionadas con el desempeño en RSE para hallar una causalidad sobre el resultado económico de la empresa es una cuestión sumamente compleja.

Es importante resaltar que, mediante el desarrollo de esta tesis, se pudieron desprender distintas proposiciones que serán detalladas clasificadas a continuación:

\section{1- Proposiciones originalmente propuestas:}

- Las empresas que aplican prácticas de RSE, lo hacen en todas sus dimensiones (económica, social y medioambiental), es decir, consideran la RSE en su sentido amplio.

- Cuanto mayor sea el tamaño de la empresa, mayor será la implementación integral de prácticas de RSE.

- Cuanto mayor sea la implementación integral de prácticas de RSE, mejor será el desempeño económico y la reputación de la empresa.

\section{2- Proposiciones que surgieron de los diferentes análisis realizados en el desarrollo} de la tesis, que pueden ser corroborados con datos contenidos en la tesis:

- Si mejoran las prácticas de RSE en alguna de las dimensiones mejoran también las prácticas en cualquiera de las otras.

- Si se expanden las prácticas de RSE en la dimensión laboral, en la de recursos humanos o en las de prácticas de producto, se expanden en mayor medida las prácticas en la dimensión social.

- Las empresas que elaboraron las memorias de sustentabilidad de acuerdo a la Guía G3 presentaron mayor divulgación de prácticas de RSE respecto a las dimensiones Medioambiental, Prácticas sociales, Derechos humanos y Prácticas laborales y trabajo decente. 
- Las empresas que elaboraron las memorias de sustentabilidad de acuerdo a la Guía G3 presentaron mayor divulgación de prácticas de RSE de manera integral.

- Cuanto menor sea el tamaño de la empresa, tanto mayor será la aplicación de prácticas de RSE en las dimensiones Prácticas Laborales, Derechos Humanos y Medioambiental.

- Cuanto menor sea el tamaño de la empresa, tanto mayor será la aplicación de prácticas de RSE de manera integral.

\section{3- Proposiciones que pueden ser sometidas a verificación empírica en futuras investigaciones}

- El nivel de endeudamiento influye positivamente en el nivel de aplicación de prácticas de RSE.

- La aplicación de RSE genera una ventaja competitiva para la empresa.

- A mayor aplicación de prácticas de RSE, mayor la utilidad por acción.

- A mayor aplicación de prácticas de RSE, mejor la imagen de la organización.

- La aplicación de prácticas de RSE, disminuye la rotación del personal y mejora la eficiencia laboral.

- La aplicación de prácticas de RSE, impacta de manera positiva en la capacidad innovadora.

- A mayor aplicación de prácticas de RSE, mayor el crecimiento de las ventas.

Por último, es menester destacar que esta tesis planteó la escasez de investigaciones que se centren en analizar las prácticas de RSE que están implementando las empresas argentinas; y si las mencionadas prácticas guardan algún tipo de relación con la rentabilidad y la reputación corporativa. Al respecto mediante la tesis en principio de desarrollo una metodología para la medición de prácticas de RSE. Luego, mediante la metodología fue factible analizar la situación particular de las empresas argentinas 
adheridas al GRI que cotizan en la CNV, y a su vez poder arribar a una conclusión respecto a la relación entre las prácticas de RSE con la rentabilidad y la reputación corporativa. A su vez, al crearse un instrumento para la recolección y análisis de datos referentes a prácticas de RSE y gracias al extenso análisis teórico desarrollado, se sugieren como en futuras investigaciones estudiar adecuadamente la RSE en relación a otras variables.

\section{RECOMENDACIONES}

\subsection{Recomendaciones y posibles líneas de investigación}

Se puede concluir que resulta de suma importancia para futuras investigaciones ahondar en cada una de las dimensiones, fundamentalmente en la Dimensión Social, en primer lugar, la de Derechos humanos para analizar qué indicadores están omitiendo informar las empresas, es decir que prácticas no estarían desarrollando y cuáles podrían ser las causas. En segundo lugar, la Dimensión Social Prácticas laborales, al ser la que más se informa, para poder profundizar y cuantificar más exhaustivamente los indicadores que la componen, como ser evaluaciones, prestaciones otorgadas por sexo y categoría profesional, la reincorporación luego de baja por maternidad/paternidad, entre otros. Este análisis permitiría profundizar el conocimiento respecto a que prácticas se estarían llevando a cabo respecto a esta dimensión.

Luego, respecto a las conclusiones enfocadas en la metodología del análisis de regresión, para futuras investigaciones sería interesante aplicar un desfase temporal de tres años al medir la relación entre la RSE y los resultados económicos de las empresas y discriminar el análisis entre empresas de sectores cuyo comportamiento (desde un punto de vista RSE) sea homogéneo o heterogéneo. También sería recomendable ampliar el período de análisis para que sea factible llevar a cabo el desfase temporal y contar a su vez con un mayor número de observaciones.

Por otra parte cabe agregar, que el desempeño económico de una organización se ve afectado por distintos generadores de valor, tales como: margen operativo, el costo de 
financiamiento, las tasas impositivas, por lo tanto es difícil aislar el efecto que generarían las prácticas de RSE en el desempeño económico, sin considerar muchas de las variables intermedias generadoras de valor.

Como se mencionó anteriormente, del análisis efectuado no se evidencia relación lineal entre las variables dependientes y las variables independientes. Al respeto cabe destacar que aunque la mayoría de los estudios existentes parten de alguna de estas hipótesis lineales sobre la relación RSE y resultados económicos, también existen trabajos que consideran que existe un nivel óptimo de RSE a partir del cual los gastos adicionales realizados afectan negativamente al resultado económico, por lo que consideran la posibilidad de la existencia de una relación no lineal o en forma de $U$ invertida, esta relación supone.

Más allá de la relación que se evidencie entre RSE y rentabilidad, y RSE y reputación corporativa, es importante volver a destacar que la ética que le corresponde a la Responsabilidad Social no es una ética de la intención, sino de la voluntad, de la acción y de la responsabilidad por las consecuencias no sólo inmediatas, sino a futuro, en el sentido: soy bueno si mis acciones tienen buenos efectos, sin importar mis intenciones personales, mis motivos para realizarlas. Es así como hoy en día, empresarios alrededor del mundo sostienen que la empresa tiene una responsabilidad social adicional a la de producir ganancias.

En virtud del extenso desarrollo del marco teórico y del desarrollo de metodología para la medición de la RSE, es viable el análisis de la relación de la RSE con otras variables que impactan en la generación de valor para las organizaciones, tales como: ventaja competitiva, grado de apalancamiento financiero, utilidad por acción, imagen de la organización, rotación del personal y capacidad innovadora. Esta tesis podría entonces considerarse no como el final de la investigación, sino como el inicio de futuras investigaciones.

El esfuerzo por seguir estudiando este tema bien vale la pena, pues a través de la RSE es posible construir una sociedad mejor en la que se obtenga un progreso sustentable dentro de la ética hacia todos, en un camino hacia el bien común. 
Cabe destacar que recientemente se ha otorgado el premio nobel de economía a William Nordhaus y Paul Romer por sus contribuciones al crecimiento sostenible de los macromercados, ambos especialistas han diseñado métodos para abordar algunos de los problemas más fundamentales de nuestra época: el crecimiento sostenible y el bienestar de la población mundial, esto deja en claro la importancia a nivel mundial que tienen tanto los Objetivos de Desarrollo Sustentable y a nivel empresa la RSE.

Resulta ineludible finalizar esta investigación resaltando que el empresario debería ser socialmente responsable, no en búsqueda de efectos positivos para sí mismo o para su empresa, sino que debería dejar atrás conceptos como "los negocios son los negocios, lo demás no importa" concomitante con la idea que la única responsabilidad de las empresas es respecto de sus dueños (shareholders) y de nadie más. Es así como los empresarios deberían centrarse en actuar según la "ética común", que en todo caso es aplicable en todos los órdenes de la vida, no solo en su ámbito personal sino dentro de sus organizaciones, esto será clave ya que organizaciones responsables desarrollan individuos responsables y organizaciones insensibles generan ciudadanos desaprensivos. 
ANEXO 1: INDICADORES PROPUESTO POR EL GRI - GUIA G4

\author{
Dimensión Económica \\ EC1 Valor económico directo generado y distribuido. \\ Consecuencias financieras y otros riesgos y oportunidades para las actividades de la organización debido al \\ EC2 cambio climático. \\ EC3 Cobertura de las obligaciones de la organización derivadas de plan de prestaciones \\ EC4 Ayudas financieras significativas recibidas de gobiernos \\ Relación entre salario base de los hombres con respecto al de las mujeres, desglosado por categoría \\ EC5 profesional \\ Porcentaje de altos directivos procedentes de la comunidad local en lugares donde se desarrollan \\ EC6 operaciones significativas \\ Desarrollo e impacto de las inversiones en infraestructuras y los servicios prestados principalmente para el \\ EC7 beneficio público mediante compromisos comerciales, pro bono, o en especie. \\ Impactos ambientales significativos del transporte de productos y materiales utilizados para las actividades \\ EC8 de la organización, así como del transporte de personal. \\ EC9 Porcentaje del gasto en los lugares con operaciones significativas que corresponden a proveedores locales

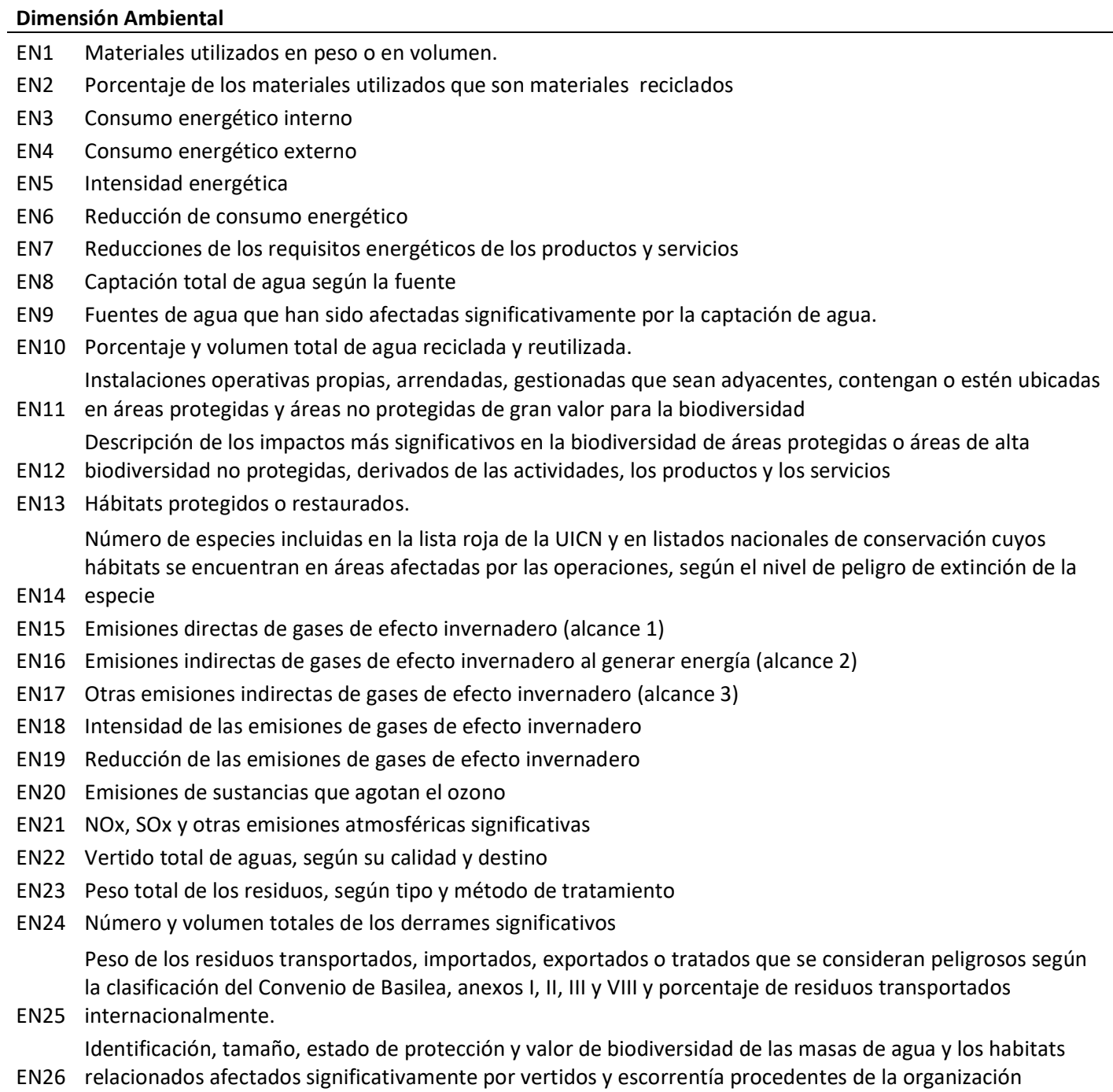


EN27 Grado de mitigación del impacto ambiental de los productos y servicios

Porcentaje de los productos vendidos y sus materiales de embalaje que se recuperan al final de su vida útil,

EN28 por categorías de productos

Valor monetario de las multas significativas y número de sanciones no monetarias por cumplimiento de la

EN29 legislación y la normativa ambiental

Impactos ambientales significativos del transporte de productos y materiales utilizados para las actividades

EN30 de la organización, así como del transporte de personal.

EN31 Desglose de los gastos y las inversiones ambientales

EN32 Porcentaje de nuevos proveedores que se examinaron en función de criterios ambientales

Impactos ambientales negativos significativos, reales y potenciales, en la cadena de suministro, y medidas al

EN33 respecto

Número de reclamaciones ambientales que se han presentado, abordado y resuelto mediante mecanismos

EN34 formales de reclamación

Dimensión Social: Prácticas laborables y ética en el trabajo

LA1 Número total de empleados y rotación media de empleados, desglosado por grupos de edad, sexo y región.

Prestaciones sociales para los empleados a jornada completa que no se ofrece a los empleados temporales o

LA2 a media jornada, desglosadas por ubicaciones significativas de actividad

Índice de reincorporación al trabajo y retención tras la baja por maternidad o paternidad, desglosados por

LA3 sexo

LA4 Plazos mínimos de preaviso de cambios operativos y posible inclusión de estos en los convenios colectivos

Porcentaje del total de trabajadores que está representado en comités de salud y seguridad conjuntos de dirección-empleados, establecidos para ayudar a controlar y asesorar sobre programas de salud y seguridad

LA5 en el trabajo.

Tipo y tasa de lesiones, enfermedades profesionales, días perdidos, absentismo y número de víctimas

LA6 mortales relacionadas con el trabajo por región y por sexo

LA7 Trabajadores cuya profesión tiene una incidencia o un riesgo elevados de enfermedad

LA8 Asuntos de salud y seguridad cubiertos en acuerdos formales con sindicatos.

LA9 Promedio de horas de capacitación anuales por empleado, desglosado por sexo y por categoría laboral

LA10 Promedio de horas de formación al año por empleado, desglosado por categoría de empleados.

Porcentaje de empleados que reciben evaluaciones regulares del desempeño y de su desarrollo profesional,

LA11 desglosado por sexo y por categoría profesional

Composición de los órganos de gobierno corporativo y plantilla, desglosado por sexo, grupo de edad,

LA12 pertenencia a grupo minoritario y otros indicadores de diversidad.

Relación entre salario base de los hombres con respecto al de las mujeres, desglosado por categoría

LA13 profesional y por ubicaciones significativas de actividad

LA14 Porcentaje de nuevos proveedores que se examinaron en función de criterios relativos a prácticas laborales Impactos negativos significativos, reales y potenciales, en las prácticas laborales en la cadena de suministro,

LA15 y medidas al respecto

Número de reclamaciones sobre prácticas laborales que se han presentado, abordado y resuelto mediante

LA16 mecanismos formales de reclamación

\section{Dimensión Social: Derechos Humanos}

Porcentaje y número total de contratos y acuerdos de inversión significativos que incluyan cláusulas de

HR1 derechos humanos o que hayan sido objeto de análisis en materia de derechos humanos.

Horas de formación de los empleados sobre políticas y procedimientos relacionados con aquellos aspectos

HR2 de los derechos humanos relevantes para sus actividades, incluido el porcentaje de empleados capacitados

HR3 Número total de incidentes de discriminación y medidas adoptadas.

Identificación de centros y proveedores significativos en los que la libertad de asociación y el derecho de acogerse a convenios colectivos pueden infringirse o estar amenazados, y medidas adoptadas para defender

HR4 estos derechos

Identificación de centros de proveedores con un riesgo significativo de casos de explotación infantil, y

HR5 medidas adoptadas para contribuir a la abolición de la explotación infantil

Centros y proveedores con un riesgo significativo de ser origen de episodios de trabajo forzoso, y medidas

HR6 adoptadas para contribuir a la eliminación de todas las formas de trabajo forzoso

Porcentaje de personal de seguridad que ha recibido capacitación sobre políticas o procedimientos de la

HR7 organización en materia de derechos humanos relevantes para las operaciones

HR8 Número de casos de violación de los derechos de los pueblos indígenas y medidas adoptadas 
Número y porcentaje de centros que han sido objeto de exámenes o evaluaciones de impactos en materia

HR9 de derechos humanos

Porcentaje de nuevos proveedores que se examinaron en función de criterios relativos a los derechos

HR10 humanos

Impactos negativos significativos en materia de derechos humanos, reales y potenciales, en las prácticas

HR11 laborales en la cadena de suministro, y medidas al respecto

Número de reclamaciones sobre derechos humanos que se han presentado, abordado y resuelto mediante

HR12 mecanismos formales de reclamación

\section{Dimensión Social: Sociedad}

Porcentaje de centros donde se han implementado programas de desarrollo, evaluaciones de impactos y

SO1 participación de la comunidad local

SO2 Centros de operaciones con efectos negativos significativos, posibles o reales, sobre las comunidades locales Número y porcentaje de centros en los que se han evaluado los riesgos relacionados con la corrupción y

SO3 riesgos significativos detectados

SO4 Políticas y procedimientos de comunicación y capacitación sobre la lucha contra la corrupción

SO5 Casos confirmados de corrupción y medidas adoptadas

SO6 Valor de las contribuciones políticas, por país y destinatario

Número de demandas por competencia desleal, prácticas monopolísticas o contra la libre competencia y

SO7 resultado de las mismas

Valor monetario de sanciones y multas significativas y número total de sanciones no monetarias derivadas

SO8 del incumplimiento de las leyes y normativas

Porcentaje de nuevos proveedores que se examinaron en función de criterios relacionados con la

SO9 repercusión social

Impactos negativos significativos y potenciales para la sociedad en la cadena de suministro, y medidas

SO10 adoptadas

Número de reclamaciones sobre impactos sociales que se han presentado, abordado y resuelto mediante

SO11 mecanismos formales de reclamación

Dimensión Social: Responsabilidad sobre productos

Porcentaje de categorías de productos y servicios significativos cuyos impactos en materia de salud y

PR1 seguridad se han evaluado para promover mejoras

Número total de incidentes derivados del incumplimiento de la regulación legal o de los códigos voluntarios relativos a los impactos de los productos y servicios en la salud y la seguridad durante su ciclo de vida,

PR2 distribuidos en función del tipo de resultado de dichos incidentes.

Tipos de información sobre los productos y servicios que son requeridos por los procedimientos en vigor y la

PR3 normativa, y porcentaje de productos y servicios sujetos a tales requerimientos informativos.

Número total de incumplimientos de la regulación y de los códigos voluntarios relativos a la información y al etiquetado de los productos y servicios, distribuidos en función del tipo de resultado de dichos incidentes.

PR5 Resultados de las encuestas para medir la satisfacción de los clientes

PR6 Venta de productos prohibidos o en litigio

Número de casos de incumplimiento de la normativa o los códigos voluntarios relativos a las comunicaciones de mercadotecnia, tales como la publicidad, la promoción y el patrocinio, desglosados en función del tipo de

PR7 resultado

Número total de reclamaciones debidamente fundamentadas en relación con el respeto a la privacidad y la

PR8 fuga de datos personales de clientes.

Costo de las multas significativas fruto del incumplimiento de la normativa en relación con el suministro y el PR9 uso de productos y servicios de la organización. 


\section{BIBLIOGRAFÍA}

- Albareda Vivó, L. \& Balaguer Franch, M. R. (2008). La responsabilidad social de la empresa y los resultados financieros. Revista de contabilidad y dirección, 7, $11-26$.

- Alonso-Almeida, M. D. M., Rodríguez García, M. D. P., Alejandro, C., Aimer, K., \& Abreu Quintero, J. L. (2010). La responsabilidad social corporativa y el desempeño financiero: un análisis en empresas mexicanas que cotizan en la bolsa. Contaduría y administración, 57(1), 53-77.

- Álvarez, M \& Vargas, R. (2011). Beneficios que trae para las empresas la incorporación de la RSE en sus objetivos corporativos: caso colombiano. Contaduría Universidad de Antioquia, 58-59, 55-71

- Argandoña, A. (2011). La Teoría de los Stakeholdersy la Creación de Valor. En: Transformar el Mundo, Humanizar la Técnica Ética, Responsabilidad Social e Innovación. EBEN.

- Barbei, A. A. (2012). Las mediciones y la calidad de la información contable: Un análisis desde la perspectiva de la regulación contable internacional. Contabilidad y auditoría, (28), 37.

- BID (2016). INDES. Indicadores para el desarrollo. Cadenas de Objetivos e Indicadores.

- Bonsón, E., \&Bednárová, M. (2015). CSR reporting practices of Eurozone companies. Revista de Contabilidad, 18(2), 182-193.

- Carné, D. M. (2007). Responsabilidad Social de la Empresa: Una Revisión Crítica a las Principales Teorías. Ekonomiaz: Revista Vasca de Economía, (65), 50-67.

- Charlo Molina, M. J. \& Moya Clemente, I. (2010). El Comportamiento Financiero De Las Empresas Socialmente Responsables. Investigaciones Europeas de 
Dirección y Economía de la Empresa. Vol. 16, № 2, 2010, pp. 15-25, ISSN: 11352523

- Cheng, B., loannou, I., \&Serafeim, G. (2014). Corporate social responsibility and access to finance. Strategic Management Journal, 35(1), 1-23. Consultado el día 29/12/2015) en: http://nrs.harvard.edu/urn-3:HUL.InstRepos:9887635

- Chivite, M.P. \& Enciso, V. (2015): “Alcance de la creación de valor en las Empresas Responsables", CIRIEC-España, Revista de Economía Pública, Social y Cooperativa, 85, 11-31.

- Correa García, J. A (2016). De la partida doble al análisis financiero. Contaduría Universidad de Antioquia, (46), 169-194.

- Demo, Silvia del Milagro (2016). El desempeño de una empresa de servicio público: propuesta para el análisis y monitoreo de indicadores. 2016. Tesis de Maestría.

- De Nobrega, F. (2011). El sistema de contabilidad en la complejidad de las organizaciones. Actualidad Contable Faces, 14(22).

- Diente Serna, S. (2016). Divulgación de información sobre responsabilidad social en las empresas de Valladolid y su vinculación con el rendimiento financiero (Tesis: Universidad de Valladolid, Facultad de Ciencias del Trabajo).

- Escobar Huarhua, E. (2015). La responsabilidad social empresarial como medio de rentabilidad y competitividad. Tesis

- Fassio, A. (2016). Apuntes para desarrollar una investigación en el campo de la administración y el análisis organizacional. EUDEBA.

- FerranAranaz, M., González Aragüena, E.., García, C. M. M., \& Ortega Castello, E. (2001). SPSS para Windows: análisis estadístico. OsborneMacGraw-Hill.

- Gallardo-Vázquez, D., \& Sánchez-Hernández, M. I. (2013). Análisis de la incidencia de la Responsabilidad Social Empresarial en el éxito competitivo de las microempresas y el papel de la innovación***/Impactanalysis of Managerial Social Responsibility in competitivesuccess of microenterprises and the role of innovation. Universia Business Review, (38), 14. 
- González-Ramos, M. I., Manzanares, M. J. D., \& Gómez, F. G. (2014). Propuesta de una escala para la medición de la responsabilidad social corporativa. Pecvnia, (18), 1.

- GRI (2012). La Elaboración de Memorias de Sostenibilidad de GRI: ¿Vale la Pena el Viaje?

- GRI (2013). Guía para la Elaboración de Memorias de Sostenibilidad.

- Gorrochategui, N. (2012). Cumplimiento del Principio 10 del Pacto Global sobre corrupción por parte de las empresas que adhieren a la iniciativa en la Argentina. Tesis Doctorado Facultad de Ciencias Económicas UBA.

- Gujarati, D. N. (1997). Econometría, 3ra. Edición. Santa fe de Bogotá, Colombia: Mc Graw-Hill interamericana, XXIII.

- Hernández, C. A., \&Bonomie, M. E. (2010). Responsabilidad social empresarial: Estrategia de competitividad en el marco de la globalización. Revista de Formación Gerencial, 9(1), 144-168.

- Hernández Perlines, F. \& Infante Hernández, J. P. S. (2015). La influencia de la Responsabilidad Social Empresaria (RSE), en los resultados económicos (RE) de las micro, pequeñas y medianas empresas (MIPYMES). In XXIII Congreso EBEN España (p. 17). Universidad Pablo de Olavide, de Sevilla.

- Herrera, T. J. F., Gómez, J. M., \& Granadillo, E. J. D. L. H. (2012). Aplicación de análisis discriminante para evaluar el comportamiento de los indicadores financieros en las empresas del sector carbón en Colombia. Entramado, 8(2), 64-73.

- Herrero, P. P. (2000). Evaluación del impacto de la formación de las organizaciones. Educar, (27), 119-133.

- IARSE (2014). Indicadores ETHOS - IARSE Para Negocios Sustentables Y Responsables (Agosto, 2014). Disponible en http://www.iarse.org/seccion/publicaciones-iarse/ Consulta realizada el $17 / 06 / 2016$. 
- INCAE (2010). Manual de Indicadores de Responsabilidad Social Empresarial Modelo Integral INCAE. Costa Rica: INCAE.

- Iqbal, N., Ahmad, N., Basheer, N. A., \& Nadeem, M. (2012). Impact of corporate social responsibility on financial performance of corporations: Evidence from Pakistan. International journal of learning and development, 2(6), 107-118.

- Izquierdo, J. Á. M. (2004). Responsabilidad Social Corporativa y Competitividad: una Visión desde la Empresa. Revista Valenciana de Economía y Hacienda, 12, 9-50.

- Kaplan, R. \& Norton D. (2002).El Cuadro de Mando integral. Ediciones Gestión 2000, S.A. Barcelona, 2002.

- Larrán Jorge, M., Madueño, J. H., \& Martínez, D. M. (2013). Relación entre la RSE y el performance competitivo en la pequeña y mediana empresa: Un estudio empírico. AECA: Revista de la Asociación Española de Contabilidad y Administración de Empresas, 104, 9-12.

- López, C. P. (2013). Técnicas de segmentación: conceptos, herramientas y aplicaciones. Alfaomega.

- Marín Rives, L. \& Rubio Bañón, A.(2008). La responsabilidad social corporativa como determinante del éxito competitivo: un análisis empírico. Revista Europea de Dirección y Economía de la empresa, 17(3), 27-42.

- Martinez, J. R., Gómez J. M., \& Álvarez, J. C. (2012) Competencias organizacionales y su impacto en el desempeño organizacional: innovación y creatividad, trabajo en equipo y RSE. Disponible en https://www.researchgate.net/profile/Jesus Cruz Alvarez/publication/298070 624 Impacto de las Competencias de Creatividad Innovacion Trabajo en Equipo Innovador y RSE en el Desempeno de las MYPYMES/links/56e60d4e08ae68afa112c131.pdf (consultado 10/11/2016)

- MERCO (2017). El proceso de elaboración de MERCO 2017 en la Argentina. Consultado el 01/12/2017 en: http://www.merco.info/ar/ranking-mercoempresas 
- Minor, Dylan B., and Morgan John (2011). "CSR as Reputation Insurance: Primum Non Nocere." California Management Review 53, no. 3 (Spring 2011): 40-59.

- Morillo, M. (2001). Rentabilidad financiera y reducción de costos. Actualidad contable FACES, 4(4).

- Morillo, M. (2004). Indicadores no financieros de la contabilidad de gestión: herramienta del control estratégico. Actualidad contable FACES, 7(8).

- Muso Lalaleo, J. C. (2016). Análisis de relación causal de la responsabilidad social empresarial en la imagen corporativa y rendimiento financiero de las Pymes (Bachelor'sthesis, Universidad Técnica de Ambato. Facultad de Contabilidad y Auditoría. Carrera Contabilidad y Auditoría).

- Ochoa Ramírez, S. A. \& Toscano Moctezuma, J. A. (2012). Revisión crítica de la literatura sobre el análisis financiero de las empresas. Nóesis: Revista de Ciencias Sociales y Humanidades, 21(41), 73-100.

- Olcese, A. (2011). Creación de valor y responsabilidad social de la empresa (RSE) en las empresas del IBEX 35. Publicaciones de la Real Academia de Ciencias Económicas y Financieras, Barcelona.

- Ostengo H. (2014). La Contabilidad de Gestión. En un enfoque de control de gestión y evaluación del desempeño, para lograr la medición integral de la gestión 1a. ed. - Buenos Aires. Osmar D. Buyatti - Librería Editorial, 2014.

- Palmer, H. J. (2012). Corporate Social Responsibility and Financial Performance: Does it Pay to Be Good?.Disponible: http://scholarship.claremont.edu/cmc_theses/529/. Consulta realizada el $27 / 06 / 2016$.

- Pereyra, C. B. (2009). Exploraciones preliminares y reflexiones preparatorias sobre investigación científica en contabilidad. Quantum: revista de administración, contabilidad y economía, 4(1), 36-57. 
- Perera, L. (2011) Indicadores para la gestión de la RSE en Vives, A., \& PeinadoVara, E. LA RESPONSABILIDAD SOCIAL DE LA EMPRESA EN AMÉRICA LATINA. Publicación del Banco Interamericano de Desarrollo.

- PiñuelRaigada, J. L. (2002). Epistemología, metodología y técnicas del análisis de contenido. Estudios de sociolingüística, 3(1), 1-42.

- Poyatos León, J. A. Análisis de la relación causal de la responsabilidad social corporativa y la performance financiera de las empresas. 2015. Tesis Doctoral.

- Prado, A., Flores, J., Pratt, L. y Leguizamón, F. (2004). Manual de Indicadores de Responsabilidad Social Empresarial para Costa Rica. Alajuela, Costa Rica, INCAE. Proyecto diseño y elaboración de un modelo de RSE para Costa Rica.

- Ríos Manríquez, M, Lopez Salazar, A., \&LopezMateo, C. (2015). Ética y calidad laboral: impacto en el desempeño empresarial. Un estudio empírico. HOLOS, 3, 308-320.

- Salgado Cabrera, H., y González Navarro, M. V. (2014). Un Índice de Responsabilidad Social Empresarial para la Industria Salmonicultora en Chile. Revista Interamericana de Ambiente y Turismo-RIAT, 9(2), 52-68.

- Sallenave J. (1993).Gerencia y Planeación Editorial Norma S.A., Colombia, Julio 1993.

- Sánchez Gutiérrez, J. (2016). Responsabilidad Social y ventaja competitiva: percepción de la gerencia de la empresa pequeña y mediana de Guadalajara, Jalisco. Mercados y Negocios (1665-7039), 1(34), 75-96.

- Sautú, R., Boniolo, P., Dalle, P., \&Elbert, R. (2005). Manual de metodología: construcción del marco teórico, formulación de los objetivos y elección de la metodología. Buenos Aires: Clacso.

- Solari, D., 2002. Ética en los negocios. Comentarios desde la Economía. Conferencia en Universidad de La Paz, Bolivia, Diciembre de 2002. 
- Soto, E. M., Galvis, O. D. J. M., \& Salazar, C. A. M. (2010). Análisis de los métodos de medición de las cuentas ambientales en el modelo contable financiero y concepciones alternativas. Entramado, 6(2), 106-128.

- Tenorio Ronda, J. G. \&Perez Rodríguez, M. J. (1999). El éxito empresarial. Sus niveles de análisis y formas alternativas para su evaluación. Dirección y Organización, (21).

- Trejo, D. J. M., Gutiérrez, J. S., y Cotón, S. H. (2014). Responsabilidad Social Corporativa e Innovación: Propuesta de Diseño para su Medición. Disponible en: https://papers.ssrn.com/sol3/papers.cfm?abstract_id=2397922. Recuperado el, 15/02/2018.

- Vallaeys, F. (2006). La responsabilidad social de las organizaciones. CD Multimedia Programa de Apoyo a Iniciativas de Responsabilidad Social, Ética y Desarrollo. Lima-Perú.

- Valleys, F. (2006). Responsabilidad Social de las Organizaciones. Strategia, (4), 15-17.

- Velenzuela Fernández, L., Jara-Bertin, M., \&Pineaur, F. V. (2015). Prácticas de responsabilidad social, reputación corporativa y desempeño financiero/Práticas de responsabilidade social, reputação corporativa e desempenhofinanceiro/Social responsabilitypractices, corporatereputation and financial performance. Revista de Administração de Empresas, 55(3), 329.

- Vílchez, E., Báscones, I., \& García, N. (2009). Indicadores para la medida del grado de desarrollo sostenible de una organización. In Forum Calidad (Vol. 198, No. 09, pp. 36-42).

- Vintró Sánchez, C. ComajuncosaCasabella, J. C., \&Trench, M. T. (2009, April). Propuesta de un sistema de indicadores de responsabilidad social corporativa. In XIII Congreso de Ingeniería de Organización (pp. 1993-2003).

- Weber, O., Koellner, T., Habegger, D., Steffensen, H., \&Ohnemus, P. (2008). The relation between the GRI indicators and the financial performance of firms. Progress in Industrial Ecology, an International Journal, 5(3), 236-254. 
- Welsch, G. A. Presupuestos: Planificación y control de utilidades/por Gleen A. Welsh, Ronald Welsch, Ronald W. Hilton Y Paul Gordon (No. 657 W4 1990.).

- Zetterberg, H., \& Cuadernos de investigacion social. (1968). Teoría y verificación en sociología. Nueva Visión.

- Zometa Saborío, A.(2017) Propuesta de un sistema de valor económico agregado, como indicador financiero en la asociación solidarista de empleados de la Empresa Financiera SA. (TESIS) 